\title{
Social orienting and social seeking behaviors in ASD. A meta analytic investigation
}

Article

Accepted Version

Hedger, N., Dubey, I. and Chakrabarti, B. ORCID:

https://orcid.org/0000-0002-6649-7895 (2020) Social orienting and social seeking behaviors in ASD. A meta analytic investigation. Neuroscience \& Biobehavioral Reviews, 119. pp. 376-395. ISSN 0149-7634 doi:

https://doi.org/10.1016/j.neubiorev.2020.10.003 Available at https://centaur.reading.ac.uk/93687/

It is advisable to refer to the publisher's version if you intend to cite from the work. See Guidance on citing.

To link to this article DOI: http://dx.doi.org/10.1016/j.neubiorev.2020.10.003

Publisher: Elsevier

All outputs in CentAUR are protected by Intellectual Property Rights law, including copyright law. Copyright and IPR is retained by the creators or other copyright holders. Terms and conditions for use of this material are defined in the End User Agreement. 


\section{CentAUR}

Central Archive at the University of Reading

Reading's research outputs online 
7 Social Orienting and Social Seeking Behaviors in ASD. A Meta Analytic Investigation 8 Nicholas Hedger* a, Indu Dubey ${ }^{\mathrm{b}}$, Bhismadev Chakrabarti ${ }^{\mathrm{a}}$

$12{ }^{a}$ Centre for Autism, School of Psychology and Clinical Language Sciences, University of Reading, Reading, RG6 6AL, UK

14

b School of Applied Social Sciences, De Montfort University, The Gateway, Leicester, LE1 $159 \mathrm{BH}, \mathrm{UK}$

16

17 *Corresponding author: Nicholas Hedger (n.hedger@reading.ac.uk). Centre for Autism, 18 School of Psychology and Clinical Language Sciences, University of Reading, Reading, RG6

21 Declarations of interest: none. 
Abstract

2

3 Social motivation accounts of autism spectrum disorder (ASD) posit that individuals with

4 ASD find social stimuli less rewarding than neurotypical (NT) individuals. Behaviorally, this

5 is proposed to manifest in reduced social orienting (individuals with ASD direct less attention

6 towards social stimuli) and reduced social seeking (individuals with ASD invest less effort to

7 receive social stimuli). In two meta-analyses, involving data from over 6000 participants, we

8 review the available behavioral studies that assess social orienting and social seeking

9 behaviors in ASD. We found robust evidence for reduced social orienting in ASD, across a

10 range of paradigms, demographic variables and stimulus contexts. The most robust predictor

11 of this effect was interactive content - effects were larger when the stimulus involved an

12 interaction between people. By contrast, the evidence for reduced social seeking indicated

13 weaker evidence for group differences, observed only under specific experimental conditions.

14 The insights gained from this meta-analysis can inform design of relevant task measures for

15 social reward responsivity and promote directions for further study on the ASD phenotype.

16

17

18 Keywords: meta-analysis; autism; social motivation; social seeking, social orienting, social 


\section{Introduction}

Autism Spectrum Disorder (ASD) are commonly characterised by atypical patterns

4 of social behaviour as well as restricted range of interests and repetitive behaviour. In

5 describing the social behavioural features of ASD, diagnostic accounts refer to "persis tent

6 deficits in social communication and social interaction", including "failure to initiate or

7 respond to social interactions', 'deficits in nonverbal behaviors used for social interaction'

8 and 'deficits in developing, maintaining and understanding relationships' (American

9 Psychiatric Association, 2013). A tremendous amount of theoretical and experimental

10 effort has been expended in an attempt to understand these differences in social behaviours

11 observed in ASD.

Historically, many efforts to understand these atypicalities have been cognitive

models that ascribed a central role to concepts such as 'theory of mind' (Frith \& Frith, 2005),

‘central coherence' (Happé, 2005) or 'executive dysfunction' (Hill, 2004). By contrast, an

independent category of accounts instead emphasise deficits in motivational processes

(Dawson, et al., 2005; Kohls et al., 2011; Kohls et al., 2012). According to such accounts, social behaviors in ASD may signal a "little or no social interest" (Grelotti et al., 2002), or even "an aversion to social stimuli" (Helt et al., 2008). These social motivation deficit accounts were synthesised in 2012 and formalised as the Social Motivation Theory (SMT) of ASD (Chevallier et al., 2012).

SMT states that individuals with ASD have an altered reward neurocircuitry

22 (Bachevalier \& Loveland, 2006; Dölen, 2015; Modi \& Young, 2012; Peça et al., 2011) and as

23 a consequence, find social stimuli less rewarding than neurotypical (NT) individuals. SMT

24 describes the typical behavioral consequences of this reduced social motivation. There are

25 three components of SMT: social orienting, social seeking, and social maintaining that relate 
1 to distinct cognitive processes and can be evidenced by distinct sets of behaviors (Chevallier et al 2012). SMT holds that these behaviors are reduced in ASD.

Social orienting relates to the extent to which social stimuli are prioritised in attentional selection. Social seeking relates to the overt behavioral effort expended to obtain social stimuli. Researchers have developed several related, circumscribed paradigms to measure these components that have been employed in multiple studies (Dubey et al., 2017;

$7 \quad$ Kohls et al., 2011; Pierce et al., 2011). The third component, social maintaining, relates instead to the behavioural adaptations to present oneself in a socially desirable manner to ensure long term social affiliations. In contrast to the first two components, social maintaining involves a range of diverse complex behaviours such as reputation management, prosocial acts, flattering, imitation, that are generally difficult to measure in lab-based settings. Empirical attempts to quantify these diverse social maintaining behaviors have used a rather heterogeneous set of paradigms, which renders a meta-analytic combination of these effects problematic (Cage at al., 2013; Liebal et al., 2008; Barbaro and Dissanayake., 2007; Marsh et al., 2013; Vivanti et al., 2017). Therefore, in the interest of consistency and interpretability, whilst reflecting the majority of empirical work on SMT, this paper focuses its scope by only reviewing the first two components (orienting and seeking).

\subsection{Justification and Scope of the Present Review}

As the research base surrounding SMT has grown, so too has skepticism. Some neuroimaging studies indicate that atypical reward responsivity in ASD may be more generalised than initially theorised - and may extend to processing of both social and nonsocial stimulus categories (Dichter et al., 2012; Scott-Van Zeeland et al., 2010). Recent years, in particular, have seen robust challenges to SMT accounts of ASD (Jaswal \& Akhtar, 
1 timely and important. Here, we provide this via a meta-analysis of the available behavioral

2 literature.

To help place the present review in the context of previous efforts, in Table 1, we summarise the existing reviews that examine social motivation in relation to ASD alongside the present effort. There are eight existing reviews. Five of these contain a quantitative element. However, the total number of subjects and studies included in these reviews are limited by their restricted focus. Moreover, inspecting this list of reviews reveals some important gaps in the literature. Several meta analyses of social orienting behaviors have been conducted (Chita-Tegmark, 2016a, 2016b; Frazier et al., 2017). Critically though, these only consider data emanating specifically from studies employing an eye-tracking methodology and therefore ignore data from other experimental paradigms that index social orienting. More gaps are apparent when we examine the existing reviews of social seeking behaviors. There has only been one quantitative synthesis of the existing literature, conducted by Clements and colleagues (2018). This review only considered neuroimaging studies, of which only 13 met their eligibility criteria. The remaining articles are either narrative reviews or theoretical commentaries (i.e. with no quantitative element). In this context, there is a clear need for an updated, more comprehensive quantitative synthesis of the available behavioral evidence. To focus this effort, we begin by providing definitions of social orienting and social seeking with reference to example paradigms and studies.

\subsubsection{Definition}


Given capacity limits, our perceptual systems must direct processing resources to salient inputs for further processing (Marois \& Ivanoff, 2005). Here, we define 'social orienting' as the extent to which social stimuli are prioritised in this selection process. This broad definition is motivated by the initial description of SMT, which proposed that reduced social orienting in ASD was evidenced by 'looking more at background than characters while watching static social photographs", "fixating less on people, faces and eyes than on other regions of interest" and "showing a preference for nonsocial patterns" (Chevallier et al., 2012). It is important to note, therefore, that this concept of 'orienting' is somewhat broader than the definition of 'attentional orienting' commonly used in experimental cognitive psychology, where orienting tends to refer solely to the initial allocation of attention and is distinguished from the subsequent 'maintenance' of attention (Posner, 1980; Posner, Snyder, \& Davidson, 1980). Social orienting has been operationalised in a number of ways. This includes direct measures, such as recording of an observer's gaze preference via eye-tracking (Klin et al., 2009), or more indirect, such as via manual responses that measure the latency at which an observer detects a stimulus (e.g., in a visual search task, such as Pruett et al., 2013), or responds to a co-located probe at the location previously occupied by a social stimulus (e.g., in a dot-probe task, such as Moore et al., 2012). Some typical social orienting paradigms are explained below.

\subsubsection{Typical Paradigms}

1.2.2.1. Gaze Preference Paradigms. In gaze-preference paradigms, eye-tracking is employed to record the location of an observers gaze. In the context of social orienting studies, an observer's gaze is recorded during (typically passive) viewing of either i) a single scene involving social (people) and non-social elements (objects) (Amso et al., 2014) ii) a competing social and non-social stimulus, presented either side of fixation (Pierce et al., 
1 2011) (See Figure 1a). Social orienting is then typically measured via one of three metrics i)

2 The proportion of total gaze duration directed at a social stimulus ii) The latency at which an

3 observer first fixates on a social stimulus. iii) The proportion of trials wherein an observer's

4 first fixation is directed to a social stimulus. In such studies, reduced social orienting in ASD

5 would be evidenced by i) a smaller proportion of gaze directed towards the social stimulus ii)

6 later first fixations on a social stimulus, or iii) a smaller proportion of trials wherein an

7 observer's first fixation is directed to a social stimulus.

8

1.2.2. Visual Probe. The generic trial sequence of a typical visual probe task is shown in Figure 1b (Chica et al., 2014). Firstly, observers maintain a central fixation. Next, a social and non-social image (cues) are presented on either side of fixation for a brief duration (typically $\sim 500 \mathrm{~ms}$ ). After the cues are removed, a probe is presented, either at the location preceded by the social image (valid location), or the non-social image (invalid location) (Shah et al., 2013). The observer's task is typically to indicate the location of the probe (left or right of fixation) as quickly and accurately as possible. The logic is that if observers preferentially orient to the social image, this would result in faster response times when the probe appears in the valid location, relative to the invalid location (i.e. an effect of cue validity). Reduced orienting to social stimuli in ASD would be manifested in a smaller effect of validity.

1.2.2.3. Visual Search. In the visual search paradigm (Figure 1c), observers are typically presented with an array of multiple stimuli and are instructed to make a manual response upon their detection of a target amongst distractor objects (Pruett et al., 2013). Reduced orienting to social stimuli in ASD would be manifested in delayed detection of social targets. 
1.2.2.4. Breaking Continuous Flash Suppression (bCFS). In bCFS, a dynamic

masking pattern is presented to one eye, which suppresses conscious perception of a target

stimulus presented to the other for long durations until it breaks this suppression and becomes visible (Figure 1d). In such paradigms, the initial suppression duration is used as a correlate of the perceptual selection of the target stimulus (Hedger et al., 2016; Stein et al., 2011). An observer is instructed to respond when they are able to report the location of the target. In such studies, reduced orienting to social stimuli in ASD would be manifested in delayed detection of social stimuli.

INSERT FIGURE 1 HERE

\subsection{Social Seeking}

\subsubsection{Definition}

Social seeking relates to the behavioural effort made to receive social stimuli. It is proposed that our reward system is driven by the experience of hedonic pleasure which generates "psychomotor eagerness" to approach sources of pleasure (Wright \& Panksepp, 2012). The state of seeking has a clear declarative goal and/or explicit expectations of outcome, distinguishing it from other states of reward motivation such as "liking" which can be a conscious or unconscious experience of pleasure (Berridge et al., 2009). The appetitive state of seeking is hence tightly linked to associative learning, anticipatory predictions, and psychomotor activation (Alcaro et al., 2007). Seeking of social stimuli can be inferred from behavioral responses that index the incentive value of social stimuli. This may include i) faster, or more accurate responses under conditions where social rewards are anticipated, ii) increased frequency of choices based on the learned association that social rewards will be 
1 received iii) investing greater effort/time in exchange for social stimuli. Thus, the key

2 difference between tasks measuring social orienting and social seeking is that seeking tasks

3 index the participant's behavioural response in anticipation of receiving the desired reward.

4 Some typical categories of paradigm designed to index "social seeking" are explained below.

5

$6 \quad$ 1.3.2. Typical Paradigms

7 the start.

1.3.2.1. Social Incentive Tasks. This set of tasks use an anticipatory response as a measure of social seeking (Spreckelmeyer et al., 2009). In such tasks, fast or accurate responses are incentivised by a preceding cue that signals the subsequent reward of a social or non-social stimulus. This set of tasks therefore encompasses paradigms such as social incentive delay tasks (Kohls et al., 2018), or incentive go/ no go tasks (Kohls et al., 2011). Such tasks are generally structured into blocks of trials containing presentations of social and non-social rewards. Participants are informed about the type of reward expected in a block at

A generic trial sequence of a typical social incentive task is shown in Figure 2a. At the beginning of the trial, participants are typically presented with a cue indicative of the ensuing reward. For instance, a cross may indicate the receipt of a social stimulus, and a circle may indicate the receipt of a non-social stimulus. In the anticipation phase, the participant waits for a brief duration. During the subsequent target phase, participants are expected to make a response (or non-response) within a specific duration to receive the anticipated social or non-social reward. Critically, if the response is made too late, or an inappropriate response is made, then the anticipated stimulus is not received. In such studies, enhanced seeking of social stimuli may be reflected in a faster reaction time, or a larger proportion of accurate responses in social than non-social trials. 
1.3.2.2. Choice-based Tasks. This set of tasks use alternative forced-choice behaviors as an index of social seeking. In such paradigms, participants are presented with a

3 display of multiple (usually two) cue stimuli. One of these cues is associated with the subsequent receipt of a social outcome (e.g., images or videos of smiling people) and the other is associated with a non-social outcome (e.g., images or videos household objects, cars, trains) (Dubey et al., 2017; Ruta et al., 2017). On each trial, participants are given a free choice to either select the cue associated with social or non-social outcome. Participants make choices based on associative learning and experience of pleasure on receiving the social/nonsocial rewards over the course of the experiment. In such tasks, reduced social seeking in ASD is manifested in a lower proportion of choosing the cue associated with the receipt of social stimuli. An example of a choice-based task is presented in Figure $2 b$.

1.3.2.3. Expenditure Tasks. In this set of tasks, the effort expended to prolong / increase exposure to social stimuli is used to index social seeking. For example, participants are presented a stimulus briefly and they are expected to make multiple/ quick button presses to increase the duration that a stimulus is presented for, or the amount of it that is presented (Ewing et al., 2013; Gilbertson et al., 2017; Traynor et al., 2019). An example of an expenditure task is presented in Figure 2c. In such studies, reduced social seeking would be reflected in a lower number of / slower speed of button presses made to receive social stimulation.

INSERT FIGURE 2 HERE

\subsection{Methods}




\section{2.1.1. General Inclusion Criteria}

2 We implemented the following criteria to determine the studies eligible for our analysis.

1. The study was conducted on human participants.

2. The study was published before November 2019 .

3. We only included studies that contained both a group of participants reported to have a diagnosis of an ASD and a group of NT control subjects. This decision was made because only this design allows computation of an outcome measure that reflects reduced social orienting/seeking in ASD relative to NT subjects. Note that this decision implies the following:

i) We excluded studies that examined social motivation exclusively in a group of ASD subjects or exclusively a group of NT subjects (e.g., Yamasue et al., 2018).

ii) We did not consider groups that were defined by some other clinical diagnosis as being a control group (e.g., Schizophrenia, Williams Syndrome). For instance, studies that compared social motivation between individuals with ASD and fragile X syndrome were excluded (e.g., Crawford et al., 2015; Riby et al., 2008).

iii) We did not include studies whose design was correlational. This excluded studies whose primary outcome measure was the association between autistic traits (for instance, as defined by the autism quotient - AQ) and social motivation in the general population (e.g., Madipakkam et al., 2019).

iv) We did not include studies that investigated ASD by employing a group of participants at 'high familial risk' of ASD (e.g., Chawarska et al., 2016; Dalton et al., 2007; Merin et al., 2007)

v) We did not include case studies/ clinical observations of individual participants. 
vi) Some studies included two control groups - those identified as being at 'high risk of ASD' and those identified as being at 'low risk of ASD' (e.g., Chawarska et al., 2013). In these cases, we opted to include only those at 'low risk' as our NT group.

4. We only included studies that contained presentations of both social and non-social stimuli. Studies that included exclusively social stimuli were excluded, because group differences in behavior could reflect generalised differences in motivation/engagement that are not specific to social stimuli. Additionally, we also did not include comparisons between stimuli that varied in sociality if both stimuli were inherently social in nature. For instance, in the context of some studies, a face with eyes concealed by sunglasses is considered the less socially engaging stimulus, whilst a face with unconcealed eyes is considered the more socially engaging stimulus (e.g., Cañigueral \& Hamilton, 2019). Since neither of these stimuli constitute a 'nonsocial' stimulus, we did not include such effects in our analysis.

5. Our focus on behavioral outcomes implied that we did not include neuroimaging studies (e.g., fMRI, EEG), or studies of peripheral physiological responses (e.g., galvanic skin response) unless they also reported behavioral data.

6. If studies included a mood induction, therapeutic intervention or drug administration expected to modulate social orienting/ seeking behaviors, only data from before the intervention (i.e. at baseline) were included (e.g., Kanat et al., 2017).

7. Studies that were reanalyses of existing data were excluded. In addition, some studies reported that a portion of their subjects came from an existing dataset (Pierce et al., 2011). We excluded such studies if they did not independently report the outcome measures for the novel subjects. 
8. Papers were only included if sufficient information was available to compute an effect size. If the information was not reported via means, standard deviations, $t, F$ or $p$ values in the text, we extracted these values from figures using 'Graphclick' software (Arizona Software, n.d.). Additionally, if ranges or interquartile ranges were the only measures of dispersion reported/ plotted, we used standard routines for estimating standard deviations from these values (Wan et al., 2014). If no exact $p$ value was reported (e.g., $p<.050$ ) we estimated an effect size by making the most conservative assumption (i.e. $p=.049$ ). Following meta-analytic convention, if an effect was reported to be 'non-significant', without any further statistics reported, we estimated an effect size assuming that $p=.50$ (Cooper \& Hedges, 1993). In practice, these strategies were only applied to 2 and 1 of the total number of effects, respectively (see supplementary table S2). Also note that this latter strategy was only employed if sufficient information were available to determine the direction of the effect (from the text or figures).

\subsubsection{Additional Coding and Inclusion Decisions for 'Social Orienting' Effects}

In our analysis of social orienting, we examined studies that allowed us to assess reduced orienting to social stimuli (relative to non-social stimuli) in ASD relative to NT participants. We therefore adopted the following additional criteria for this class of studies.

1. Most importantly, included effects had to involve direct, competing presentations of social and non-social stimuli within the experimental display. This competition could be between two distinct scenes on either side of a display (e.g., Pierce et al., 2011), or between multiple stimuli within the same scene (e.g., Fletcher-Watson et al., 2009; Klin et al., 2002). Studies that involved only isolated presentations of social stimuli 
were excluded. Most commonly, this implied the exclusion of eye-tracking studies that investigate emotional expression recognition strategies (e.g., Auyeung et al., 2015; Pelphrey et al., 2002). In such studies, the stimulus is typically an isolated face presented on a uniform background. The primary outcome measures in such studies are the proportion of fixations on different facial features (eyes, mouth etc). As such, there is no real attentional competition between social and non-social stimuli in such paradigms. Therefore, a minimum requirement for the inclusion of gaze reference studies was that at least one alternate area of interest (AOI) was defined in addition to the social AOI.

2. Several gaze-preference studies reported data for multiple AOIs within social stimuli. For instance, some studies reported the proportion of gaze directed into the eyes and mouth (e.g., Tenenbaum et al., 2017). An analysis of gaze differences to distinct subregions of face stimuli is beyond the scope of this review. In these cases, we followed a similar procedure to Chita-Tegmark (2016b) and pooled the data across the AOIs to define a singular social AOI. Note that, in addition to pooling means, this also required a method for pooling the variances across AOIs, which we report in Supplementary Material S1.

3. We only included studies wherein orienting was measured via objective behavioral criteria, such as eye-tracking, or by the speed of an observer's manual responses. This entailed excluding a subset of infant studies, wherein experimenters make observational judgements as to what constitutes 'orienting' behavior (Bhat et al., 2010; G. Dawson et al ., 1998; Mosconi et al., 2009). Such studies often rely on retrospective analyses of video tapes, which implies obvious limitations, including 
great variations in settings and poor reliability both spatially and temporally in estimating the location of an infant's gaze (Zwaigenbaum et al., 2007).

4. Visual search paradigms were excluded unless the dependent variable was the latency to detect/ fixate on a single social stimulus amongst non-social distractors. For instance, studies whose stimulus conditions involved multiple non-social and social distractors were not included (e.g., Wang et al., 2014). In such studies, the dependent variable is the time taken to detect a specific social target. For our purposes, this is a suboptimal description of social orienting, because participants could potentially fixate multiple social stimuli before detecting the target itself and making their response.

5. Note that we did not include data from change detection studies (e.g., New et al., 2010; Sheth et al., 2011). In such studies, the dependent measure is how efficiently an observer detects the deletion of a social/ non-social element in a scene. However, to avoid ceiling performance, such tasks typically involve the deletion of only one social element from a scene with many such elements (New et al., 2010). Again, it is therefore possible that observers may orient to multiple social elements before detecting the deletion of one relevant element.

\subsubsection{Effect Size Metric}

The effect size index used for all outcome measures was Cohen's $d$; the standardized

difference between means. Since all of our effects emanated from independent sample designs, our choice of standardizer for $d$ was the pooled within-groups SD. This standardizer was chosen because it has more degrees of freedom than other standardizers (since it is 
1 derived from two groups) and is thus likely to be the most precise estimate of the population

2 SD (Lakens, 2013). For social orienting studies, social and non-social stimuli were typically

3 engaged in direct online competition on a trial-by-trial basis. Therefore, since trials are of a

4 fixed duration, enhanced attention to social stimuli naturally implies decreased attention to

5 non-social stimuli. Therefore, we computed d as:

6

$$
d=\frac{N T M-A S D M}{S D \text { pooled }}
$$

Where $M$ is a measure of attention to social stimuli (e.g., gaze duration). Note that we reversed the numerator of the formula (i.e. $A S D M-N T M$ ) for measures where a large value indicates reduced orienting to social stimuli (e.g., latency to first fixation, response time). This ensured that, in all cases, a positive value of $d$ indicates enhanced social orienting in the NT group relative to the ASD group.

\subsubsection{Model Decisions}

We made an a priori decision to analyze our effect size data in a random effects model, due to its tolerance of heterogeneous effect sizes and conservative nature of estimation. The random effects model assumes that each study estimates different values from a distribution of population parameters, rather than assuming that studies are direct replications of each other (Schmidt et al., 2009). We assessed heterogeneity across effect sizes by using Cochran's $Q$ and $I^{2}$ statistics. All analyses were conducted with the 'metafor' package (Viechtbauer, 2010) implemented in the $R$ programming language.

\subsubsection{Handling Dependency}

For each paradigm, we coded the number of included conditions (nested within samples) and samples (independent groups of participants, nested within studies). Many of 
1 the samples were exposed to multiple conditions, which generates multiple effect sizes for

2 these samples. For instance, in some cases, samples were exposed to both an image and video

3 stimulus (Kou et al., 2019), meaning that this important moderator (stimulus type) occurs at

4 the within sample level and potentially important information would be lost by aggregating

5 these effects. Thus, to minimize this information loss and increase statistical power, we used

6 conditions, rather than samples as the unit of analysis in our models ( $k=$ conditions). When

7 samples contribute multiple effect sizes in this way, the assumption of independence may be

8 violated and bias the outcome of the meta-analysis, particularly if there is anything

9 unrepresentative about these samples (Matt \& Cook, 2009; Rosenthal, 1991). To examine the

10 influence of dependency on our results, we employed sensitivity analyses: using random

11 selection procedures, we created data sets where dependency was eliminated by selecting one

12 effect size per independent sample (Greenhouse \& Iyengar, 1994).

\subsubsection{Search and Coding Strategies}

The search for relevant studies and their coding was conducted by two authors (NH and ID). After agreeing on search terms and inclusion criteria, the search for orienting articles was led by NH. Any initial uncertainties that arose about the eligibility of articles, and the information used to compute effect size estimates were resolved between the two authors. First, 32 independent PubMed database searches were conducted, which involved screening an initial pool of 2413 articles. Second, the reference sections of all relevant literature reviews were examined for additional studies. Third, the reference sections of all qualifying articles were searched. In the process of collecting studies, each study was coded in terms of a set of sample and experimental-level variables identified as potential moderators of the effect (see Table 2). After the resulting set of studies was produced, any remaining uncertainties about the eligibility of effects was resolved via discussion between all three 
1 authors until a consensus was reached. Database search terms, and a summary of the excluded articles are presented according to the PRISMA ('Preferred Reporting Items for Systematic reviews and Meta-Analysis') guidelines (Moher et al., 2009). The search terms and associated PRISMA flowcharts can be found in Supplementary Material S3. A full summary of the included studies/effects, with notes can be found in Supplementary Material 6 S4.

7

\subsubsection{Moderator Analyses}

To attempt to account for heterogeneity in effects, we investigated the influence of several moderators, which are described in Table 2. Our investigation of moderators consisted of three phases:

\subsubsection{1. 'First Pass Phase'.}

Attempting to evaluate all candidate moderators within a single model will entail an unjustifiably complex model, with a low number of observations per coefficient. Therefore, in our initial 'first pass' phase, we fit a series of independent models that contained each one of the moderators individually. This phase allowed us to determine a subset of potentially explanatory variables for further exploration. Statistical tests of model coefficients were computed via likelihood ratio tests, comparing a model including the moderator to an empty (intercept only) model, using maximum likelihood estimation. We additionally used a pseudo- $R^{2}$ statistic (Raudenbush, 1994) to assess the extent of effect size heterogeneity that was explained by moderators included in the model (see Supplementary Material S2). 
The difficulty with interpreting the outcomes of the 'first pass' approach is that moderator variables may be correlated. Fitting a multiple regression model allows us to test

3 hypotheses about the effect of each one of these moderators whilst controlling for the

4 influence of the others. Therefore, in the subsequent 'multiple regression' phase, we

5 determined whether the coefficients that were detected in the 'first pass' phase remained

6 detectable in the context of a single multiple regression model.

7

\subsubsection{3. 'Model Comparison Phase'.}

Although the model fit in the multiple regression phase has a structure that allows us to test many relevant hypotheses, it is important to acknowledge that it is by no means the most parsimonious, or best performing model of the data and it fails to take into account competing models of the data. Moreover, the inferences drawn from the previous phases are implicitly grounded in null hypothesis significance testing, which does not allow us to draw inferences about the relative importance of/ support for each moderator. Therefore, in the 'model comparison' phase, we instead employed an information theoretic approach and evaluated the importance of each moderator across a wider population of models.

\subsection{Results}

In our presentation of results, we report outcomes as follows: $i$ ) we first summarise the structure of the effects contributing to the analysis ii) we then examine global model properties iii) we next examine the effect of bias on model properties $i v$ ) we explore plausible moderators of the effect size, and their relative importance.

\subsubsection{Summary of Included Effects}


From the initial pool of 2413 screened articles, 96 met our inclusion criteria. Within

2 the 96 articles, there were data from 102 independent samples and we were able to calculate 167 effect sizes. The total number of participants included in the analyses were $N=5195$, of which $N=2546$ were ASD participants and $N=2649$ were NT participants.

\subsubsection{Model Properties}

Figure 3a depicts a forest plot of the effects included in the analysis. The Random

effects model indicated a medium overall effect size $k=166, d=0.50,[0.410 .59], p<.001$.

According to the 'probability of superiority' metric (Lakens, 2013), this indicates that there is

a $63.89 \%$ chance that a randomly sampled participant from the NT population will have enhanced social orienting relative to a randomly sampled participant from the ASD population. Framed differently, Cohen's U3 statistic indicates that $69.25 \%$ of the NT population will have enhanced social orienting relative to the mean of the ASD population. Substantial heterogeneity was detected $Q(166)=742.48, p<.001$ and the $I^{2}$ statistic indicated that $75.65 \%$ of heterogeneity between effects could not be explained by sampling variability.

\subsubsection{Bias}

2.2.3.1. Influential Case Diagnostics. We first used standard leave one out procedures to diagnose particularly influential, or outlying effects. Based on an examination of these effects, we reasoned that there was no justification to remove any from the analysis (Supplementary Material S5).

2.2.3.2. Publication Bias. A number of analyses were performed to examine potential file-drawer effects. A funnel plot of the observed outcomes, as a function of their sampling variances is displayed in Figure 3b. The fail-safe $N$ statistic (Rosenthal, 1979) indicated that 
126649 additional, null studies would be required to reduce the pooled effect size to below an

2 undetectable magnitude. The relationship between the number of unpublished studies

3 averaging null effects and the reduction in the pooled effect size is shown in Figure 3c. Based

4 on the asymmetry of the funnel plot, the 'trim and fill' method (Duval \& Tweedie, 2000)

5 estimated that 26 studies may have been suppressed due to publication bias. When these

6 unpublished effects were imputed, the overall effect size reduced by $0.15 \quad(k=192, d=0.35$

$7 \quad[0.250 .45], p<.001)$. The regression test (Egger et al., 1997) for funnel plot asymmetry

8 detected a relationship between sampling variances and effect magnitudes, indicating further

9 evidence for publication bias $(z=5.15, p=.005$ respectively).

10

2.2.3.3. Dependency. To characterise the influence of dependency on our global outcomes, the random effects model was fit to 500 resampled data sets, each of which contained one randomly selected effect size from each of our independent samples, yielding a total of 102 effect sizes for each data new dataset. These models also detected a similar, moderate pooled effect size (mean $d=0.50, S D=0.02$ ) indicating that dependency did not exaggerate the true magnitude of the pooled effect.

\section{INSERT FIGURE 3 HERE}

\subsubsection{Moderator Analysis: 'First pass' Phase}

INSERT TABLE 2 HERE 
1 were detected $(Q(1)=2.31, p=.128)$. An effect of diagnostic assessment was detected

$2(Q(2)=9.76, p=.008$, see Figure 4a). Effect sizes tended to be smaller in samples where

3 diagnoses were verified via ADOS assessment.

4

2.2.4.2. Main effects: Experimental Properties. No effect of orienting measure was detected $(Q(5)=8.12, p=.150)$. Notably, effects were only detected for eye-tracking metrics - total gaze duration $(k=135, \beta=0.48,[0.38,0.58], p<.001)$, latency to first fixation $(k=18$, $\beta=0.84,[0.55,1.12], p<.001)$ and proportion of first fixations $(k=18, \beta=0.48,[0.01,0.95]$, $p=.042)$, but no effects were detectable for dot probe latency $(k=4, \beta=0.29,[-0.27,0.85], p$ $=.315)$, visual search latency $(k=2, \beta=0.01,[-0.78,0.81], p=.973)$ or bCFS detection latency $(k=2, \beta=0.17,[-0.65,0.99], p=.683)$. No effect of stimulus modality was detected $(Q(1)=0.03, p=.867)$ - effect size magnitudes were comparable between studies employing image $(k=71, \beta=0.51,[0.37,0.66], p<.001)$ and video stimuli $(k=96, \beta=0.49,[0.38$ $0.61], p<.001)$

An effect of social AOI was detected $(Q(4)=11.02, p=.026)$. Effects were detected for each stimulus type (Figure 4b). Contrasts revealed that social scene AOIs were associated with larger effect sizes than face AOIs $(\beta=0.44, p=.002)$, and person AOIs $(\beta=0.34, p=$ .018). An effect of stimulus context was detected $(Q(7)=16.56, p=.011$ (Figure 4c) .

Enhanced social orienting in NT populations was detected under free-viewing conditions $(k=$ $109, \beta=0.60,[0.49,0.71], p<.001)$, conditions where a person in the display engaged in conversation with the observer $(k=13, \beta=0.52,[0.24,0.80], p<.001)$ and conditions where the observer was explicitly instructed to attend to the social stimulus $(k=14, \beta=0.49,[0.18$, $0.82], p=.002)$. No effects were detected under any of the other stimulus contexts. An effect of interactive content was detected $(Q(2)=12.63, p=.002$, Figure $4 \mathrm{~d})$. The largest effects were observed when the stimulus display depicted interaction between people $(k=43, \beta=$ 
$10.76,[0.58,0.93], p<.001)$ - these effects were larger than when there was no interaction

2 present in the display $(k=99, \beta=0.45,[0.34,0.56], p<.001)$, or when a person in the

3 stimulus display bidded for interaction with the observer $(k=25, \beta=0.29,[0.07,0.51], p$

$4=.011)$.

6

7

\section{INSERT FIGURE 4 HERE}

6

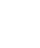

(1)

considering just 2-way interactions would incur 45 tests. Moreover, whereas we have

theoretical justification for including each moderator as a main effect in our analysis - there is

weaker or no justification for investigating these interaction effects in any detail in the

present paper. For those who wish to test targeted hypotheses regarding interaction effects of interest, the data underlying our analysis, as well as plots of two-way interactions, fitted model parameters and interaction contrasts can be found in Supplementary Material S7.

\subsubsection{Moderator Analysis: Multiple Regression Phase}

We next fit a single regression model that included the 4 main effects that were detected in the first pass phase. Subsequent linear hypothesis tests revealed that only interactive content remained detectable when controlling for the influence of other variables. (see Table 3).

INSERT TABLE 3 HERE

\subsubsection{Moderator analysis: Model Comparison Phase}

To evaluate the relative importance of moderators, we fit all 16 models that contained all combinations of all 4 parameters that were identified in the 'first pass' phase. We then 
1 ranked the model performances according to Bayes Information Criterion (BIC). Inspecting

2 the BIC scores of this population of models allows us to determine which moderators tend to

3 produce more robust models. Specifically, we summed the Akaike weights (Wagenmakers \&

4 Farrell, 2004) for each model in which each moderator appeared and normalised these values

5 so that they summed to 1 . Critically, the resulting value reflects the overall 'support' for the

6 term across the population of models. These results are shown in Figure 5. Inspection of this

7 figure reveals that interactive content and diagnostic assessment received the most support

8 across the population of models.

9

INSERT FIGURE 5 HERE

\subsection{Interim Discussion: Social Orienting}

Orienting effects were found to be stable across demographic variables, including age and sex. The stability across age agrees with the notion that social orienting difficulties in ASD develop very early in life and remain relatively stable throughout development. It is important to note, however, that the range of ages represented in the studies was biased towards child/adolescent samples, with an under-representation of adults $(M=10.65$ years, range $=0.53-41.03)$. Another caveat is, particularly within these adult samples, results were averaged across large age ranges, which limits the precision with which this relationship can be investigated. Similarly, the stability of effects across sex ratios may be unsurprising, given that females are very much under-represented in such studies. On average, around 6 times more males were recruited in these social orienting studies than females. This problematic nature of this sex imbalance was highlighted by recent research indicating sex differences in social attention in ASD - females observers with ASD were shown to exhibit social attention that was more comparable to NT observers (Harrop et al., 2018, 2019). Findings such as 
1 these highlight the need for Improved understanding of the female social phenotype in ASD

2 to enhance early screening efforts and the development of sex-sensitive social interventions.

It is important to note that the global difference in orienting behaviors observed

4 between the groups was not found to be affected by IQ matching. Since a large number of

5 people with ASD also have associated intellectual disabilities, it is often hard to understand

6 whether groups differences in social orienting result from simple differences in intellectual

7 functioning or in autistic features. While recruiting an additional IQ matched group can help

8 this problem, globally matching participants on intellectual abilities comes with additional

9 challenges, because the intellectual profile of individuals with ASD may differ to those with

10 general deficits in intellectual functioning (Jarrold \& Brock, 2004). The findings from this

11 meta-analysis support the claim that the social orientation difficulties observed in ASD are

12 not a simple function of differences in intellectual ability between the groups. This is

13 consistent with numerous studies with developmentally delayed (DD) control groups, which

14 show reduced social attention in ASD relative to both DD and NT subjects (Chawarska et al.,

15 2012; Klin et al., 2009).

16 One other, less-intuitive finding was that diagnostic assessment modulated effect size

17 outcomes - effects tended to be smaller when diagnosis was confirmed via ADOS/ADI-R

18 assessment. While ADOS is sometimes considered a 'gold standard' for ASD diagnosis,

19 some research groups often use alternative, briefer and more convenient tools such as

20 Childhood Autism Rating Scale (CARS) (Chlebowski et al., 2010) or Social Responsiveness

21 Scale (SRS) to evaluate current symptom severity or diagnosis. It is possible that these different approaches to defining experimental groups may lead to the selection of different subsections of the ASD phenotype. ADOS measures and more abbreviated measures (e.g.,

24 SRS) differ in their type 1 and type 2 error rates and so may differ in terms of the extent to

25 which they exclude subsections of the wider autistic population, or conversely, the extent to 
1 which they admit participants with similar, but distinct developmental disorders (Jones \&

2 Lord, 2013).

It is also important to consider the gradual evolution of the definition of ASD from a

narrowly defined homogenous population to a wider, heterogeneous population. This evolution has been cited as one of the principal causes of the increased prevalence estimates of ASD that have been observed over time (Fombonne, 2018). In parallel, it has also been proposed to account for the meta-analytic finding that group differences between individuals with and without ASD have generally decreased over time, with more recent articles reporting smaller effects (Rødgaard et al., 2019). Accordingly, it is possible that these more recent articles are those also assessing autism via the ADOS and/or ADI-R, as this is often requested as publication criteria in recent years.

In terms of experimental-level variables, we found evidence that larger effect sizes tended to be observed under conditions where social interactions between people were present within the stimulus. This finding was robust in the multiple regression model and was found to be the most important predictor in the model comparison stage. This replicates the findings of previous meta-analyses (Chita-Tegmark, 2016b; Frazier et al., 2017), and the conclusions of multiple studies that have manipulated 'social richness' of stimuli (Chevallier et al., 2015; Liang \& Wilkinson, 2018; Parish-Morris et al., 2019; Speer et al., 2007), which typically indicate larger group differences in social orienting when viewing interactions. This supports the idea that reduced social attention in ASD is highly context dependent (ParishMorris et al., 2019) and may reflect difficulties with monitoring multiple agents within a scene (Koldewyn et al., 2013). Social interactions require constantly updating ones understanding of the mental state and intentions of other people. While focusing on one person may impose the demand to understand their mental state, a higher number of agents may increase these demands by not just monitoring the mental states of two or more agents 
1 but also trying to understand the dynamic interaction these agents may have in relation to the

2 context. Beyond the cognitive demands mentioned above, multi-agent stimuli can also be

3 perceived to be more aversive given the life experiences of autistic individuals. Autistic

4 individuals often have unpleasant interactions in largely neurotypical group settings (e.g.,

5 classrooms, jobs) (Chen \& Schwartz, 2012). It is perhaps unsurprising to expect greater

6 aversion toward stimuli that represent groups of other people.

7

With our investigation of the 'stimulus context' moderator, we were able to

8 investigate the context dependency of social attention differences at a more fine-grained

9 level. Interestingly, in addition to passive viewing conditions, reduced social attention in

10 ASD was also detected during tasks that encouraged attending to social elements in the scene

11 (e.g., how is this person feeling?). This supports the notion that individuals with ASD adopt different sampling strategies for forming inferences about a person's state, as indicated by recent data (Tang et al., 2019). It is notable, however, that the relative importance of this

'stimulus context' moderator was low compared to interactive content, indicating that interactive content provides a more parsimonious account of the data.

In our analyses of separate orienting measures, we found good evidence for reduced social orienting in ASD for all 3 eye-tracking measures - notably, in addition to detecting effects for total gaze duration, we also detected effects in metrics that index 'earlier' phases

19 of orienting, such as latency to first fixation and proportion of first fixations. This supports

20 the idea that social attention differences in ASD may manifest more widely than generalised

21 differences in sustained attention. By contrast, no effects were detected for non-eye tracking measures, such as visual probe tasks, visual search tasks and bCFS paradigms. These differ

23 from preferential looking tasks as they tend to require the observer to follow additional task

24 instructions and make a rapid manual response after detecting stimuli. These additional

25 demands could reduce the sensitivity of such tasks. In general, visual probe, bCFS and visual 
1 search tasks all rely on indirect outcome measures such as response time, which are likely to

2 have reduced sensitivity to attentional processes relative to the direct oculomotor correlates

3 of attention indexed via eye-tracking. Equally, this could also reflect that these paradigms

4 tend to prioritise experimental control and therefore consist of very simple, circumscribed

5 stimulus displays. These inferences are tentative, however, in the light of the relative lack of 6 data from these tasks. In terms of social AOIs, it is notable that the most reliable group differences were detected when effect sizes emanated from paradigms where observers view competing social and non-social scenes. These effects were larger than those produced by gaze differences to 10 distinct AOIs within the same scene (face, person). This indicates that paradigms such as the

11 GEOPREF test, which measures attentional preferences for videos of geometric patterns in competition with social videos, may be associated with the most reliable differences between NT and ASD individuals (Pierce et al., 2016, 2011). This is in keeping with the findings of a recent study that directly compared different preferential looking paradigm formats (Kou et al., 2019).

\section{Study 2: Meta Analysis of Social Seeking Effects}

\subsection{Methods}

\subsubsection{General Inclusion Criteria}

All the general inclusion criteria listed in section 2.1.1 of study 1 also applied to our analysis of social seeking effects.

\subsubsection{Additional Coding and Inclusion Decisions for 'Social Orienting' Effects}

In our analysis of social seeking, we examined studies that directly compared the following additional criteria for this category of studies. 
1. We only included studies where participant's response/performance (defined by the speed, frequency, or accuracy of their responses) was incentivised by the subsequent receipt of a stimulus. This entailed excluding studies evaluating social seeking using questionnaires, interviews (e.g., Mattys et al., 2018) and studies where the stimulus was presented irrespective of the task responses of the participant (e.g., Corbett et al., 2014).

8

2. Several studies involved a manipulation of reward magnitude (e.g., Delmonte et al., 2012). For instance, in incentive delay paradigms, participants may receive either a slightly (low reward), or intensely smiling (high reward) face. In our analysis, we pooled across reward magnitude, such that the effect size represents social seeking across reward magnitudes. This decision was taken because i) the interaction between reward magnitude and stimulus sociality is beyond the scope of this review ii) the magnitude of reward intensity manipulations is unlikely to be comparable between studies, and iii) Only a handful of studies included manipulations of reward magnitude, which limits the utility of a meta-analysis of these effects. In practice, this was applied to 3 of the included effects (see Supplementary Table S3).

3. Some studies investigated processing differences between "high autism interest" and "low autism interest" non-social stimuli (Traynor et al., 2019; Watson et al., 2015). Again, since this manipulation was rare, and was not pertinent to our research question, we pooled across these conditions. In practice, this was applied to only 2 of the included effects (see Supplementary Table S3). 


\section{3.1.3. Effect Size Metric}

2

We again used Cohen's $d$ as our effect size metric for social seeking studies. In such studies, social and non-social stimuli were typically presented on discrete trials. Therefore, we defined $d$ as:

$$
d=\frac{N T S M-A S D S M}{S D \text { pooled }}-\frac{N T N S M-A S D N S M}{S D \text { pooled }}
$$

Here, we calculate one effect size representing the enhanced seeking of social stimuli in the NT group relative to the ASD group. We then adjust this for baseline differences in non-social seeking behavior, by subtracting the equivalent effect size involving non-social stimuli. Therefore, a positive value of the resulting effect size reflects enhanced social seeking in the NT group relative to the ASC group.

\subsubsection{Model Decisions \& Handling Dependency}

All methodological details relating to modelling decisions and handling dependency reported in study 1 also applied to our meta analysis of social seeking effects.

\subsubsection{Search and Coding Strategies}

The search for seeking studies was led by ID, using the same strategies as reported for Study 1. First, 25 independent PubMed database searches were conducted, which involved screening an initial pool of 853 articles. Coded moderator variables are displayed in Table 4 . The search terms and associated PRISMA flowcharts can be found in Supplementary Material S3. A full summary of the included studies/effects, with notes can be found in Supplementary Material S4. 


\subsubsection{Moderator Analyses}

To attempt to account for heterogeneity in effects, we investigated the influence of several moderators, which are described in Table 4. Our approach to moderator analysis was the same as detailed in Study 1.

\subsection{Results}

\subsubsection{Summary of Included Effects}

From the initial pool of 853 screened articles, 22 met our inclusion criteria. Within the 22 articles, there was data from 22 independent samples and we were able to calculate 28 effect sizes. The total number of participants included in the analyses were $N=945$, of which $N=448$ were ASD participants and $N=497$ were NT participants.

\subsubsection{Model Properties}

Figure 6a depicts a forest plot of the effects included in the analysis. The Random effects model indicated a small overall effect size $k=28, d=0.24$ [0.05 0.47], $p=.015$. The 'probability of superiority' indicated a $57.0 \%$ chance that a randomly sampled participant from the NT population will have enhanced social seeking relative to a randomly sampled participant from the ASD population. Cohen's $U 3$ indicated that $59.6 \%$ of the NT population will have enhanced social seeking relative to the mean of the ASD population. Substantial heterogeneity was detected $Q(27)=73.00, p<.001$ and the $\mathrm{I}^{2}$ statistic indicated that $63.83 \%$ of heterogeneity between effects could not be explained by sampling variability.

\subsubsection{Bias}


3.2.3.1. Influential Case Diagnostics. After inspecting influential studies identified

2 by leave-one out procedures, we reasoned that there was no justification to remove any

3 effects from the analysis (Supplementary Material S5).

4

3.2.3.2. Publication Bias. A funnel plot of the observed outcomes, as a function of their sampling variances is displayed in Figure 6b. The fail-safe $N$ statistic indicated that 144 additional, null studies would be required to reduce the pooled effect size to an undetectable magnitude. The 'trim and fill' method did not estimate the suppression of any studies due to publication bias. The regression test for funnel plot asymmetry did not detect a relationship between sampling variances and effect magnitudes $(z=1.53, p=.126)$.

\section{INSERT FIGURE 6 HERE}

3.2.3.3. Dependency. To characterise the influence of dependency on our global outcomes, the random effects model was fit to 500 resampled data sets, each of which contained one randomly selected effect size from each of our independent samples, yielding a total of 22 effect sizes for each data new dataset. Each of these models detected a small pooled effect size (mean $d=0.27, S D=0.02$ ) indicating that dependency did not exaggerate

19 the true magnitude of the effect.

\subsubsection{Moderator Analysis: 'First Pass' Phase.}

To attempt to account for the heterogeneity in effects, we examined several moderators of the group differences in social seeking, which are described in Table 4. A full

24 set of parameter estimates and contrasts for each of the single moderator models can be found in Supplementary Material S6. 
3.2.4.1. Sample Properties. No effect of verbal IQ matching $(Q(1)=3.50, p=.061)$

was detected, but an effect of nonverbal IQ matching was detected $(Q(1)=7.43, p=.006)$.

6 Effect size magnitudes were lower when nonverbal IQ was matched $(k=17, \beta=0.04,[-0.17$,

7 0.26], $p=.706)$ than unmatched $(k=10, \beta=0.51,[0.25,0.78], p<.001$, Figure 7a). No effect

8 of age was detected $(\beta=0.00, Q(1)=0.08 p=.774)$. However, an effect of sex ratio was

9 detected, whereby a larger proportion of female participants gave rise to larger effect sizes $(\beta$

$10=-.039, Q(1)=7.71, p=.006$, Figure 7b). Finally, an effect of diagnostic assessment was

11 detected $(Q(1)=8.33, p=.004)$. Effect sizes tended to be smaller in samples where diagnoses

12 were verified via ADOS assessment (Figure 7c).

3.2.4.2. Experimental Properties. An effect of seeking measure was detected $(Q(3)=12.56 p=.006)$. Large effects were detected for studies that assessed choice proportions $(k=7, \beta=0.65,[0.35,0.94], p<.001)$, whereas no effects were detected when studies involved accuracy $(k=9, \beta=0.11,[-0.17,0.38], p=.438)$, response time $(k=8, \beta=-$ 0.04, [-0.32, 0.23], $p=.749)$, or button presses $(k=4, \beta=0.29,[-0.14,0.72], p=.184)$ (Figure

$7 \mathrm{~d})$. No effect of social stimulus type, $(Q(5)=6.21, p=.286)$ or stimulus modality $(Q(3)=1.47, p=.690)$ were detected. 
We fit a single regression model that included the 4 main effects that were detected in the first pass phase. Subsequent linear hypothesis tests revealed that none of these effects remained detectable when controlling for the influence of other variables. (see Table 5).

\subsubsection{Moderator Analysis: Model Comparison Phase}

The summed Akaike weights across the population of models are shown in Figure 8.

The 3 sample characteristics (diagnostic assessment, nonverbal IQ matching and sex ratio)

\section{INSERT FIGURE 8 HERE}

\subsection{Interim Discussion: Social Seeking}

For social seeking, the evidence for moderating effects was less robust. However, in keeping with meta-analysis and the tradition of estimation-based approaches, it is important to reflect on the relative evidential support for each moderator. For instance, relative to the orienting studies, the data indicated some increased support for the influence of demographic variables, such as nonverbal IQ matching and sex ratio. Regarding nonverbal IQ matching, effects were found to be larger in unmatched samples. Social seeking paradigms, particularly social incentive tasks, typically involve remembering a set of task instructions and executing a behavioural response to acquire specific stimulus. Moreover, social incentive and expenditure tasks are more performance-dependent than the majority of gaze preference tasks, which tend to involve simple free-viewing. Therefore, inferences based on samples 
1 unmatched on NVIQ may be partially confounded by differences in generalized abilities in

2 memory, motor planning and action.

Regarding sex ratio, there was a suggestion that a greater proportion of females were associated with a larger effect size. Research in typical populations indicates that socially reserved traits, such as shyness are typically more tolerated in girls than boys (Costa et al., 2001; Geelhand et al., 2019) implying that reduced social seeking is relatively normalised in females. As such, females with ASD tend to be identified later than males and diagnoses tend to be given when autistic characteristics and behavioural difficulties are more severe (Dworzynski et al., 2012). It is possible therefore, that females with ASD need to present with more difficulties in social seeking to receive diagnoses and therefore represent a more extreme endophenotype (Lai et al., 2011; Puleo et al., 2012). Although none of these factors were detectable in a multiple regression model, the relative support for demographic moderators is higher for seeking than orienting (see Figure 5, Figure 8), highlighting the need for these variables to be explicitly characterised in future investigations.

Our analyses of seeking measures revealed some support for the idea that choicebased tasks tend to reveal more reliable differences between ASD and NT subjects. In contrast to social incentive tasks, these tasks directly measure social seeking in context of an online, forced-choice between types of reward (social and non-social) instead of via incentivised responses in different trials, so the preference for social over non-social stimuli is more directly measured in these paradigms (Dubey et al., 2018). This pattern of results emphasises the utility of simple, direct paradigms such as the 'choose a movie' task in indexing differential sensitivity to social rewards (Dubey et al., 2017; Dubey et al., 2015). Because of their simplicity, similar tasks can be adapted to scalable tablet-based versions and can be successfully administered in very young children (Ruta et al., 2017). 
Notably, effects that indexed seeking behaviors via response time or accuracy

2 (typically social incentive paradigms) did not yield detectable differences in social seeking

3 behaviors. Crucially, in such paradigms, individuals are frequently found to be faster to

4 respond in rewarded trials than non rewarded trials. Thus, these paradigms are generally

5 sensitive to reward per se (Demurie et al., 2011; Kohls et al., 2011, 2018). Critically, though,

6 the pooled data from such tasks indicate no differences in seeking behaviors directed towards

7 social (relative to non-social) stimuli in ASD. This observation is interesting given that

8 several of the studies employing such tasks have observed concurrent differences in neural

9 activity consistent with reduced incentive value of social stimuli in ASD (Delmonte et al.,

10 2012; Kohls et al., 2018). It is therefore important to understand this discrepancy between

11 neural and behavioral signatures of social seeking in ASD.

These inferences, must remain tentative however, given that these moderating effects were not detectable in the context of a multiple regression model. This is likely to be a product of the relative lack of statistical power - the number of included participants was roughly $20 \%$ that of the social orienting meta-analysis. As such, we present the outcome of our moderator analyses as supporting inferences that demand replication and further investigation.

\section{General Discussion}

The present meta-analyses examined social reward responsivity in ASD by providing a census, synthesis and analysis of paradigms that measure orienting to or seeking of social stimuli. To put the findings into context, we discuss the novel contributions of our analysis, the global pattern of results, some caveats and the implications for future research. 
This investigation provides the first, quantitative synthesis of the available behavioral

2 literature for both social orienting and social seeking behaviors in ASD. Numerically, this

3 review provides an advance on previous efforts, involving data from 6140 participants and

4118 studies. Moreover, in our analysis of social orienting effects, we move beyond an

5 investigation of data from gaze-preference/eye-tracking studies and investigate data from a

6 wider range of paradigms.

\section{4.2. Global Results}

By quantitatively combining 167 effect size estimates, we detected good evidence for

9 reduced social orienting in ASD, relative to the NT population. The pooled effect size was

10 medium $(d=0.50)$ and slightly smaller than previous estimates (Chita-Tegmark, 2016b). In

11 contrast, it is important to note that the evidence base for social seeking studies lags behind that of orienting, both in terms of the number of available articles and the pooled effect magnitude. We were able to combine 28 effect sizes, from which the estimated pooled effect size was $d=0.24$. It is important to note that substantial heterogeneity was detected in both meta-analyses. Inspecting the corresponding forest plots reveals many null effects and effects in the negative direction. To a large extent, this reflects the substantial heterogeneity in the corresponding sample characteristics and experimental designs.

Notwithstanding these sources of heterogeneity, it is worth considering the potential theoretical implications of the unbalanced strength of evidence we observed for reduced social orienting and social seeking in ASD. First, it may indicate that social motivation is not generally and uniformly atypical in ASD, providing precision to SMT accounts of autism. At the most basic level, this emphasises the need to highlight the similarities in which autistic and non-autistic behaviors appear socially motivated. Such similarities should be investigated

24 further, and given the treatment of being just as theoretically interesting and important as any differences that are detected. 
Second, it is noteworthy that folk psychological accounts would expect some

dependency between these processes: if social stimuli are prioritised in the orienting process, we would, in turn, expect to observe seeking behaviour towards them. Recently, however, it has been observed that autism traits may modulate the link between these processes. When presented with multiple alternatives to choose from, we tend to look more towards stimuli that we later choose. In an eye-tracking task, it was observed that this relationship is reduced in individuals with high autism traits - an increase in gaze to a stimulus was associated with a smaller increase in choice probability (Hedger \& Chakrabarti, 2020). Thus, the difference between the magnitude of orienting and seeking effects we observe here may compliment this evidence that indicates fundamental differences in how the generation of preferences are linked to attentional orienting in ASD. The potential dissociation between these components of social motivation requires further examination using carefully controlled measures of orienting and seeking. In particular, there is a notable dearth of studies that have investigated both of these components in a within-sample design.

One finding that was common to both meta-analyses was that paradigms with simple task demands (e.g., passive viewing paradigms to measure orienting or choice-based tasks to measure seeking) tend to capture more robust group differences in social motivation. Paradigms with more complex task demands, such as those that involve tracking the reward type during the current experimental block, or encourage fast/ accurate task performance (e.g., social incentive tasks) involve more complex executive functions, which may impact upon the measurement of social preference. Moreover, as social situations rarely involve explicit task directives, paradigms with no instructions to complete a "task" may have the advantage of better reflecting the true nature of social interactions and thus elicit larger effects. A related point is that, for practical reasons, the application of such 'passive' tasks may also be preferred when studying individuals presenting with more severe autistic signs 
1 (e.g., non-verbal individuals), which could explain why they tend to produce more robust

2 group differences. By extension, this implies a selection bias towards higher functioning

3 individuals in more 'active' tasks, meaning that data from such paradigms may not be

4 generalisable to a disorder that often co-occurs with intellectual disability (Brown, Chouinard

5 \& Crewther, 2017). Regardless, these considerations encourage the use of simple task designs

6 and recording techniques that do not require complex verbal instruction or sustained attention

7 - thereby allowing the full, diverse intellectual spectrum of ASD to be represented in autism

8 research.

\subsection{Caveats}

One common criticism of meta-analysis is that researchers may combine very different types of studies in a single analysis (i.e., a problem of "apples and oranges"). The power of meta-analytic approach, however, lies in the fact that we are able to quantify these differences in a way that would not be possible based on considering individual studies in isolation. Some variables we assessed have rarely been manipulated within a single study and thus their influence could only be assessed meta-analytically. Another limitation is that the effect sizes presented here are insensitive to possible sub-phenotypes of ASD. For example, Moore et al (2018) have found that only a subgroup of toddlers with ASD showed preference for geometric patterns as opposed to social images and that they were characterized by worse cognitive, language, and social skills relative to those toddlers with ASD that preferred attending to social images.

An important interpretative caution is that while many of the findings reviewed here may apparently support the SMT account of ASD, lower preference of social stimuli in context of competing non-social stimuli may also reflect an aversion or avoidance of social stimuli. Autistic individuals show a lower tolerance to vagueness or uncertainty (Joyce et al., 
12017 ) and there is a reliably higher level of social anxiety in this group (Simonoff et al.,

2 2008). The natural uncertainty of social situations and vagueness of these tasks may therefore

3 contribute to produce stronger aversion based responses in ASD. Future empirical work

4 should focus on explicitly testing this alternative explanation against that suggested by SMT.

5 A more general consideration is that whilst SMT provides a parsimonious account of the

6 atypical social behaviours observed in ASD, it does not speak to other known atypical

7 features of ASD that are unrelated to social behaviour, such as altered sensory reactivity

8 (Tavassoli et al, 2016; Tavassoli et al, 2018; MacLennan et al., 2020). As such, it is crucial to

9 note that our inferences are limited to the social phenotypic features of ASD.

Another point on the specificity of our analyses is that it is essential to note that

reduced responsivity to social stimuli relative to the NT population may indeed be observed

in multiple other conditions, including psychopathy (Viding \& McCrory, 2019), social

anxiety (Richey et al, 2019), hyperkinetic disorders (Santosh \& Mijovic, 2004) and

schizophrenia (Blanchard et al., 2001). As such, to the extent that reductions in social

responsivity are observed in other conditions, this complicates the notion that they tell us something specific or explanatory about ASD. For this reason, it maybe more useful to consider social reward responsivity as a dimension to characterise social behaviour within a transdiagnostic framework such as the Research Domain Criteria (RDoC, Insel et al., 2010).

One other thing that needs to be borne in mind is that the constructs of social orienting and social seeking as measured through these lab-based paradigms may not be aligned to selfreported social motivation in some autistic individuals. As highlighted by recent reviews, behavioral studies indicating a lack of social motivation in ASD often conflict with the testimony of the individuals themselves (Jaswal \& Akhtar, 2019). As such, the current analysis is more a direct test of social reward responsivity than of a broadly construed term of 'social motivation'. However, this dissociation opens up at least two broad directions for 
1 future research. The first of these should test if autistic individuals show a greater

2 dissociation between self-report and task performance across multiple constructs. The second

3 avenue for future research should focus more on the measurement of social motivation

4 through a systematic investigation of the structure of inter-relationships between self-report

5 and behavioural measures in the general population. Similar large-scale exercises have been

6 carried out on 'self-regulation', which revealed very weak or no relationship between self-

7 report and task measures (Eisenberg et al., 2019). If similar results are observed for social

8 motivation, these would help resolve this apparent discrepancy.

It is also the case that dependency may have had an unmeasured influence on our

10 results. Meta-analysis is based on the assumption that the samples reported in each study are

11 independent. However, individual ASD research labs within a specific geographic location may unwittingly recruit overlapping sets of participants. Larger collaborative studies with multi-site data collection may prevent such issues of unknown participant overlap. In the case

14 of autism research, we must be particularly sensitive to the possibility that the independence assumption may have been violated. Since case-control designs are notoriously timeconsuming and practically difficult to conduct, it is possible that even the same lab group may rely on overlapping groups of participants from study to study, but fail to report this information.

Finally, despite our large sample size and parsimonious approach to moderator analysis, many of our statistical tests were conducted with quite few observations per cell and so may have been under-powered. It is important therefore, to interpret our results not just on a binary rule on accepting or rejecting the null hypothesis, but on a consideration of the estimated effect sizes, the precision of these estimates and the associated relative strength of evidence for each moderator. 


\section{4.4. Implications for future research}

On the most basic level, the quantitative combination of effect sizes here provides a good basis for power calculations and sample size planning for future studies. Moreover, in many large scale ASD studies such as the EU-AIMS study in the EU (Charman et al., 2017) and the ABC-CT study in the USA (McPartland et al., 2019), there is a drive towards employing diverse batteries of tasks to understand the ASD phenotype. As such, there is a pressing need for an evidence base to inform the choice of tasks to include in such batteries.

The results from this meta-analysis can inform design of relevant task measures for social reward responsivity in future such studies, using lab-based or mobile technology.

\subsection{Conclusions}

The available data indicate that reduced social orienting in ASD is an effect that is detected across a range of sample characteristics, experimental paradigms and measures. By contrast, based on the current behavioral data, uncritical acceptance of the idea of reduced social seeking in ASD may be premature - the pooled effect size was small and only detected under specific experimental conditions. Moreover, our data indicate several sample and experimental design properties that may modulate group differences in responsivity to social stimuli. These inferences can be validated via well controlled and novel experimental designs. Moreover, the data we present can inform the design of enhanced behavioral endophenotypes for ASD. 


\section{References}

2 Alcaro, A., Huber, R., \& Panksepp, J. (2007). Behavioral functions of the mesolimbic

3 dopaminergic system: an affective neuroethological perspective. Brain Research $4 \quad$ Reviews, 56(2), 283-321.

5 Amso, D., Haas, S., Tenenbaum, E., Markant, J., \& Sheinkopf, S. J. (2014). Bottom-up attention orienting in young children with autism. Journal of Autism and Developmental Disorders, 44(3), 664-673.

8 Arizona Software. (n.d.). GraphClick - Graph and Movie Digitizer for Mac OS X - Free

Auyeung, B., Lombardo, M. V., Heinrichs, M., Chakrabarti, B., Sule, A., Deakin, J. B., ... Baron-Cohen, S. (2015). Oxytocin increases eye contact during a real-time, naturalistic

Bachevalier, J., \& Loveland, K. A. (2006). The orbitofrontal-amygdala circuit and selfregulation of social-emotional behavior in autism. Neuroscience and Biobehavioral Reviews, 30(1), 97-117.

Berridge, K. C., Robinson, T. E., \& Aldridge, J. W. (2009). Dissecting components of reward: 'liking', 'wanting', and learning. Current Opinion in Pharmacology, 9(1), 65-

Bhat, A. N., Galloway, J. C., \& Landa, R. J. (2010). Social and non-social visual attention patterns and associative learning in infants at risk for autism. Journal of Child Psychology and Psychiatry, and Allied Disciplines, 51(9), 989-997.

Blanchard, J. J., Horan, W. P., \& Brown, S. A. (2001). Diagnostic differences in social anhedonia: A longitudinal study of schizophrenia and major depressive disorder. Journal of Abnormal Psychology, 110(3), 363-371. https://doi.org/10.1037//0021$\underline{843 \times .110 .3 .363}$ 
1 Bottini, S. (2018). Social reward processing in individuals with autism spectrum disorder: A systematic review of the social motivation hypothesis. Research in Autism Spectrum Disorders, 45, 9-26.

Brown, A. C., Chouinard, P. A., \& Crewther, S. G. (2017). Vision Research Literature May Not Represent the Full Intellectual Range of Autism Spectrum Disorder. Frontiers in Human Neuroscience, 11. https://doi.org/10.3389/fnhum.2017.00057

Cage, E., Pellicano, E., Shah, P., \& Bird, G. (2013). Reputation Management: Evidence for Ability But Reduced Propensity in Autism. Autism Research, 6(5), 433-442. https://doi.org/10.1002/aur.1313

Cañigueral, R., \& Hamilton, A. F. de C. (2019). Do Beliefs About Whether Others Can See Modulate Social Seeking in Autism? Journal of Autism and Developmental Disorders, 49(1), 335-348.

Chanel, G., Pichon, S., Conty, L., Berthoz, S., Chevallier, C., \& Grèzes, J. (2016). Classification of autistic individuals and controls using cross-task characterization of

Chawarska, K., Macari, S., Powell, K., DiNicola, L., \& Shic, F. (2016). Enhanced Social fMRI activity. NeuroImage. Clinical, 10, 78-88.

Charman, T., Loth, E., Tillmann, J., Crawley, D., Wooldridge, C., Goyard, D., ... Buitelaar, J. K. (2017). The EU-AIMS Longitudinal European Autism Project (LEAP): clinical

Chawarska, K., Macari, S., \& Shic, F. (2012). Context modulates attention to social scenes in toddlers with autism. Journal of Child Psychology and Psychiatry, and Allied Disciplines, 53(8), 903-913.

Chawarska, K., Macari, S., \& Shic, F. (2013). Decreased spontaneous attention to social scenes in 6-month-old infants later diagnosed with autism spectrum disorders. Biological 
Psychiatry, 74(3), 195-203.

Chen, P.-Y., \& Schwartz, I. S. (2012). Bullying and Victimization Experiences of Students With Autism Spectrum Disorders in Elementary Schools. Focus on Autism and Other Developmental Disabilities, 27(4), 200-212.

Chevallier, C., Kohls, G., Troiani, V., Brodkin, E. S., \& Schultz, R. T. (2012). The social motivation theory of autism. Trends in Cognitive Sciences, 16(4), 231-239.

Chevallier, C., Parish-Morris, J., McVey, A., Rump, K. M., Sasson, N. J., Herrington, J. D., \& Schultz, R. T. (2015). Measuring social attention and motivation in autism spectrum disorder using eye-tracking: Stimulus type matters. Autism Research: Official Journal of the International Society for Autism Research, 8(5), 620-628.

Chica, A. B., Martín-Arévalo, E., Botta, F., \& Lupiáñez, J. (2014). The Spatial Orienting 2 paradigm: How to design and interpret spatial attention experiments. Neuroscience and Biobehavioral Reviews, 40, 35-51. Retrieved 24 September 2015 from

Chita-Tegmark, M. (2016a). Attention Allocation in ASD: a Review and Meta-analysis of Eye-Tracking Studies. Review Journal of Autism and Developmental Disorders, 3(3), $209-223$.

Chita-Tegmark, M. (2016b). Social attention in ASD: A review and meta-analysis of eyetracking studies. Research in Developmental Disabilities, 48, 79-93.

Chlebowski, C., Green, J. A., Barton, M. L., \& Fein, D. (2010). Using the childhood autism rating scale to diagnose autism spectrum disorders. Journal of Autism and Developmental Disorders, 40(7), 787-799.

Clements, C. C., Zoltowski, A. R., Yankowitz, L. D., Yerys, B. E., Schultz, R. T., \& Herrington, J. D. (2018). Evaluation of the Social Motivation Hypothesis of Autism: A Systematic Review and Meta-analysis. JAMA Psychiatry . Retrieved from https://doi.org/10.1001/jamapsychiatry.2018.1100 
1 Constantino, J. N., \& Gruber, C. P. (2012). Social responsiveness scale: SRS-2. Western Psychological Services Torrance, CA.

3 Cooper, H., \& Hedges, L. V. (1993). The Handbook of Research Synthesis. Russell Sage Foundation.

5 Corbett, B. A., Swain, D. M., Newsom, C., Wang, L., Song, Y., \& Edgerton, D. (2014).

6 Biobehavioral profiles of arousal and social motivation in autism spectrum disorders. Journal of Child Psychology and Psychiatry, and Allied Disciplines, 55(8), 924-934.

Costa, P., Terracciano, A., \& McCrae, R. R. (2001). Gender differences in personality traits across cultures: Robust and surprising findings. Journal of Personality and Social Psychology, 81(2), 322-331. Retrieved 12 May 2020 from

Crawford, H., Moss, J., Anderson, G. M., Oliver, C., \& McCleery, J. P. (2015). Implicit Discrimination of Basic Facial Expressions of Positive/Negative Emotion in Fragile X Syndrome and Autism Spectrum Disorder. American Journal on Intellectual and Developmental Disabilities, 120(4), 328-345.

Dalton, K. M., Nacewicz, B. M., Alexander, A. L., \& Davidson, R. J. (2007). Gaze-fixation, brain activation, and amygdala volume in unaffected siblings of individuals with autism. Biological Psychiatry, 61(4), 512-520.

Dawson, G., Meltzoff, A. N., Osterling, J., Rinaldi, J., \& Brown, E. (1998). Children with autism fail to orient to naturally occurring social stimuli. Journal of Autism and Developmental Disorders, 28(6), 479-485.

Dawson, G., Webb, S. J., \& McPartland, J. (2005). Understanding the nature of face processing impairment in autism: insights from behavioral and electrophysiological studies. Developmental Neuropsychology, 27(3), 403-424.

Delmonte, S., Balsters, J. H., McGrath, J., Fitzgerald, J., Brennan, S., Fagan, A. J., \& Gallagher, L. (2012). Social and monetary reward processing in autism spectrum 
disorders. Molecular Autism, 3(1), 7.

Demurie, E., Roeyers, H., Baeyens, D., \& Sonuga-Barke, E. (2011). Common alterations in sensitivity to type but not amount of reward in ADHD and autism spectrum disorders. Journal of Child Psychology and Psychiatry, and Allied Disciplines, 52(11), 1164-1173.

Dichter, G. S., Richey, J. A., Rittenberg, A. M., Sabatino, A., \& Bodfish, J. W. (2012). Reward circuitry function in autism during face anticipation and outcomes. Journal of Autism and Developmental Disorders, 42(2), 147-160.

Dölen, G. (2015). Autism: Oxytocin, serotonin, and social reward. Social Neuroscience, $10(5), 450-465$.

Dubey, I., Ropar, D., \& de C Hamilton, A. F. (2017). Brief Report: A Comparison of the Preference for Viewing Social and Non-social Movies in Typical and Autistic Adolescents. Journal of Autism and Developmental Disorders, 47(2), 514-519.

Dubey, I., Ropar, D., \& Hamilton, A. (2018). Comparison of choose-a-movie and approachavoidance paradigms to measure social motivation. Motivation and Emotion, 42(2), 190199.

Dubey, I., Ropar, D., \& Hamilton, A. F. de C. (2015). Measuring the value of social engagement in adults with and without autism. Molecular Autism, 6, 35.

Duval, S., \& Tweedie, R. (2000). A Nonparametric ‘Trim and Fill' Method of Accounting for Publication Bias in Meta-Analysis. Journal of the American Statistical Association, 95(449), 89-98.

Dworzynski, K., Ronald, A., Bolton, P., \& Happé, F. (2012). How different are girls and boys above and below the diagnostic threshold for autism spectrum disorders? Journal of the American Academy of Child and Adolescent Psychiatry, 51(8), 788-797.

Egger, M., Davey Smith, G., Schneider, M., \& Minder, C. (1997). Bias in meta-analysis detected by a simple, graphical test. BMJ, 315(7109), 629-634. 
1 Eisenberg, I. W., Bissett, P. G., Zeynep Enkavi, A., Li, J., MacKinnon, D. P., Marsch, L. A., \& Poldrack, R. A. (2019). Uncovering the structure of self-regulation through datadriven ontology discovery. Nature Communications, 10(1), 2319. https://doi.org/10.1038/s41467-019-10301-1

Ewing, L., Pellicano, E., \& Rhodes, G. (2013). Reevaluating the selectivity of faceprocessing difficulties in children and adolescents with autism. Journal of Experimental Child Psychology, 115(2), 342-355.

Fischer, J., Koldewyn, K., Jiang, Y. V., \& Kanwisher, N. (2014). Unimpaired Attentional Disengagement and Social Orienting in Children with Autism. Clinical Psychological Science, 2(2), 214-223.

Fletcher-Watson, S., Leekam, S. R., Benson, V., Frank, M. C., \& Findlay, J. M. (2009). Eyemovements reveal attention to social information in autism spectrum disorder. Neuropsychologia, 47(1), 248-257.

Fombonne, E. (1999). The epidemiology of autism: A review. Psychological Medicine, 29(4), 769-786. https://doi.org/10.1017/s0033291799008508

Frazier, T. W., Strauss, M., Klingemier, E. W., Zetzer, E. E., Hardan, A. Y., Eng, C., \& Youngstrom, E. A. (2017). A Meta-Analysis of Gaze Differences to Social and Nonsocial Information Between Individuals With and Without Autism. Journal of the American Academy of Child and Adolescent Psychiatry, 56(7), 546-555.

Frith, C., \& Frith, U. (2005). Theory of mind. Current Biology: CB, 15(17), R644-6.

Geelhand, P., Bernard, P., Klein, O., van Tiel, B., \& Kissine, M. (2019). The role of gender in the perception of autism symptom severity and future behavioral development. Molecular Autism, 10, 16.

Gilbertson, L. R., Lutfi, R. A., \& Ellis Weismer, S. (2017). Auditory preference of children with autism spectrum disorders. Cognitive Processing, 18(2), 205-209. 
1 Gotham, K., Risi, S., Pickles, A., \& Lord, C. (2007). The Autism Diagnostic Observation Schedule: revised algorithms for improved diagnostic validity. Journal of Autism and Developmental Disorders, 37(4), 613-627.

Greenhouse, J. B., \& Iyengar, S. (1994). Sensitivity analysis and diagnostics. In H. Cooper (Ed.), The handbook of research synthesis , (pp (Vol. 573, pp. 383-398). New York, NY, US: Russell Sage Foundation, xvi.

Grelotti, D. J., Gauthier, I., \& Schultz, R. T. (2002). Social interest and the development of cortical face specialization: what autism teaches us about face processing.

Happé, F. (2005). The weak central coherence account of autism. Handbook of Autism and Pervasive Developmental Disorders, Volume 1, Third Edition, 640-649.

Harrop, C., Jones, D., Zheng, S., Nowell, S., Schultz, R., \& Parish-Morris, J. (2019). Visual attention to faces in children with autism spectrum disorder: are there sex differences? Molecular Autism, 10, 28.

Harrop, C., Jones, D., Zheng, S., Nowell, S. W., Boyd, B. A., \& Sasson, N. (2018). Sex differences in social attention in autism spectrum disorder. Autism Research: Official Journal of the International Society for Autism Research, 11(9), 1264-1275.

Hedger, N., Gray, K. L. H., Garner, M., \& Adams, W. J. (2016). Are visual threats prioritized without awareness? A critical review and meta-analysis involving 3 behavioral paradigms and 2696 observers. Psychological Bulletin, 142(9), 934-968.

Hedger, N., Haffey, A., McSorley, E., \& Chakrabarti, B. (2018). Empathy modulates the temporal structure of social attention. Proceedings. Biological Sciences / The Royal Society, 285(1893), 20181716.

Helt, M., Kelley, E., Kinsbourne, M., Pandey, J., Boorstein, H., Herbert, M., \& Fein, D. (2008). Can children with autism recover? If so, how? Neuropsychology Review, 18(4), 
339-366.

2 Hill, E. L. (2004). Executive dysfunction in autism. Trends in Cognitive Sciences, 8(1), 26-

3

4

5

6

7 32.

Insel, T., Cuthbert, B., Garvey, M., Heinssen, R., Pine, D. S., Quinn, K., Sanislow, C., \& Wang, P. (2010). Research Domain Criteria (RDoC): Toward a New Classification Framework for Research on Mental Disorders. American Journal of Psychiatry, 167(7), 748-751. https://doi.org/10.1176/appi.ajp.2010.09091379

Jarrold, C., \& Brock, J. (2004). To match or not to match? Methodological issues in autismrelated research. Journal of Autism and Developmental Disorders, 34(1), 81-86.

Jaswal, V. K., \& Akhtar, N. (2019). Being versus appearing socially uninterested: Challenging assumptions about social motivation in autism. The Behavioral and Brain Sciences, 42. Retrieved 13 December 2019 from https://doi.org/10.1017/S0140525X18001826

Jones, R. M., \& Lord, C. (2013). Diagnosing autism in neurobiological research studies. Behavioural Brain Research, 251, 113-124.

Jones, W., Carr, K., \& Klin, A. (2008). Absence of preferential looking to the eyes of approaching adults predicts level of social disability in 2-year-old toddlers with autism spectrum disorder. Archives of General Psychiatry, 65(8), 946-954.

Joyce, C., Honey, E., Leekam, S. R., Barrett, S. L., \& Rodgers, J. (2017). Anxiety, Intolerance of Uncertainty and Restricted and Repetitive Behaviour: Insights Directly from Young People with ASD. Journal of Autism and Developmental Disorders, 47(12), 3789-3802.

Kanat, M., Spenthof, I., Riedel, A., van Elst, L. T., Heinrichs, M., \& Domes, G. (2017). Restoring effects of oxytocin on the attentional preference for faces in autism. Translational Psychiatry, 7(4), e1097. 
1 Kleberg, J. L., Thorup, E., \& Falck-Ytter, T. (2017). Visual orienting in children with autism: Hyper-responsiveness to human eyes presented after a brief alerting audio-signal, but hyporesponsiveness to eyes presented without sound. Autism Research: Official Journal of the International Society for Autism Research, 10(2), 246-250.

Klin, A., Jones, W., Schultz, R., Volkmar, F., \& Cohen, D. (2002). Visual fixation patterns during viewing of naturalistic social situations as predictors of social competence in individuals with autism. Archives of General Psychiatry, 59(9), 809-816.

Klin, A., Lin, D. J., Gorrindo, P., Ramsay, G., \& Jones, W. (2009). Two-year-olds with autism orient to non-social contingencies rather than biological motion. Nature, 459(7244), 257-261.

Kohls, G., Antezana, L., Mosner, M. G., Schultz, R. T., \& Yerys, B. E. (2018). Altered reward system reactivity for personalized circumscribed interests in autism. Molecular Autism, 9, 9.

Kohls, G., Chevallier, C., Troiani, V., \& Schultz, R. T. (2012). Social 'wanting' dysfunction in autism: neurobiological underpinnings and treatment implications. Journal of Neurodevelopmental Disorders, 4(1), 10.

Kohls, G., Peltzer, J., Schulte-Rüther, M., Kamp-Becker, I., Remschmidt, H., HerpertzDahlmann, B., \& Konrad, K. (2011). Atypical brain responses to reward cues in autism as revealed by event-related potentials. Journal of Autism and Developmental Disorders, 41(11), 1523-1533.

Koldewyn, K., Weigelt, S., Kanwisher, N., \& Jiang, Y. (2013). Multiple object tracking in autism spectrum disorders. Journal of Autism and Developmental Disorders, 43(6), 1394-1405.

Kou, J., Le, J., Fu, M., Lan, C., Chen, Z., Li, Q., ... Kendrick, K. M. (2019). Comparison of three different eye-tracking tasks for distinguishing autistic from typically developing 
children and autistic symptom severity. Autism Research: Official Journal of the International Society for Autism Research, 12(10), 1529-1540.

Kuhn, G., Kourkoulou, A., \& Leekam, S. R. (2010). How magic changes our expectations about autism. Psychological Science, 21(10), 1487-1493.

Lai, M.-C., Lombardo, M. V., Pasco, G., Ruigrok, A. N. V., Wheelwright, S. J., Sadek, S. A., ... Baron-Cohen, S. (2011). A behavioral comparison of male and female adults with high functioning autism spectrum conditions. PloS One, 6(6), e20835.

Lakens, D. (2013). Calculating and reporting effect sizes to facilitate cumulative science: a practical primer for t-tests and ANOVAs. Frontiers in Psychology, 4, 863.

Liang, J., \& Wilkinson, K. (2018). Gaze Toward Naturalistic Social Scenes by Individuals With Intellectual and Developmental Disabilities: Implications for Augmentative and Alternative Communication Designs. Journal of Speech, Language, and Hearing Research: JSLHR, 61(5), 1157-1170.

Liebal, K., Colombi, C., Rogers, S. J., Warneken, F., \& Tomasello, M. (2008). Helping and Cooperation in Children with Autism. Journal of Autism and Developmental Disorders, 38(2), 224-238. https://doi.org/10.1007/s10803-007-0381-5

MacLennan, K., Roach, L., \& Tavassoli, T. (2020). The Relationship Between Sensory Reactivity Differences and Anxiety Subtypes in Autistic Children. Autism Research, 13(5), 785-795. https://doi.org/10.1002/aur.2259

Madipakkam, A. R., Rothkirch, M., Dziobek, I., \& Sterzer, P. (2019). Access to awareness of direct gaze is related to autistic traits. Psychological Medicine, 49(6), 980-986.

Marois, R., \& Ivanoff, J. (2005). Capacity limits of information processing in the brain. Trends in Cognitive Sciences, 9(6), 296-305. Retrieved 13 April 2018 from

Marsh, L., Pearson, A., Ropar, D., \& Hamilton, A. (2013). Children with autism do not overimitate. Current Biology: CB, 23(7), R266-268. 
Matt, G. E., \& Cook, T. D. (2009). Threats to the validity of generalized inferences. The Handbook of Research Synthesis and Meta-Analysis., 2nd Ed., 2, 537-560.

Mattys, L., Noens, I., Evers, K., \& Baeyens, D. (2018). 'Hold Me Tight So I Can Go It Alone': Developmental Themes for Young Adults With Autism Spectrum Disorder. Qualitative Health Research, 28(2), 321-333.

McPartland, J. C., Bernier, R. A., Jeste, S. S., Dawson, G., Nelson, C. A., Chawarska, K., ... Others. (2019). The Autism Biomarkers Consortium for Clinical Trials (ABC-CT):

Moher, D., Liberati, A., Tetzlaff, J., Altman, D. G., \& The PRISMA Group. (2009). Preferred

Moore, A., Wozniak, M., Yousef, A., Barnes, C. C., Cha, D., Courchesne, E., \& Pierce, K.

Modi, M. E., \& Young, L. J. (2012). The oxytocin system in drug discovery for autism: animal models and novel therapeutic strategies. Hormones and Behavior, 61(3), 340350. Reporting Items for Systematic Reviews and Meta-Analyses: The PRISMA Statement. PLoS Medicine, 6(7), e1000097. Retrieved 23 September 2015 from (2018). The geometric preference subtype in ASD: identifying a consistent, earlyemerging phenomenon through eye tracking. Molecular Autism, 9, 19.

Moore, D. J., Heavey, L., \& Reidy, J. (2012). Attentional processing of faces in ASD: a Dot- 
Probe study. Journal of Autism and Developmental Disorders, 42(10), 2038-2045.

2 Moore, D. J., Reidy, J., \& Heavey, L. (2016). Attentional allocation of autism spectrum disorder individuals: Searching for a Face-in-the-Crowd. Autism: The International Journal of Research and Practice, 20(2), 163-171.

Mosconi, M. W., Steven Reznick, J., Mesibov, G., \& Piven, J. (2009). The Social Orienting Continuum and Response Scale (SOC-RS): a dimensional measure for preschool-aged children. Journal of Autism and Developmental Disorders, 39(2), 242-250.

New, J. J., Schultz, R. T., Wolf, J., Niehaus, J. L., Klin, A., German, T. C., \& Scholl, B. J. (2010). The scope of social attention deficits in autism: prioritized orienting to people and animals in static natural scenes. Neuropsychologia, 48(1), 51-59.

Norbury, C. F., Brock, J., Cragg, L., Einav, S., Griffiths, H., \& Nation, K. (2009). Eyemovement patterns are associated with communicative competence in autistic spectrum disorders. Journal of Child Psychology and Psychiatry, and Allied Disciplines, 50(7), 834-842.

Parish-Morris, J., Pallathra, A. A., Ferguson, E., Maddox, B. B., Pomykacz, A., Perez, L. S., ... Brodkin, E. S. (2019). Adaptation to different communicative contexts: an eye tracking study of autistic adults. Journal of Neurodevelopmental Disorders, 11(1), 5.

Peça, J., Feliciano, C., Ting, J. T., Wang, W., Wells, M. F., Venkatraman, T. N., ... Feng, G. (2011). Shank3 mutant mice display autistic-like behaviours and striatal dysfunction. Nature, 472(7344), 437-442.

Pelphrey, K. A., Sasson, N. J., Reznick, J. S., Paul, G., Goldman, B. D., \& Piven, J. (2002). Visual Scanning of Faces in Autism. Journal of Autism and Developmental Disorders, 32(4), 249-261.

Pierce, K., Conant, D., Hazin, R., Stoner, R., \& Desmond, J. (2011). Preference for geometric patterns early in life as a risk factor for autism. Archives of General Psychiatry, 68(1), 
$1 \quad 101-109$.

2 Pierce, K., Marinero, S., Hazin, R., McKenna, B., Barnes, C. C., \& Malige, A. (2016). Eye

3 Tracking Reveals Abnormal Visual Preference for Geometric Images as an Early

4 Biomarker of an Autism Spectrum Disorder Subtype Associated With Increased

$5 \quad$ Symptom Severity. Biological Psychiatry, 79(8), 657-666.

6 Posner, M. I. (1980). Orienting of attention. The Quarterly Journal of Experimental

$7 \quad$ Psychology, 32(1), 3-25.

8 Posner, M. I., Snyder, C. R., \& Davidson, B. J. (1980). Attention and the detection of signals.

9 Journal of Experimental Psychology, 109(2), 160-174.

10 Pruett, J. R., Jr, Hoertel, S., Constantino, J. N., Moll, A. L., McVey, K., Squire, E., ...

11 Petersen, S. E. (2013). Impaired eye region search accuracy in children with autistic

12 spectrum disorders. PloS One, 8(3), e58167.

Puleo, C. M., Schmeidler, J., Reichenberg, A., Kolevzon, A., Soorya, L. V., Buxbaum, J. D., \& Silverman, J. M. (2012). Advancing paternal age and simplex autism. Autism: The International Journal of Research and Practice, 16(4), 367-380.

Raudenbush, S. W. (1994). Random effects models. In H. Cooper (Ed.), The handbook of research synthesis , (pp (Vol. 573, pp. 301-321). New York, NY, US: Russell Sage Foundation, xvi.

Riby, D. M., Doherty-Sneddon, G., \& Bruce, V. (2008). Exploring face perception in disorders of development: evidence from Williams syndrome and autism. Journal of Neuropsychology, 2(1), 47-64.

Riby, D. M., \& Hancock, P. J. B. (2009). Do faces capture the attention of individuals with Williams syndrome or autism? Evidence from tracking eye movements. Journal of Autism and Developmental Disorders, 39(3), 421-431. 
spectrum disorders: visual scanning of dynamic social scenes in school-aged children. Journal of the American Academy of Child and Adolescent Psychiatry, 51(3), 238-248.

Richey, J. A., Brewer, J. A., Sullivan-Toole, H., Strege, M. V., Kim-Spoon, J., White, S. W., \& Ollendick, T. H. (2019). Sensitivity shift theory: A developmental model of positive affect and motivational deficits in social anxiety disorder. Clinical Psychology Review, 72, 101756. https://doi.org/10.1016/j.cpr.2019.101756

Rødgaard, E.-M., Jensen, K., Vergnes, J.-N., Soulières, I., \& Mottron, L. (2019). Temporal Changes in Effect Sizes of Studies Comparing Individuals With and Without Autism: A Meta-analysis. JAMA Psychiatry, 76(11), 1124-1132. https://doi.org/10.1001/jamapsychiatry.2019.1956

Rosenthal, R. (1979). The file drawer problem and tolerance for null results. Psychological Bulletin, 86(3), 638-641.

Rosenthal, R. (1991). Meta-analytic procedures for social research. Sage. Retrieved 28 February 2020 from

Ruta, L., Famà, F. I., Bernava, G. M., Leonardi, E., Tartarisco, G., Falzone, A., ... Chakrabarti, B. (2017). Reduced preference for social rewards in a novel tablet based task in young children with Autism Spectrum Disorders. Scientific Reports, 7(1), 3329.

Rutter, M., Le Couteur, A., Lord, C., \& Others. (2003). Autism diagnostic interview-revised. Los Angeles, CA: Western Psychological Services, 29(2003), 30.

Santosh, P. J., \& Mijovic, A. (2004). Social impairment in Hyperkinetic Disorder. European Child \& Adolescent Psychiatry, 13(3), 141-150. https://doi.org/10.1007/s00787-004$\underline{0372-4}$

Sasson, N., Tsuchiya, N., Hurley, R., Couture, S. M., Penn, D. L., Adolphs, R., \& Piven, J. (2007). Orienting to social stimuli differentiates social cognitive impairment in autism and schizophrenia. Neuropsychologia, 45(11), 2580-2588.

Schmidt, F. L., Oh, I.-S., \& Hayes, T. L. (2009). Fixed- versus random-effects models in 
meta-analysis: model properties and an empirical comparison of differences in results. The British Journal of Mathematical and Statistical Psychology, 62(Pt 1), 97-128.

Scott-Van Zeeland, A. A., Dapretto, M., Ghahremani, D. G., Poldrack, R. A., \& Bookheimer, S. Y. (2010). Reward processing in autism. Autism Research: Official Journal of the International Society for Autism Research, 3(2), 53-67.

Shah, P., Gaule, A., Bird, G., \& Cook, R. (2013). Robust orienting to protofacial stimuli in autism. Current Biology: CB, 23(24), R1087-R1088. Retrieved 6 November 2017 from

Sheth, B. R., Liu, J., Olagbaju, O., Varghese, L., Mansour, R., Reddoch, S., ... Loveland, K.

A. (2011). Detecting social and non-social changes in natural scenes: performance of children with and without autism spectrum disorders and typical adults. Journal of Autism and Developmental Disorders, 41(4), 434-446.

Simonoff, E., Pickles, A., Charman, T., Chandler, S., Loucas, T., \& Baird, G. (2008).

3 Psychiatric disorders in children with autism spectrum disorders: prevalence, comorbidity, and associated factors in a population-derived sample. Journal of the American Academy of Child and Adolescent Psychiatry, 47(8), 921-929.

Speer, L. L., Cook, A. E., McMahon, W. M., \& Clark, E. (2007). Face processing in children with autism: Effects of stimulus contents and type. Autism: The International Journal of $8 \quad$ Research and Practice, 11(3), 265-277.

Spreckelmeyer, K. N., Krach, S., Kohls, G., Rademacher, L., Irmak, A., Konrad, K., ... Gründer, G. (2009). Anticipation of monetary and social reward differently activates mesolimbic brain structures in men and women. Social Cognitive and Affective Neuroscience, 4(2), 158-165.

Stein, T., Hebart, M. N., \& Sterzer, P. (2011). Breaking Continuous Flash Suppression: A New Measure of Unconscious Processing during Interocular Suppression? Frontiers in Human Neuroscience, 5, 167. 
1 Tang, J. S. Y., Chen, N. T. M., Falkmer, M., Bölte, S., \& Girdler, S. (2019). Atypical Visual Processing but Comparable Levels of Emotion Recognition in Adults with Autism During the Processing of Social Scenes. Journal of Autism and Developmental Disorders, 49(10), 4009-4018.

Tavassoli, T., Bellesheim, K., Tommerdahl, M., Holden, J. M., Kolevzon, A., \& Buxbaum, J. D. (2016). Altered tactile processing in children with autism spectrum disorder. Autism Research: Official Journal of the International Society for Autism Research, 9(6), 616620. https://doi.org/10.1002/aur.1563

Tenenbaum, E. J., Amso, D., Abar, B., \& Sheinkopf, S. J. (2014). Attention and word 
of Statistical Software, Articles, 36(3), 1-48.

Vivanti, G., Hocking, D. R., Fanning, P., \& Dissanayake, C. (2017). The social nature of overimitation: Insights from Autism and Williams syndrome. Cognition, 161, 10-18. https://doi.org/10.1016/j.cognition.2017.01.008

Wagenmakers, E.-J., \& Farrell, S. (2004). AIC model selection using Akaike weights. Psychonomic Bulletin \& Review, 11(1), 192-196.

Wan, X., Wang, W., Liu, J., \& Tong, T. (2014). Estimating the sample mean and standard deviation from the sample size, median, range and/or interquartile range. BMC Medical Research Methodology, 14(1), 135. https://doi.org/10.1186/1471-2288-14-135

Wang, S., Xu, J., Jiang, M., Zhao, Q., Hurlemann, R., \& Adolphs, R. (2014). Autism spectrum disorder, but not amygdala lesions, impairs social attention in visual search. Neuropsychologia, 63, 259-274.

Watson, K. K., Miller, S., Hannah, E., Kovac, M., Damiano, C. R., Sabatino-DiCrisco, A., ... Dichter, G. S. (2015). Increased reward value of non-social stimuli in children and adolescents with autism. Frontiers in Psychology, 6, 1026.

Wright, J. S., \& Panksepp, J. (2012). An Evolutionary Framework to Understand Foraging, Wanting, and Desire: The Neuropsychology of the SEEKING System. Neuropsychoanalysis, 14(1), 5-39.

Yamasue, H., Okada, T., Munesue, T., Kuroda, M., Fujioka, T., Uno, Y., ... Kosaka, H. (2018). Effect of intranasal oxytocin on the core social symptoms of autism spectrum disorder: a randomized clinical trial. Molecular Psychiatry. Retrieved from https://doi.org/10.1038/s41380-018-0097-2

Zwaigenbaum, L., Thurm, A., Stone, W., Baranek, G., Bryson, S., Iverson, J., ... Sigman, M. (2007). Studying the emergence of autism spectrum disorders in high-risk infants: methodological and practical issues. Journal of Autism and Developmental Disorders, $37(3), 466-480$. 
2 BC was supported by the Leverhulme Trust (Grant No: PLP2015-329), Medical Research

3 Council UK (Grant No: MR/ P023894/1), and SPARC UKIERI funds (Grant No: P1215)

4 during this period of work. NH is currently funded by an individual fellowship from the

$5 \quad$ Leverhulme Trust (ECF 2019-305).

6

7 
3

4

5

6 7

Figure 1. Schematic of typical orienting paradigms. Left panels depict typical experimental display/ trial sequence for a) Gaze preference b) Visual probe c) Visual Search d) bCFS. Right panels depict typical patterns of data predicted by an SMT account of autism. (1)

Figure 2. Schematic of typical seeking paradigms. Left panels depict typical experimental display/ trial sequence for a) an example of social incentive task, b) an example of choice task, c) an example of an expenditure task. Right panels depict typical patterns of data predicted by an SMT account of autism.

Figure 3. Social orienting: Model properties. a) Forest plot of all 167 effect sizes. Error bars are $95 \%$ confidence intervals (CI). Dashed white vertical line is the pooled summary effect, shaded vertical red region is the $95 \%$ CI. b) Funnel plot. Dotted vertical line indicates pooled meta-analytic estimate of effect size. Diagonal lines indicate $p$ values (outward from centre: $.05, .01, .001, .0001$, etc). c) Depicts the number of unpublished studies required to reduce the meta-analytic estimate of the effect size to target levels.

Figure 4. Moderators detected for social orienting effects. Random effects models with a) Diagnostic Assessment b) Social AOI, c) Stimulus context and d) Interactive content as the sole moderator. Error bars are 95\% confidence intervals. Size of points is inversely proportional to the standard error of the effect (larger $=$ more precision). A key is shown at the top of the figure to relate point size to the smallest and largest SE in the dataset. 
2 Figure 5. Shows the importance (as defined by summed Akaike weights) of each of the 3 coefficients across the population of tested models. Larger values can be thought of as 4 reflecting the extent to which including the moderator generates better-performing models.

6 Figure 6. Social seeking: Model properties. a) Forest plot of all 28 effect sizes. Error bars are $795 \%$ confidence intervals (CI). Dotted white vertical line is the pooled summary effect, 8 shaded vertical red region is the $95 \%$ CI. b) Funnel plot. Dotted vertical line indicates pooled 9 meta-analytic estimate of effect size. Diagonal lines indicate $p$ values (outward from centre: $10.05, .01, .001, .0001$, etc). c) Depicts the number of unpublished studies required to reduce the 11 meta-analytic estimate of the effect size to target levels.

13 Figure 7. Moderators detected for social seeking effects. Random effects models with a)

14 Nonverbal IQ matching b) Sex ratio, c) Diagnostic Assessment and d) Seeking measure as 15 the sole moderator. Error bars are 95\% confidence intervals. Size of points is inversely 16 proportional to the standard error of the effect (larger $=$ more precision). A key is shown at 17 the top of the figure to relate point size to the smallest and largest SE in the dataset.

19 Figure 8. Shows the importance (defined as summed Akaike weights) for each of the 20 coefficients across the population of tested models. 
3 Table 1

$4 \quad$ Existing Reviews That Examine Social Motivation in Relation to ASD

\begin{tabular}{|c|c|c|c|c|c|}
\hline Paper & Review Type & Focus & $\begin{array}{l}\text { Included } \\
\text { methodologies }\end{array}$ & $\begin{array}{l}\text { Studies in } \\
\text { analysis }\end{array}$ & $\begin{array}{l}\text { Participants in } \\
\text { analysis }\end{array}$ \\
\hline $\begin{array}{l}\text { (Chevallier et } \\
\text { al., 2012) }\end{array}$ & $\begin{array}{l}\text { Narrative/ } \\
\text { theoretical }\end{array}$ & $\begin{array}{l}\text { Orienting, } \\
\text { seeking, }\end{array}$ & $\begin{array}{l}\text { Behavioral, } \\
\text { neuroimaging }\end{array}$ & NA & NA \\
\hline $\begin{array}{l}\text { (Kohls et al., } \\
\text { 2012) }\end{array}$ & Narrative & Seeking & $\begin{array}{l}\text { Behavioral, } \\
\text { neuroimaging }\end{array}$ & NA & NA \\
\hline $\begin{array}{l}\text { (Chita- } \\
\text { Tegmark, } \\
\text { 2016b) }\end{array}$ & $\begin{array}{l}\text { Quantitative } \\
\text { (meta-analysis) }\end{array}$ & Orienting & $\begin{array}{l}\text { Behavioral (only } \\
\text { eye-tracking) }\end{array}$ & 38 & $\begin{array}{l}1215 \text { ASD } \\
1314 \mathrm{NT}\end{array}$ \\
\hline $\begin{array}{l}\text { (Chita- } \\
\text { Tegmark, } \\
\text { 2016a) }\end{array}$ & $\begin{array}{l}\text { Quantitative } \\
\text { (meta-analysis) }\end{array}$ & Orienting & $\begin{array}{l}\text { Behavioral (only } \\
\text { eye-tracking) }\end{array}$ & 68 & $\begin{array}{l}1319 \text { ASD } \\
1496 \mathrm{NT}\end{array}$ \\
\hline $\begin{array}{l}\text { (Frazier et al., } \\
\text { 2017) }\end{array}$ & $\begin{array}{l}\text { Quantitative } \\
\text { (meta-analysis) }\end{array}$ & Orienting & $\begin{array}{l}\text { Behavioral (only } \\
\text { eye-tracking) }\end{array}$ & 122 & $\begin{array}{l}2418 \text { NT } \\
2199 \text { ASD }\end{array}$ \\
\hline (Bottini, 2018) & $\begin{array}{l}\text { Qualitative ( } \\
\text { Summary of } \\
\text { studies that } \\
\text { 'support' or } \\
\text { 'contradict' } \\
\text { SMT, but no } \\
\text { meta-analysis) }\end{array}$ & $\begin{array}{l}\text { Orienting / } \\
\text { seeking }\end{array}$ & $\begin{array}{l}\text { Behavioral, } \\
\text { physiological }\end{array}$ & 27 & $\begin{array}{l}789 \mathrm{NT} \\
593 \mathrm{ASD}\end{array}$ \\
\hline $\begin{array}{l}\text { (Clements et } \\
\text { al., 2018) }\end{array}$ & $\begin{array}{l}\text { Quantitative } \\
\text { (meta-analysis) }\end{array}$ & Seeking & Neuroimaging & 13 & $\begin{array}{l}259 \text { ASD, } 246 \\
\text { NT }\end{array}$ \\
\hline $\begin{array}{l}\text { (Jaswal \& } \\
\text { Akhtar, 2019) }\end{array}$ & $\begin{array}{l}\text { Narrative/ } \\
\text { opinion piece }\end{array}$ & $\begin{array}{l}\text { Orienting/ } \\
\text { seeking }\end{array}$ & $\begin{array}{l}\text { Behavioral, } \\
\text { neuroimaging }\end{array}$ & NA & NA \\
\hline $\begin{array}{l}\text { The present } \\
\text { paper }\end{array}$ & $\begin{array}{l}\text { Quantitative } \\
\text { (meta-analysis) }\end{array}$ & $\begin{array}{l}\text { Orienting/ } \\
\text { Seeking }\end{array}$ & Behavioral & 117 & $\begin{array}{l}2994 \text { ASD } \\
3146 \text { NT }\end{array}$ \\
\hline
\end{tabular}

5

6 Note. Reviews were identified via an exhaustive search of all articles citing (Chevallier et al., 7 2012). 


\section{$1 \quad$ Table 2}

2 Summary of Potential Moderators of Social Orienting Effects.

\begin{tabular}{|c|c|c|}
\hline Moderator & Variable type & Description/ justification \\
\hline VIQ match & Boolean & $\begin{array}{l}\text { Description: Whether or not groups were matched on verbal } \\
\text { IQ. Justification: There are concerns that group differences } \\
\text { may be driven by generalised differences in cognitive } \\
\text { functioning, rather than autism symptoms per se (Norbury et } \\
\text { al., 2009). Note that we code as 'unmatched' if only nonverbal } \\
\text { IQ measures are reported in the paper. Following previous } \\
\text { meta-analyses, if full scale IQ is matched, then we additionally } \\
\text { code VIQ as being matched (Chita-Tegmark, 2016b). }\end{array}$ \\
\hline NVIQ match & Boolean & $\begin{array}{l}\text { Description: Whether or not groups differed on nonverbal IQ. } \\
\text { Justification: As above. }\end{array}$ \\
\hline Sex ratio & & $\begin{array}{l}\text { Description: The mean sex ratio of the sample (values above } 1 \\
\text { indicate greater number of males than females). Justification: } \\
\text { Female observers tend to exhibit greater social attention } \\
\text { (Harrop et al., 2018). Note: Sex ratio is defined as } N \text { males/ } N \\
\text { females. Thus a value of } 1 \text { indicates an equal number of males } \\
\text { and females. In rare cases where the sample was entirely male, } \\
\text { we report the sex ratio as being equal to the number of males. }\end{array}$ \\
\hline Age & Continuous & $\begin{array}{l}\text { Description: The average age of the sample (in years). } \\
\text { Justification: The distinction between social attention behavior } \\
\text { in early and later development may not reflect the same } \\
\text { psychological processes. As Rice et al. (2012) point out: "the } \\
\text { data from adults represent the cumulative effects of long-term } \\
\text { atypical experiences, whereas the data from toddlers represent } \\
\text { a time in which symptomatology profiles are still emerging", } \\
\text { (p. 239) (Rice, Moriuchi, Jones, \& Klin, 2012). }\end{array}$ \\
\hline
\end{tabular}

Descriptive statistics

Matched $(k=67)$

Unmatched $(k=100)$

Matched $(k=67)$

Unmatched $(k=100)$

$M=6.4$, Range: $0-29.5$

$M=10.65$, Range: 0.53

41.03

No ADOS $(k=55)$

$\operatorname{ADOS}(k=103)$

Diagnostic

Categorical

Description: The assessment used to confirm diagnosis of

ASD . Justification: The autism diagnostic observation

schedule (ADOS) (Gotham, Risi, Pickles, \& Lord, 2007) and autism diagnostic interview revised (ADI-R) (Rutter, Le Couteur, Lord, \& Others, 2003) are thorough assessments that require trained clinicians to administer. When no ADOS is administered, typically briefer measures are implemented, such as relying on prior psychiatric records, or measures such as the social responsiveness scale (Constantino \& Gruber, 2012). It is possible that these different diagnostic measures could lead to the selection of different sub-samples of the ASD population.

Orienting Categorical

Description: How the dependent variable is operationalised. Justification: There is some evidence to suggest that autistic differences in social attention are a function of the component of attention being measured (e.g., early components are measured by latency to first fixation, later components may be better captured by total gaze duration) (Fischer, Koldewyn, Jiang, \& Kanwisher, 2014; Hedger, Haffey, McSorley, \& Chakrabarti, 2018).

ADOS + ADI-R $(k=9)$

Total gaze duration $(k=$ 135)

Latency to first fixation $(k=18)$

Proportion of first

fixations $(k=6)$

Dot probe latency $(k=4)$

Visual search latency $(k$ $=2$ )

CFS detection latency $(k$ $=2$ ) 
modality

Stimulus AOI Categorical

Stimulus Categorical context

Interactive Categorical content image. Justification: Some analyses indicate that effect sizes may be larger for stimuli with more dynamic content (Chevallier et al., 2015; Speer, Cook, McMahon, \& Clark, 2007).

Description: The social AOI within which orienting is compared between the groups. For instance, some studies only reported group differences in gaze to 'eye' (Kleberg, Thorup, \& Falck-Ytter, 2017) or 'face' (Riby \& Hancock, 2009) regions within the display, whereas other studies reported gaze differences to additional 'body' regions (Klin et al., 2002). If sufficient data for both a 'body' and 'face' AOI were available, we pooled across these AOIs to create a 'person' AOI (see Supplementary Material S1). Note, therefore, that a 'person' AOI comprises of a 'face' AOI and additional body parts. In some cases, the group differences relate to gaze to an entire social scene presented on one side of the screen that competes with a nonsocial scene on the other side of the screen (A. Moore et al., 2018; Pierce et al., 2016). Justification: The type of social stimulus in the display can modulate the degree of social attention differences. For instance, some studies have observed gaze behavior in viewing dynamic social scenes is more diagnostic of group differences than displays involving biological motion patterns (Kou et al., 2019).

Description: The context in which the observers are presented with social stimuli. Justification: Some gaze preference tasks may explicitly or implicitly encourage observers to direct attention towards the social (or nonsocial) stimulus, whereas others may simply be passive viewing tasks. These different stimulus contexts are likely to modulate the effect size (Chawarska, Macari, \& Shic, 2012).

Definitions:

1) Free viewing: No instruction given to the observer (Pierce et al., 2016).

2) Active engage: A person in the stimulus engages the observer in conversation (W. Jones, Carr, \& Klin, 2008).

3) Active present: A person in the video presents the observer with an object (Tenenbaum, Amso, Abar, \& Sheinkopf, 2014).

4) Active social task: The observer is given a task that specifically encourages them to attend to the social stimulus. E.g., "How is this person feeling?" (Sasson et al., 2007).

5) Active nonsocial task: The observer is given a task that specifically encourages them to attend to nonsocial elements of the display. E.g., "How did this person perform the magic trick?" (Kuhn, Kourkoulou, \& Leekam, 2010).

6) Active joint attention: A person looks at the observer and then towards an object in the display (Chawarska et al., 2012).

7) Search: The observer is specifically required to search for a social item in the display (Moore, Reidy, \& Heavey, 2016).

Description: Describes whether the stimulus involves an interaction between people. Justification: Some research has indicated that group differences may only be present in conditions where realistic interactions are depicted and not when social stimuli are isolated and static (Speer et al., 2007).
Video $(k=96)$

Face $(k=75)$

Person $(k=61)$

Social Scene $(k=21)$

Biological Motion $(k=7)$

Eyes $(k=3)$

Free-viewing $(k=109)$

Active engage $(k=15)$

Active present $(k=8)$

Active social task $(k=$ 14)

Active nonsocial task ( $k$ $=6$ )

Active joint attention $(k$ $=11$ )

Active search $(k=4)$

None $(k=99)$

Interaction in viewed stimulus $(k=43)$ Interaction with observer $(k=25)$ 
$1 \quad$ Table 3

2 Outcome of Linear Hypothesis Tests from the Multiple Regression Model.

\begin{tabular}{lll}
\hline \multicolumn{1}{l}{ Coefficient } & \multicolumn{2}{l}{$Q(d f)$} \\
\hline Diagnostic Assessment & $Q(2)=5.32$ & .070 \\
Social AOI & $Q(4)=5.56$ & .234 \\
Stimulus context & $Q(6)=9.60$ & .143 \\
Interactive content & $Q(2)=8.02$ & $.018^{*}$ \\
\hline
\end{tabular}

3

$4 \quad$ Note. ${ }^{*} p<.05$

5

6 


\section{$1 \quad$ Table 4}

2 Summary of Moderators for Social Seeking Effects.

\begin{tabular}{|c|c|c|}
\hline Moderator & Variable type & Description/ justification \\
\hline VIQ match & Boolean & See Table 2 \\
\hline NVIQ match & Boolean & See Table 2 \\
\hline Sex ratio & Continuous & See Table 2 \\
\hline Age & Continuous & See table 2 \\
\hline $\begin{array}{l}\text { Diagnostic } \\
\text { assessment }\end{array}$ & Categorical & See Table 2 \\
\hline \multirow[t]{6}{*}{$\begin{array}{l}\text { Seeking } \\
\text { measure }\end{array}$} & \multirow[t]{6}{*}{ Categorical } & $\begin{array}{l}\text { Description: The dependent variable used to assess seeking } \\
\text { behavior. Justification: Enhanced social seeking can be } \\
\text { indexed via various outcome measures, which may vary in } \\
\text { their sensitivity. }\end{array}$ \\
\hline & & Definitions: \\
\hline & & $\begin{array}{l}\text { 1) Accuracy: The proportion of correct responses within a } \\
\text { task where receipt of a social or nonsocial stimulus is } \\
\text { contingent on an accurate response. }\end{array}$ \\
\hline & & $\begin{array}{l}\text { 2) Response Time: The latency of a response in a } \\
\text { paradigm wherein receipt of a social or nonsocial } \\
\text { stimulus is dependent on a response within a finite time } \\
\text { window. }\end{array}$ \\
\hline & & $\begin{array}{l}\text { 3) Button Presses: The number of button presses that are } \\
\text { made within a finite time window to receive increased } \\
\text { exposure to a social or nonsocial stimulus. (In some } \\
\text { paradigms, a stimulus was presented for longer } \\
\text { durations, or a larger proportion of the stimulus was } \\
\text { made physically visible in a manner that was } \\
\text { proportional to the frequency of button presses). }\end{array}$ \\
\hline & & $\begin{array}{l}\text { 4hoice Proportion: The proportion of choices made to } \\
\text { receive a social (as opposed to nonsocial) stimulus } \\
\text { when given a choice between the two options. }\end{array}$ \\
\hline
\end{tabular}

Social

stimulus type

Stimulus modality
Descriptive statistics

Matched $(k=14)$

Unmatched $(k=14)$

Matched $(k=17)$

Unmatched $(k=11)$

$M=9.67$ Range: $1-21$

$M=14.57$ Range: 2.75

37.24

No ADOS $(k=3)$

$\operatorname{ADOS}(k=25)$

Accuracy $(k=9)$

Response time $(k=8)$

Button presses $(k=4)$

Choice proportion $(k=7)$
Description: The social stimulus received contingent on the appropriate response. Justification: Seeking behaviors may be modulated by the type of social stimulus that incentivises the task behavior.

See Table 2.

Note: In one study, participants were rewarded with participation in a 'real-world' activity based on their choices. This is thus coded as a separate category.
Smiling face $(k=15)$

Interaction $(k=3)$

Neutral face $(k=4)$

Praise $(k=3)$

Social Activity $(k=2)$

Speech $(k=1)$

Video $(k=7)$

Image $(k=17)$

Sound $(k=2)$

Real-world $(k=2)$ 
$1 \quad$ Table 5

2 Outcome of Linear Hypothesis Tests from Multiple Regression Model

\begin{tabular}{lll}
\hline Coefficient & $Q(d f)$ & $p$ \\
\hline NVIQ matching & $Q(1)=3.64$ & .056 \\
Sex ratio & $Q(1)=0.53$ & .467 \\
Diagnostic Assessment & $Q(1)=2.96$ & .086 \\
Seeking measure & $Q(3)=4.46$ & .216 \\
\hline
\end{tabular}

3

4

5

6

7

8

9

10

11

12

13

14 


\section{Supplementary Material}

\section{Supplementary Material S1: Method for Pooling Across Standard Deviations}

In several eye-tracking studies, means and variances were reported separately for multiple distinct areas of interest (e.g., mouth, eyes, upper face, lower face). To obtain an overall measure of social attention, we pooled across these statistics. Whereas pooling across means is straightforward, pooling the standard deviations requires an estimate of the variance of the averaged data $\left(\sigma^{2}\right)$. To do this, we assumed that the correlation across conditions ( $x$ and y) was 0.5 and so to recover the pooled standard deviation, we used the following formula:

$\sigma_{a v}^{2}=\frac{1}{4}\left(\sigma^{2}+\sigma_{y}^{2}+\sigma_{x} \times \sigma_{y}\right)$

As repeated measures designs have high precision, the correlation across conditions tends to be quite high - assuming a correlation of 0.5 is therefore quite conservative as the resulting estimate of the pooled standard deviation will likely be larger than it truly is, consequently reducing effect size. Thus, this provides a fairly conservative estimate of the precision in the effect size estimate.

\section{Supplementary Material S2: Pseudo R2 statistic}

The pseudo R² statistic (López-López, Marín-Martínez, Sánchez-Meca, Van den Noortgate, \& Viechtbauer, 2013) estimates heterogeneity reduction when moderators are included, and is computed with the formula:

$$
R^{2}=\frac{\tau_{R E}^{2}-\tau_{M E}^{2}}{\tau_{R E}^{2}}
$$


Where $\mathrm{T}^{2} \mathrm{RE}$ is the estimated heterogeneity of the random effects model without moderators, and $\mathrm{T}^{2} \mathrm{ME}$ is the estimated residual heterogeneity from the mixed effects model including the moderators. Note that the formula essentially estimates the proportional reduction in effect size heterogeneity $\left(\mathrm{T}^{2}\right)$ after including moderators, but it does not incorporate sampling variability. Hence, it is possible to observe large $R^{2}$ values, even when there are discrepancies between the regression line and the observed effect sizes (when those discrepancies do not exceed what one would expect based on sampling variability alone). In fact, when $\mathrm{T}^{2} \mathrm{ME}=0$, then $R^{2}=1$. However, unlike the interpretation of a conventional $R^{2}$ statistic, this does not imply that all data fall perfectly on the regression line, but only that the residuals do not exceed what is expected due to sampling variability. As such, this statistic should be interpreted with caution for analyses that have small $\mathrm{k}$. 


\section{Supplementary Material S3: Search Terms and PRISMA flowcharts}

\section{Table S1}

Summary of Search Terms

\begin{tabular}{lll}
\hline Autism terms & Orienting terms & Seeking terms \\
\hline$A S D^{*}$ & Orienting, eye-tracking, dot probe, & Social seeking, social wanting, \\
ASC $^{*}$ & attentional cueing, eye-movements, & social liking, social reward, choose \\
Autis $^{*}$ & gaze, visual search, CFS & a movie, button task, social \\
Asperger & & motivation. \\
\hline
\end{tabular}

Note. Searches were constructed via using combinations of the Autism terms and the terms in the remaining columns, using the AND operator. All terms were entered in the 'Title/Abstract' fields in the PubMed advanced search builder.

\section{Social Orienting: PRISMA Flowchart}




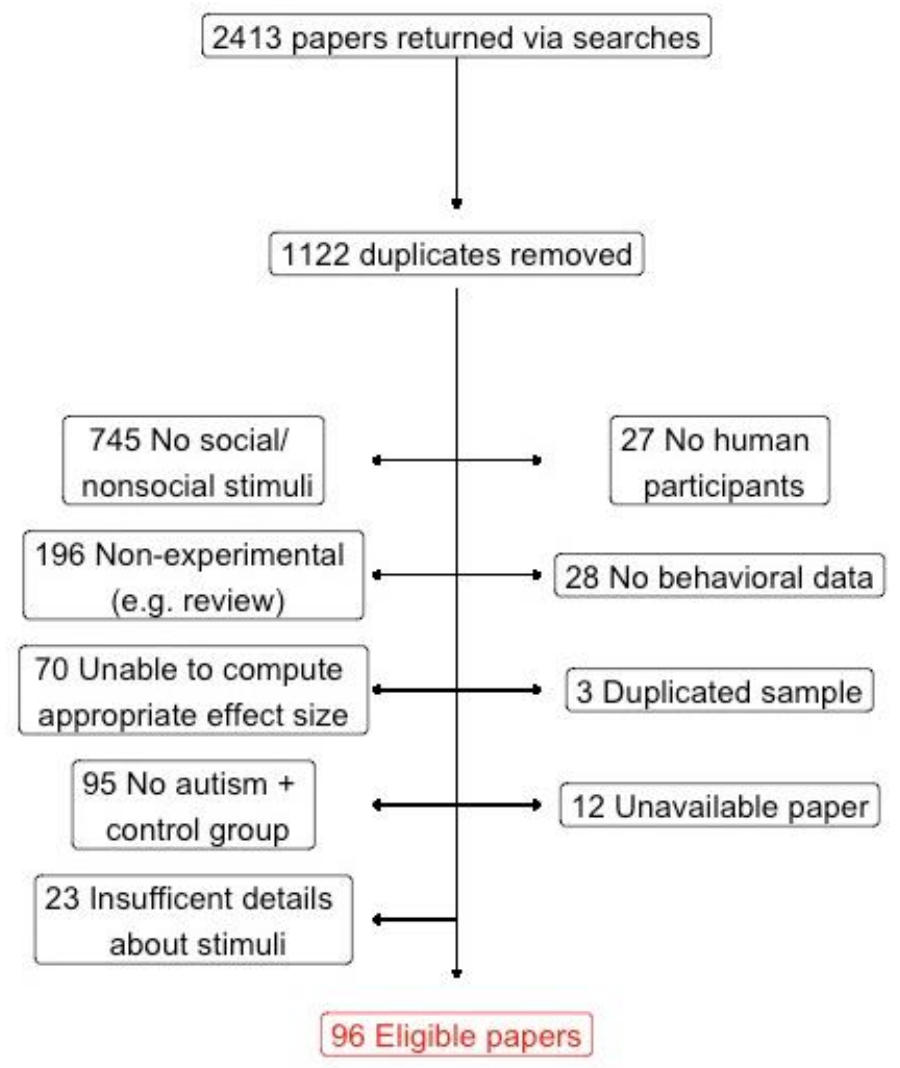

Figure S1. PRISMA flow chart that depicts the number of articles excluded as a function of each criterion (social orienting). Note that some articles were removed violated multiple inclusion criteria and so the flow chart will tend to indicate the reason that first became apparent when reading the paper.

\section{Social Seeking: PRISMA Flowchart}




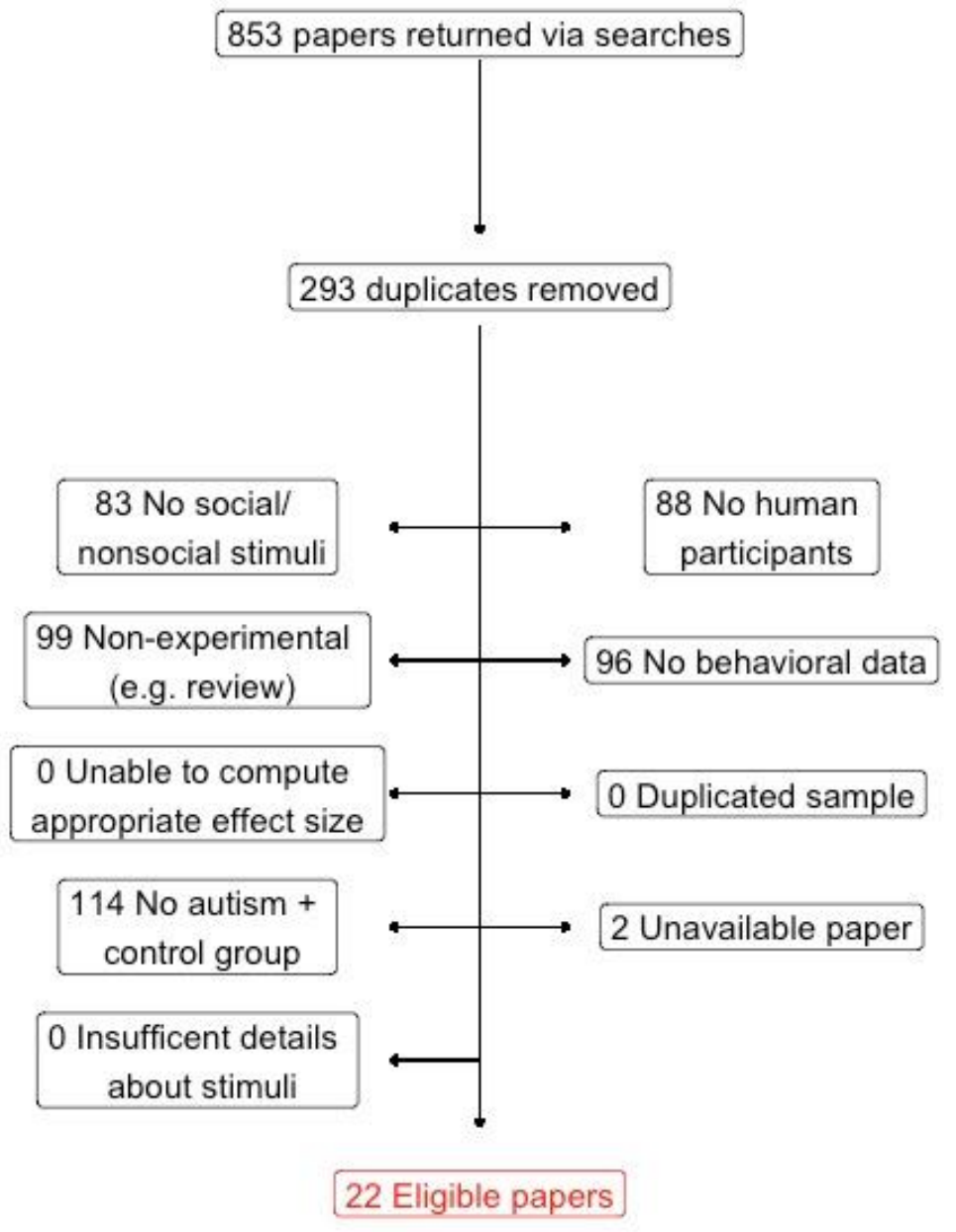

Figure S2. PRISMA flow chart that depicts the number of articles excluded for each criterion (social seeking). 


\section{Supplementary Material S4: Summary of included studies}

\section{Social Orienting}

\section{Table S2}

Summary of Effects Included in the Analysis of Social Orienting Effects

\begin{tabular}{|c|c|c|c|c|c|}
\hline Study & Paper & Sample & Effect & $N A S D, N N T$ & Notes \\
\hline $\begin{array}{l}\text { (Klin, Jones, } \\
\text { Schultz, } \\
\text { Volkmar, \& } \\
\text { Cohen, 2002) }\end{array}$ & 1 & 1 & 1 & 15,15 & $\begin{array}{l}\text { Data are pooled across AOls. Means and } \\
\text { SDs are taken from table } 3 \text { in (Chita- } \\
\text { Tegmark, 2016) }\end{array}$ \\
\hline $\begin{array}{l}\text { (van der Geest, } \\
\text { Kemner, } \\
\text { Camfferman, } \\
\text { Verbaten, \& } \\
\text { van Engeland, } \\
2002 \text { ) }\end{array}$ & 2 & 2 & 2 & 16,14 & $\begin{array}{l}\text { Data are taken from } t \text { value on } p 73 \text {. } \\
\text { Direction of effects are determined by means } \\
\text { in table } 2 .\end{array}$ \\
\hline-- & 2 & 2 & 3 & -- & (Latency to first fixation) \\
\hline $\begin{array}{l}\text { (Kemner, van } \\
\text { der Geest, } \\
\text { Verbaten, \& } \\
\text { van Engeland, } \\
2007 \text { ) }\end{array}$ & 3 & 3 & 4 & 17,16 & $\begin{array}{l}\text { Data are pooled across simple and complex } \\
\text { face conditions. Taken from table } 3 \text { in (Chita- } \\
\text { Tegmark, 2016) }\end{array}$ \\
\hline $\begin{array}{l}\text { (N. Sasson et } \\
\text { al., 2007) }\end{array}$ & 4 & 4 & 5 & 10,10 & $\begin{array}{l}\text { Data are taken from means and SDs in table } \\
3 .\end{array}$ \\
\hline-- & 4 & 4 & 6 & -- & (Latency to first fixation) \\
\hline-- & 4 & 4 & 7 & -- & (Proportion of first fixations) \\
\hline $\begin{array}{l}\text { (Speer, Cook, } \\
\text { McMahon, \& } \\
\text { Clark, 2007) }\end{array}$ & 5 & 5 & 8 & 12,12 & $\begin{array}{l}\text { Only means are reported in the table. } d \text { is } \\
\text { computed from the } p \text { value reported in the } \\
\text { text on } p 272 \text { (eye region only). }\end{array}$ \\
\hline $\begin{array}{l}\text { (Jones, Carr, \& } \\
\text { Klin, 2008) }\end{array}$ & 6 & 6 & 9 & 15,36 & $\begin{array}{l}\text { Data are taken from means and SDs in table } \\
2 \text { (pooled across AOIs). }\end{array}$ \\
\hline $\begin{array}{l}\text { (Riby \& } \\
\text { Hancock, } \\
\text { 2008) }\end{array}$ & 7 & 7 & 10 & 20,20 & $\begin{array}{l}\text { (Matched group). Means and SDs taken } \\
\text { from Figure } 2 .\end{array}$ \\
\hline-- & 7 & 8 & 11 & 20,20 & (Unmatched group). \\
\hline $\begin{array}{l}\text { (Fletcher- } \\
\text { Watson, } \\
\text { Leekam, }\end{array}$ & 8 & 9 & 12 & 12,14 & Means and SDs taken from tables 2 and 4. \\
\hline
\end{tabular}


Benson, Frank, \& Findlay,

2009)

\begin{tabular}{|c|c|c|c|c|c|}
\hline-- & 8 & 9 & 13 & -- & (Proportion of first fixations) \\
\hline-- & 8 & 9 & 14 & -- & (Gender task) \\
\hline-- & 8 & 9 & 15 & -- & (Gender task, proportion of first fixations) \\
\hline $\begin{array}{c}\text { (Klin, Lin, } \\
\text { Gorrindo, } \\
\text { Ramsay, \& } \\
\text { Jones, 2009) }\end{array}$ & 9 & 10 & 16 & 21,39 & Means and SDs are recovered from figure 1 \\
\hline $\begin{array}{l}\text { (Norbury et al., } \\
2009 \text { ) }\end{array}$ & 10 & 11 & 17 & 14,18 & $\begin{array}{l}\text { Means and SDs are recovered from table } 2 \\
\text { (language impaired group) }\end{array}$ \\
\hline-- & 10 & 12 & 18 & 14,18 & (Non language impaired group) \\
\hline $\begin{array}{c}\text { (D. M. Riby \& } \\
\text { Hancock, } \\
\text { 2009) }\end{array}$ & 11 & 13 & 19 & 22,22 & $\begin{array}{l}\text { Means and SDs taken from table } 3 \text { in (Chita- } \\
\text { Tegmark, 2016) }\end{array}$ \\
\hline-- & 11 & 13 & 20 & -- & (Latency to first fixation) \\
\hline-- & 11 & 13 & 21 & -- & (Experiment 2) \\
\hline-- & 11 & 13 & 22 & -- & (Experiment 2, latency to first fixation) \\
\hline $\begin{array}{l}\text { (D. Riby \& } \\
\text { Hancock, } \\
\text { 2009) }\end{array}$ & 12 & 14 & 23 & 20,20 & $\begin{array}{l}\text { Means and SDs are taken from various plots } \\
\text { in figure } 1 \text { (matched group, cartoon image) }\end{array}$ \\
\hline-- & 12 & 15 & 24 & -- & (Nonmatched group, 'cartoon image') \\
\hline-- & 12 & 14 & 25 & -- & (Matched group, 'cartoon movie') \\
\hline-- & 12 & 15 & 26 & -- & (Nonmatched group, 'cartoon movie') \\
\hline-- & 12 & 14 & 27 & -- & (Matched group, 'natural movie') \\
\hline-- & 12 & 15 & 28 & -- & (Nonmatched group, 'natural movie') \\
\hline $\begin{array}{c}\text { (Benson, Piper, } \\
\text { \& Fletcher- } \\
\text { Watson, 2009) }\end{array}$ & 13 & 16 & 29 & 7,9 & $\begin{array}{l}\text { Means and SDs are recovered from figure } \\
1 d .\end{array}$ \\
\hline-- & 13 & 16 & 30 & -- & ('Gender'task) \\
\hline $\begin{array}{c}\text { (Kuhn, } \\
\text { Kourkoulou, \& } \\
\text { Leekam, 2010) }\end{array}$ & 14 & 17 & 31 & 15,18 & Means and SDs are recovered from figure 1. \\
\hline-- & 14 & 17 & 32 & -- & $\begin{array}{l}\text { (Time to first fixation). Means and } S D s \\
\text { recovered from the text on page } 1490 .\end{array}$ \\
\hline $\begin{array}{c}\text { (Nadig, Lee, } \\
\text { Singh, } \\
\text { Bosshart, \& } \\
\text { Ozonoff, 2010) }\end{array}$ & 15 & 18 & 33 & 12,11 & $\begin{array}{l}\text { Means and SDs are taken from table } 3 \text { in } \\
\text { (Chita-Tegmark, 2016) }\end{array}$ \\
\hline
\end{tabular}




\begin{tabular}{|c|c|c|c|c|c|}
\hline $\begin{array}{l}\text { (Wilson, Brock, } \\
\text { \& Palermo, } \\
\text { 2010) }\end{array}$ & 16 & 19 & 34 & 13,14 & Means and SDs are recovered from figure 4. \\
\hline-- & 16 & 19 & 35 & -- & (Time to first fixation) \\
\hline $\begin{array}{l}\text { (M. Freeth, } \\
\text { Chapman, } \\
\text { Ropar, \& } \\
\text { Mitchell, 2010) }\end{array}$ & 17 & 20 & 36 & 24,24 & $\begin{array}{l}\text { Means and SDs obtained from figure } 3 . \\
\text { These statistics are pooled across upper and } \\
\text { lower face (Five second presentation). }\end{array}$ \\
\hline-- & 17 & 20 & 37 & -- & (Two second presentation) \\
\hline $\begin{array}{l}\text { (Bird, Press, \& } \\
\text { Richardson, } \\
\text { 2011) }\end{array}$ & 18 & 21 & 38 & 13,13 & $\begin{array}{l}\text { The means and SDs are recovered from the } \\
\text { text on page } 4 \text {, in the 'group comparison' } \\
\text { section of the results. }\end{array}$ \\
\hline $\begin{array}{l}\text { (Birmingham, } \\
\text { Cerf, \& } \\
\text { Adolphs, 2011) }\end{array}$ & 19 & 22 & 39 & 9,5 & $\begin{array}{l}\text { Means and standard deviations are } \\
\text { recovered from figure } 4 A \text {. Note that no } \\
\text { standard deviations are reported for initial } \\
\text { fixation proportions and so an effect size } \\
\text { cannot be estimated for this measure. }\end{array}$ \\
\hline $\begin{array}{l}\text { (Megan Freeth, } \\
\text { Ropar, Mitchell, } \\
\text { Chapman, \& } \\
\text { Loher, 2011) }\end{array}$ & 20 & 23 & 40 & 24,24 & Means and SDs obtained from table 3. \\
\hline-- & 20 & 23 & 41 & & (Time to first fixation) \\
\hline $\begin{array}{c}\text { (Kirchner, } \\
\text { Hatri, } \\
\text { Heekeren, \& } \\
\text { Dziobek, 2011) }\end{array}$ & 21 & 24 & 42 & 20,21 & $\begin{array}{l}\text { Here the relevant statistic is computed from } \\
\text { the } F \text { value reported on page } 162\end{array}$ \\
\hline $\begin{array}{l}\text { (Shic, } \\
\text { Bradshaw, Klin, } \\
\text { Scassellati, \& } \\
\text { Chawarska, } \\
\text { 2011) }\end{array}$ & 22 & 25 & 43 & 28,34 & Means and SDs taken from table 2. \\
\hline $\begin{array}{l}\text { (Pierce, } \\
\text { Conant, Hazin, } \\
\text { Stoner, \& } \\
\text { Desmond, } \\
\text { 2011) }\end{array}$ & 23 & 26 & 44 & 37,51 & Effect size computed from $t$ value on page 7 \\
\hline $\begin{array}{l}\text { (Chawarska, } \\
\text { Macari, \& Shic, } \\
\text { 2012) }\end{array}$ & 24 & 27 & 45 & 54,48 & $\begin{array}{l}\text { Means and SDs are taken from table } 3 \text { in } \\
\text { (Chita-Tegmark, 2016) (dyadic bid condition) }\end{array}$ \\
\hline-- & 24 & 27 & 46 & -- & ('Sandwich' condition) \\
\hline-- & 24 & 27 & 47 & -- & ('Joint attention' condition) \\
\hline-- & 24 & 27 & 48 & -- & ('Moving toys' condition) \\
\hline $\begin{array}{l}\text { (Hanley, } \\
\text { McPhillips, } \\
\text { Mulhern, \& }\end{array}$ & 25 & 28 & 49 & 14,14 & $\begin{array}{l}\text { Means and SDs are taken from table } 3 \text { in } \\
\text { (Chita-Tegmark, 2016) ('isolated faces') }\end{array}$ \\
\hline
\end{tabular}




\begin{tabular}{|c|c|c|c|c|c|}
\hline -- & 25 & 28 & 50 & -- & ('Social scenes') \\
\hline $\begin{array}{l}\text { (Rice, Moriuchi, } \\
\text { Jones, \& Klin, } \\
\text { 2012) }\end{array}$ & 26 & 29 & 51 & 37,26 & Means and SDs are recovered from Figure 2 \\
\hline $\begin{array}{l}\text { (Noris, Nadel, } \\
\text { Barker, } \\
\text { Hadjikhani, \& } \\
\text { Billard, 2012) }\end{array}$ & 27 & 30 & 52 & 10,10 & $\begin{array}{l}\text { Means and SDs are recovered from Figure } \\
\text { 5. Data are taken from the central FOV } \\
\text { condition. }\end{array}$ \\
\hline $\begin{array}{l}\text { (D. J. Moore, } \\
\text { Heavey, \& } \\
\text { Reidy, 2012) }\end{array}$ & 28 & 31 & 53 & 19,19 & $\begin{array}{l}\text { Effect size calculated from } F \text { value on page } \\
2042 \text {. }\end{array}$ \\
\hline $\begin{array}{l}\text { (Hosozawa, } \\
\text { Tanaka, } \\
\text { Shimizu, } \\
\text { Nakano, \& } \\
\text { Kitazawa, } \\
\text { 2012) }\end{array}$ & 29 & 32 & 54 & 25,25 & $\begin{array}{l}\text { Effect size is computed from the upper } \\
\text { bound of the p value on page } 222 \text { since no } \\
\text { exact value is reported. This is the same } \\
\text { sample as reported in (Nakano et al., 2010) - } \\
\text { but meets inclusion criteria since the Nakano } \\
\text { paper did not. }\end{array}$ \\
\hline $\begin{array}{l}\text { (Chawarska, } \\
\text { Macari, \& Shic, } \\
\text { 2013) }\end{array}$ & 30 & 33 & 55 & 12,35 & $\begin{array}{l}\text { Data taken from the ASD and LR-TYP } \\
\text { groups. In line with our coding and inlcusion } \\
\text { decisions, } L R \text { (low risk) is the most valid } \\
\text { choice of control group. Means and SDs are } \\
\text { extracted from figure } 2\end{array}$ \\
\hline $\begin{array}{l}\text { (Elsabbagh et } \\
\text { al., 2013) }\end{array}$ & 31 & 34 & 56 & 17,46 & $\begin{array}{l}\text { Means and SDs are taken from table } 3 \text { on } \\
\text { page 152. ( } 7 \text { month, first fixation proportion) }\end{array}$ \\
\hline-- & 31 & 34 & 57 & -- & (14 month, first fixation proportion) \\
\hline-- & 31 & 34 & 58 & -- & (7 month) \\
\hline-- & 31 & 34 & 59 & -- & (14 month) \\
\hline $\begin{array}{l}\text { (Falck-Ytter, } \\
\text { Rehnberg, \& } \\
\text { Bölte, 2013) }\end{array}$ & 32 & 35 & 60 & 10,14 & $\begin{array}{l}\text { Means and SDs are recovered from Figure } \\
1 b . \text { Only data from the 'Upsync' condition is } \\
\text { used. }\end{array}$ \\
\hline $\begin{array}{l}\text { (Parish-Morris } \\
\text { et al., 2013) }\end{array}$ & 33 & 36 & 61 & 60,50 & $\begin{array}{l}\text { Effect size computed from the } t \text { value on } \\
\text { page } 5 .\end{array}$ \\
\hline $\begin{array}{c}\text { (Fischer, } \\
\text { Koldewyn, } \\
\text { Jiang, \& } \\
\text { Kanwisher, } \\
\text { 2014) }\end{array}$ & 34 & 37 & 62 & 44,40 & $\begin{array}{l}\text { In line with inclusion criteria, only data from } \\
\text { the 'disengage' trials are included, since only } \\
\text { in this case do we have a social and } \\
\text { nonsocial stimulus presented simultaneously } \\
\text {. Means and SDs are taken from table } 2 \text { of } \\
\text { Supplementary material. ( } 1 \text { second trials, } \\
\text { non - soc). This is coded as latency to first } \\
\text { fixation data. }\end{array}$ \\
\hline-- & 34 & 37 & 63 & -- & (2 second trials). \\
\hline $\begin{array}{l}\text { (Shah, Gaule, } \\
\text { Bird, \& Cook, }\end{array}$ & 35 & 38 & 64 & 18,18 & $\begin{array}{l}\text { Effect size is computed from t value reported } \\
\text { in supplementary material. }\end{array}$ \\
\hline
\end{tabular}


2013)

\begin{tabular}{|c|c|c|c|c|c|}
\hline $\begin{array}{l}\text { (Pruett et al., } \\
\text { 2013) }\end{array}$ & 36 & 39 & 65 & 31,29 & $\begin{array}{l}\text { Means and SDs are recovered from figure } 4 . \\
\text { Visual search task. }\end{array}$ \\
\hline $\begin{array}{l}\text { (D. M. Riby, } \\
\text { Hancock, } \\
\text { Jones, \& } \\
\text { Hanley, 2013) }\end{array}$ & 37 & 40 & 66 & 22,22 & $\begin{array}{l}\text { Effect size computed from from } t \text { value on } \\
\text { page } 6 \text { (spontaneous condition) }\end{array}$ \\
\hline-- & 37 & 40 & 67 & -- & ('Cued' condition). \\
\hline $\begin{array}{l}\text { (Amso, Haas, } \\
\text { Tenenbaum, } \\
\text { Markant, \& } \\
\text { Sheinkopf, } \\
\text { 2014) }\end{array}$ & 38 & 41 & 68 & 15,15 & $\begin{array}{l}\text { The study is quite complex in its analyses } \\
\text { and so few global differences between } \\
\text { groups are reported. } \\
\text { Means and standard deviations are only } \\
\text { reported for the 'incongruent' condition (p.8 - } \\
\text { pubmed version). }\end{array}$ \\
\hline
\end{tabular}

(Fujisawa, $\quad 39$

42

69

19,60

Tanaka, Saito,

Kosaka, \&

Tomoda, 2014)

\begin{tabular}{|c|c|c|c|c|c|}
\hline-- & 39 & 42 & 70 & -- & ('Biological motion' condition). \\
\hline $\begin{array}{l}\text { (N. J. Sasson \& } \\
\text { Touchstone, } \\
\text { 2014) }\end{array}$ & 40 & 43 & 71 & 15,15 & Means and SDs are recovered from fig $2 A$. \\
\hline-- & 40 & 43 & 72 & -- & $\begin{array}{l}\text { Effect size computed from } p \text { value on } p 588 \\
\text { (latency to first fixation). }\end{array}$ \\
\hline $\begin{array}{l}\text { (Tenenbaum, } \\
\text { Amso, Abar, \& } \\
\text { Sheinkopf, } \\
\text { 2014) }\end{array}$ & 41 & 44 & 73 & 13,14 & $\begin{array}{l}\text { Means and SDs from table } 3 \text { in (Chita- } \\
\text { Tegmark, 2016) }\end{array}$ \\
\hline $\begin{array}{c}\text { (Vivanti, } \\
\text { Trembath, \& } \\
\text { Dissanayake, } \\
\text { 2014) }\end{array}$ & 42 & 45 & 74 & 24,24 & $\begin{array}{l}\text { Data are taken from } F \text { value on page } 698 \\
\text { (main effect of group on attention to actors } \\
\text { face) }\end{array}$ \\
\hline $\begin{array}{l}\text { (Benjamin et } \\
\text { al., 2014) }\end{array}$ & 43 & 46 & 75 & 17,18 & $\begin{array}{l}\text { Means and SDs taken from figures } 2 \text { and } 3 \\
\text { ('face' condition) }\end{array}$ \\
\hline-- & 43 & 46 & 76 & -- & ('Distractor' condition). \\
\hline $\begin{array}{l}\text { (Wilkinson \& } \\
\text { Light, 2014) }\end{array}$ & 44 & 47 & 77 & 5,5 & Means and SDs are recovered from figure 2. \\
\hline $\begin{array}{l}\text { (Vivanti \& } \\
\text { Dissanayake, } \\
\text { 2014) }\end{array}$ & 45 & 48 & 78 & 25,25 & Means and SDs are recovered from figure 2. \\
\hline
\end{tabular}

For this paper, only data from the 'geometry' and 'biological motion' conditions are included. This is because there are no nonsocial/ social AOls are defined in the 'face' and 'finger pointing' conditions. Means and SDs are taken from table 2 (people and geometry condition).

('Biological motion' condition).

(N. J. Sasson \& 40 uchstone 


\begin{tabular}{|c|c|c|c|c|c|}
\hline $\begin{array}{l}\text { (Chevallier et } \\
\text { al., 2014) }\end{array}$ & 46 & 49 & 79 & 59,22 & $\begin{array}{l}\text { Means and SDs from table } 3 \text { in (Chita- } \\
\text { Tegmark, 2016) ('dynamic' condition). }\end{array}$ \\
\hline-- & 46 & 49 & 80 & -- & ('Interactive' condition). \\
\hline-- & 46 & 49 & 81 & -- & ('Static' condition). \\
\hline $\begin{array}{l}\text { (Falck-Ytter, } \\
\text { Carlström, \& } \\
\text { Johansson, } \\
\text { 2015) }\end{array}$ & 47 & 50 & 82 & 10,25 & $\begin{array}{l}\text { Means and SDs are taken from the 'direct } \\
\text { gaze' condition and in the encoding phase. } \\
\text { This data is taken from table } 2 .\end{array}$ \\
\hline $\begin{array}{l}\text { (Marsh, } \\
\text { Pearson, } \\
\text { Ropar, \& } \\
\text { Hamilton, } \\
\text { 2015) }\end{array}$ & 48 & 51 & 83 & 20,20 & $\begin{array}{l}\text { Effect size is computed from the } F \text { value in } \\
\text { table } 4 .\end{array}$ \\
\hline $\begin{array}{l}\text { (Schwartzman, } \\
\text { Velloso, } \\
\text { D'Antino, \& } \\
\text { Santos, 2015) }\end{array}$ & 49 & 52 & 84 & 11,17 & Means and SDs are taken from table 1 \\
\hline $\begin{array}{l}\text { (Shi et al., } \\
\text { 2015) }\end{array}$ & 50 & 53 & 85 & 13,20 & $\begin{array}{l}\text { Effect size is computed from the } F \text { value on } \\
\text { page } 8 . \text { Note that there is also first fixation } \\
\text { data reported, but it isn't possible to } \\
\text { determine the direction of the effect from the } \\
\text { information reported in the paper. }\end{array}$ \\
\hline $\begin{array}{l}\text { (Akechi et al., } \\
\text { 2015) }\end{array}$ & 51 & 54 & 86 & 10,10 & $\begin{array}{l}\text { Effect size is computed assuming a p value } \\
\text { of } .5 \text { (non-significant interaction). Direction of } \\
\text { effect is inferred from figure } 2 .\end{array}$ \\
\hline $\begin{array}{l}\text { (Trembath, } \\
\text { Vivanti, lacono, } \\
\text { \& Dissanayake, } \\
\text { 2015) }\end{array}$ & 52 & 55 & 87 & 25,19 & $\begin{array}{l}\text { Means and SDs are recovered from figure } 2 \\
\text { ('speech + pictures' condition - attention to } \\
\text { face). }\end{array}$ \\
\hline $\begin{array}{l}\text { (Van } \\
\text { Herwegen, } \\
\text { Smith, \& } \\
\text { Dimitriou, } \\
\text { 2015) }\end{array}$ & 53 & 56 & 88 & 13,14 & $\begin{array}{l}\text { Means and SDs are recovered from figure } 3 \\
\text { (pooled across false belief). }\end{array}$ \\
\hline $\begin{array}{l}\text { (Pierce et al., } \\
\text { 2016) }\end{array}$ & 54 & 57 & 89 & 115,64 & $\begin{array}{l}\text { Cohen's } d \text { is reported in the text on page } 6 \\
\text { (pubmed). Note that the text indicates that } \\
\text { this group is completely non-overlapping } \\
\text { from Pierce et al } 2011 .\end{array}$ \\
\hline $\begin{array}{l}\text { (Unruh et al., } \\
\text { 2016) }\end{array}$ & 55 & 58 & 90 & 33,31 & $\begin{array}{l}\text { Means and SDs are recovered from the } \\
\text { figures on page 5. ('high autism interest' } \\
\text { condition). }\end{array}$ \\
\hline-- & 55 & 58 & 91 & -- & ('Low autism interest' condition). \\
\hline $\begin{array}{l}\text { (Shaffer et al., } \\
2017)\end{array}$ & 56 & 59 & 92 & 37,26 & $\begin{array}{l}\text { Effect size computed from the means and } \\
\text { SDs on page } 510-511 .\end{array}$ \\
\hline
\end{tabular}




\begin{tabular}{|c|c|c|c|c|c|}
\hline $\begin{array}{l}\text { (Franchini et } \\
\text { al., 2016) }\end{array}$ & 57 & 60 & 93 & 20,20 & Means and SDs are reported in table 1. \\
\hline $\begin{array}{c}\text { (Müller, } \\
\text { Baumeister, } \\
\text { Dziobek, } \\
\text { Banaschewski, } \\
\text { \& Poustka, } \\
\text { 2016) }\end{array}$ & 58 & 61 & 94 & 30,23 & $\begin{array}{l}S D \text { s are not actually reported in the paper. } \\
\text { We use the 'range rule' for estimating them } \\
\text { from the ranges reported in table } 3 .\end{array}$ \\
\hline $\begin{array}{l}\text { (Billeci et al., } \\
\text { 2016) }\end{array}$ & 59 & 62 & 95 & 17,15 & $\begin{array}{l}\text { Effect sizes computed from } p \text { values taken } \\
\text { from figure } 5 \text { ('responding' condition) }\end{array}$ \\
\hline-- & 59 & 62 & 96 & -- & ('Joint attention' condition 1) \\
\hline-- & 59 & 62 & 97 & -- & ('Joint attention' condition 2) \\
\hline $\begin{array}{l}\text { (Fujioka et al., } \\
\text { 2016) }\end{array}$ & 60 & 63 & 98 & 26,35 & ('Biological motion' condition) \\
\hline-- & 60 & 63 & 99 & -- & $\begin{array}{l}\text { For this paper, none of the 'face' conditions, } \\
\text { are included in our analysis since no } \\
\text { nonsocial AOI is defined for these (there is } \\
\text { no competing stimulus- as the face appears } \\
\text { on a uniform, grey background). The cohen's } \\
d \text { values are directly reported in table } 2 . \\
\text { ('geometry' condition) }\end{array}$ \\
\hline-- & 60 & 63 & 100 & -- & ('Small geometry' condition) \\
\hline $\begin{array}{l}\text { (N. J. Sasson, } \\
\text { Pinkham, } \\
\text { Weittenhiller, } \\
\text { Faso, \& } \\
\text { Simpson, } \\
\text { 2016) }\end{array}$ & 61 & 64 & 101 & 21,39 & $\begin{array}{l}\text { Effect size computed from the } p \text { value } \\
\text { reported on page } 679 \text {. }\end{array}$ \\
\hline $\begin{array}{l}\text { (Nuske, } \\
\text { Vivanti, \& } \\
\text { Dissanayake, } \\
\text { 2016) }\end{array}$ & 62 & 65 & 102 & 20,20 & $\begin{array}{l}\text { Means and SDs recovered from figure } 3 \\
\text { ('happy' condition). }\end{array}$ \\
\hline-- & 62 & 65 & 103 & -- & ('Fear' condition) \\
\hline $\begin{array}{l}\text { (D. J. Moore, } \\
\text { Reidy, \& } \\
\text { Heavey, 2016) }\end{array}$ & 63 & 66 & 104 & 19,19 & Effect size computed from $F$ value on $p 167$ \\
\hline $\begin{array}{l}\text { (Chawarska, } \\
\text { Macari, Powell, } \\
\text { DiNicola, \& } \\
\text { Shic, 2016) }\end{array}$ & 64 & 67 & 105 & 90,79 & $\begin{array}{l}\text { Means and SDs are taken from table } 1 \\
\text { ('person' AOI). ('dyadic bid' condition). }\end{array}$ \\
\hline-- & 64 & 67 & 106 & -- & ('Joint' condition) \\
\hline-- & 64 & 67 & 107 & -- & ('Sandwich' condition) \\
\hline-- & 64 & 67 & 108 & -- & ('Moving toys' condition) \\
\hline
\end{tabular}




\begin{tabular}{|c|c|c|c|c|c|}
\hline $\begin{array}{l}\text { (Vargas- } \\
\text { Cuentas et al., } \\
\quad 2017)\end{array}$ & 65 & 68 & 109 & 8,23 & $\begin{array}{l}\text { Effect size is computed from the } p \text { value in } \\
\text { table } 2 \text { ('automated coding'). }\end{array}$ \\
\hline $\begin{array}{l}\text { (Franchini et } \\
\text { al., 2017) }\end{array}$ & 66 & 69 & 110 & 33,37 & $\begin{array}{l}\text { Effect size is computed from } t \text { value reported } \\
\text { on } p \text { 7. (proportion of first fixations). }\end{array}$ \\
\hline-- & 66 & 69 & 111 & -- & $\begin{array}{l}\text { Effect size is computed from } t \text { value reported } \\
\text { on } p 7 .\end{array}$ \\
\hline $\begin{array}{l}\text { (Zantinge, van } \\
\text { Rijn, } \\
\text { Stockmann, \& } \\
\text { Swaab, 2017) }\end{array}$ & 67 & 70 & 112 & 28,45 & Cohen's $d$ is reported on $p 1503$. \\
\hline $\begin{array}{l}\text { (Vivanti, } \\
\text { Fanning, } \\
\text { Hocking, } \\
\text { Sievers, \& } \\
\text { Dissanayake, } \\
\text { 2017) }\end{array}$ & 68 & 71 & 113 & 35,22 & $\begin{array}{l}\text { Effect size computed from } p \text { value. No exact } \\
p \text { value is reported so a value of } p=.005 \text { is } \\
\text { assumed ( } p \text { 1870). }\end{array}$ \\
\hline-- & 68 & 71 & 114 & 35,22 & $\begin{array}{l}\text { For experiment } 2 \text { - the data are not reported } \\
\text { separately for 'static' and 'dynamic' } \\
\text { conditions and so this reflects a composite } \\
\text { score - the same way it is treated in the } \\
\text { paper. } p 1872 .\end{array}$ \\
\hline $\begin{array}{c}\text { (Sekigawa- } \\
\text { Hosozawa, } \\
\text { Tanaka, } \\
\text { Shimizu, } \\
\text { Nakano, \& } \\
\text { Kitazawa, } \\
\text { 2017) }\end{array}$ & 69 & 72 & 115 & 25,25 & $\begin{array}{l}\text { Effect size estimated from the upper bound } \\
\text { of the } p \text { value on page } 222(p=.001) \text { since } \\
\text { no exact value is reported. }\end{array}$ \\
\hline $\begin{array}{l}\text { (Kleberg, } \\
\text { Thorup, \& } \\
\text { Falck-Ytter, } \\
\text { 2017) }\end{array}$ & 70 & 73 & 116 & 15,16 & $\begin{array}{l}\text { Cohen's } d \text { is reported in the text on p } 249 \\
\text { ('unisensory' condition). }\end{array}$ \\
\hline-- & 70 & 73 & 117 & 15,16 & $\begin{array}{l}\text { Means and SDs are recovered from figure } 2 . \\
\text { ('multisensory' condition). }\end{array}$ \\
\hline $\begin{array}{l}\text { (Tenenbaum, } \\
\text { Amso, Righi, \& } \\
\text { Sheinkopf, } \\
\text { 2017) }\end{array}$ & 71 & 74 & 118 & 19,19 & $\begin{array}{l}\text { Means and SDs recovered from figure } 3 . \\
\text { The statistics are pooled across 'eye' and } \\
\text { 'mouth' AOIs ('no point' condition). }\end{array}$ \\
\hline-- & 71 & 74 & 119 & -- & ('Point' condition) \\
\hline $\begin{array}{l}\text { (Moriuchi, Klin, } \\
\text { \& Jones, 2017) }\end{array}$ & 72 & 75 & 120 & 26,38 & $\begin{array}{l}\text { Means and SDs are taken from table } 1 \\
\text { (pooled across non-object AOIS). }\end{array}$ \\
\hline $\begin{array}{l}\text { (Kanat et al., } \\
\text { 2017) }\end{array}$ & 73 & 76 & 121 & 29,30 & $\begin{array}{l}\text { Means and SDs are taken from table 2. Data } \\
\text { are taken from placebo group only (100 ms). }\end{array}$ \\
\hline-- & 73 & 76 & 122 & -- & (500 ms). \\
\hline
\end{tabular}




\begin{tabular}{|c|c|c|c|c|c|}
\hline $\begin{array}{l}\text { (Higuchi et al., } \\
\text { 2017) }\end{array}$ & 74 & 77 & 123 & 26,27 & $\begin{array}{l}\text { Means and SDs are taken from figure } 3 . \\
\text { Data are pooled across 'Japanese' and } \\
\text { 'arithmetic' condition. }\end{array}$ \\
\hline $\begin{array}{l}\text { (Burnside, } \\
\text { Wright, \& } \\
\text { Poulin-Dubois, } \\
\text { 2017) }\end{array}$ & 75 & 78 & 124 & 16,16 & Means and SDs are recovered from Figure 1 \\
\hline-- & 75 & 78 & 125 & -- & \\
\hline $\begin{array}{c}\text { (Wang, } \\
\text { Campbell, } \\
\text { Macari, } \\
\text { Chawarska, \& } \\
\text { Shic, 2018) }\end{array}$ & 76 & 79 & 126 & 112,163 & $\begin{array}{l}\text { Means and SDs are taken from the } \\
\text { supplementary material in table S1. } \\
\text { ('Sandwich' condition) }\end{array}$ \\
\hline-- & 76 & 79 & 127 & 112,163 & ('Speech' condition) \\
\hline-- & 76 & 79 & 128 & 112,163 & ('Toys' condition) \\
\hline $\begin{array}{l}\text { (A. Moore et } \\
\text { al., 2018) }\end{array}$ & 77 & 80 & 129 & 76,51 & Cohen's $d$ is reported in the paper on $p 7$ \\
\hline $\begin{array}{c}\text { (Krogh- } \\
\text { Jespersen, } \\
\text { Kaldy, Valadez, } \\
\text { Carter, \& } \\
\text { Woodward, } \\
\text { 2018) }\end{array}$ & 78 & 81 & 130 & 36,19 & $\begin{array}{l}\text { Means and SDs are recovered from figure } 3 . \\
\text { Test phase only. ('chronologically matched' } \\
\text { group comparison) }\end{array}$ \\
\hline-- & 78 & 82 & 131 & 36,20 & ('Cognitively matched’ group comparison) \\
\hline $\begin{array}{l}\text { (Vernetti et al., } \\
\text { 2018) }\end{array}$ & 79 & 83 & 132 & 14,26 & $\begin{array}{l}\text { Means and SDs are recovered from figure } 2 . \\
\text { The 'low risk group' are defined as the } \\
\text { control group. (proportion of first fixations) }\end{array}$ \\
\hline-- & 79 & 83 & 133 & -- & (Total viewing duration) \\
\hline $\begin{array}{l}\text { (Hong et al., } \\
\text { 2017) }\end{array}$ & 80 & 84 & 134 & 8,8 & $\begin{array}{l}\text { Means and SDs are taken from table } 2 . \text { The } \\
\text { demographics are not reported for the TD or } \\
\text { ASD groups, only the AS group. In the } \\
\text { abstract, the groups are referred to as 'age } \\
\text { and gender matched' and so for simplicity, } \\
\text { we assume the same demographic values } \\
\text { for all groups. }\end{array}$ \\
\hline $\begin{array}{l}\text { (Liang \& } \\
\text { Wilkinson, } \\
\text { 2018) }\end{array}$ & 81 & 85 & 135 & 10,10 & $\begin{array}{l}\text { Means and SDs are recovered from figure } 3 \\
\text { and } 6 \text { ('sharing, } 2 \text { person' condition). }\end{array}$ \\
\hline-- & 81 & 85 & 136 & -- & ('Sharing, 3 person' condition). \\
\hline-- & 81 & 85 & 137 & -- & ('No sharing, 2 person' condition). \\
\hline-- & 81 & 85 & 138 & -- & ('No sharing, 3 person' condition). \\
\hline
\end{tabular}




\begin{tabular}{|c|c|c|c|c|c|}
\hline-- & 81 & 85 & 139 & & $\begin{array}{l}\text { ('Sharing, } 2 \text { person' condition, latency to first } \\
\text { fixation) }\end{array}$ \\
\hline-- & 81 & 85 & 140 & & $\begin{array}{l}\text { ('Sharing, } 3 \text { person' condition, latency to first } \\
\text { fixation) }\end{array}$ \\
\hline-- & 81 & 85 & 141 & & $\begin{array}{l}\text { ('No sharing, } 2 \text { person' condition, latency to } \\
\text { first fixation) }\end{array}$ \\
\hline-- & 81 & 85 & 142 & & $\begin{array}{l}\text { ('No sharing, } 3 \text { person' condition, latency to } \\
\text { first fixation) }\end{array}$ \\
\hline $\begin{array}{l}\text { (Megan Freeth } \\
\text { \& Bugembe, } \\
\text { 2019) }\end{array}$ & 82 & 86 & 143 & 12,13 & $\begin{array}{l}\text { Means and SDs taken from figure } 2 \text { ('direct' } \\
\text { condition) }\end{array}$ \\
\hline-- & 82 & 86 & 144 & -- & ('Averted' condition) \\
\hline $\begin{array}{l}\text { (Gray, Haffey, } \\
\text { Mihaylova, \& } \\
\text { Chakrabarti, } \\
\text { 2018) }\end{array}$ & 83 & 87 & 145 & 28,38 & Means and SDs obtained from author. \\
\hline $\begin{array}{l}\text { (Kovarski, } \\
\text { Siwiaszczyk, } \\
\text { Malvy, Batty, \& } \\
\text { Latinus, 2019) }\end{array}$ & 84 & 88 & 146 & 16,16 & $\begin{array}{l}\text { Means and SDs are recovered from figure } 3 \\
\text { (latency to first fixation). }\end{array}$ \\
\hline $\begin{array}{l}\text { (Garon, } \\
\text { Forgeot d'Arc, } \\
\text { Lavallée, } \\
\text { Estay, \& } \\
\text { Beauchamp, } \\
\text { 2018) }\end{array}$ & 85 & 89 & 147 & 30,59 & $\begin{array}{l}\text { Only latency to first fixation data are } \\
\text { reported. Effect size computed from } t \text { value } \\
\text { on page } 8 .\end{array}$ \\
\hline $\begin{array}{l}\text { (Falck-Ytter et } \\
\quad \text { al., 2018) }\end{array}$ & 86 & 90 & 148 & 13,14 & $\begin{array}{l}\text { Means and SDs are recovered from figure } 2 . \\
\text { We define the 'low risk' group as the control } \\
\text { group. }\end{array}$ \\
\hline $\begin{array}{l}\text { (Shic, Wang, } \\
\text { Macari, \& } \\
\text { Chawarska, } \\
\text { 2019) }\end{array}$ & 87 & 91 & 149 & 50,47 & $\begin{array}{l}\text { Means and SDs taken from Table } 1 \text { ('dg+ } \\
\text { sp+' condition) }\end{array}$ \\
\hline-- & 87 & 91 & 150 & -- & ('dg+sp-' condition) \\
\hline-- & 87 & 91 & 151 & -- & ('dg- sp+' condition) \\
\hline-- & 87 & 91 & 152 & -- & ('dg- sp-' condition) \\
\hline $\begin{array}{l}\text { (Wang et al., } \\
\text { 2019) }\end{array}$ & 88 & 92 & 153 & 16,23 & $\begin{array}{l}\text { Means and SDs are taken from table 2. All } \\
\text { data are taken from the pre-training } \\
\text { condition. ('Cue' condition). }\end{array}$ \\
\hline -- & 88 & 93 & 154 & 19,23 & ‘Nocue' condition. \\
\hline
\end{tabular}




\begin{tabular}{|c|c|c|c|c|c|}
\hline $\begin{array}{l}\text { (Cao et al., } \\
\text { 2019) }\end{array}$ & 89 & 94 & 155 & 21,22 & $\begin{array}{l}\text { We estimate the mean and } S D \text { from the } \\
\text { interquartile range presented in the boxplots } \\
\text { in figure } 3 \text { and } 4 \text {. ('Human' condition). }\end{array}$ \\
\hline-- & 89 & 94 & 156 & -- & (Latency to first fixation) \\
\hline $\begin{array}{l}\text { (Harrop et al., } \\
\text { 2019) }\end{array}$ & 90 & 95 & 157 & 23,16 & $\begin{array}{l}\text { Data are pooled across the 'dyadic' and } \\
\text { 'basic' conditions. Means and SDs are } \\
\text { recovered from Figure } 2 \text { (males) }\end{array}$ \\
\hline-- & 90 & 96 & 158 & 19,16 & (Females) \\
\hline $\begin{array}{l}\text { (Tang, Chen, } \\
\text { =alkmer, Bölte, } \\
\text { \& Girdler, } \\
\text { 2019) }\end{array}$ & 91 & 97 & 159 & 23,25 & $\begin{array}{l}\text { Means and SDs are taken from the } \\
\text { 'elsewhere' AOI and the direction of this } \\
\text { effect is inverted. }\end{array}$ \\
\hline & & & & & Means and SDs are taken from figure 3 \\
\hline $\begin{array}{l}\text { (Parish-Morris } \\
\text { et al., 2019) }\end{array}$ & 92 & 98 & 160 & 28,27 & Means and SDs are taken from table 3 \\
\hline-- & 92 & 98 & 161 & -- & \\
\hline $\begin{array}{l}\text { (Bradshaw et } \\
\text { al., 2019) }\end{array}$ & 93 & 99 & 162 & 28,23 & $\begin{array}{l}\text { Means and SDs are taken from the text on } \\
\text { p786. In line with inclusion criteria, only the } \\
\text { 'socpref' data at time } 1 \text { are used (i.e. before } \\
\text { the intervention). }\end{array}$ \\
\hline $\begin{array}{l}\text { Kwon, Moore, } \\
\text { Barnes, Cha, \& }\end{array}$ & 94 & 100 & 163 & 74,43 & Means and SDs are recovered from figure 2. \\
\hline Pierce, 2019) & & & & & $\begin{array}{l}\text { Only data from experiment } 2 \text { are included, } \\
\text { since there are no competing social and } \\
\text { nonsocial displays in experiment } 1 . \text { Note that } \\
\text { the 'geopref' score is inverted to obtain a } \\
\text { social preference score. }\end{array}$ \\
\hline $\begin{array}{l}\text { (Hong et al., } \\
\text { 2019) }\end{array}$ & 95 & 101 & 164 & 17,17 & $\begin{array}{l}\text { Means and SDs are taken from figure } 2 . \\
\text { Data are taken from the 'social preference' } \\
\text { condition only. It is reported that there were } \\
\text { no significant differences between groups in } \\
\text { the 'emotional faces' task, but the direction } \\
\text { of the effect is not reported. }\end{array}$ \\
\hline $\begin{array}{l}\text { (Kou et al., } \\
\text { 2019) }\end{array}$ & 96 & 102 & 165 & 32,34 & $\begin{array}{l}\text { Effect size is computed from the } t \text { value in } \\
\text { the text on } p 1533 \text { ('dynamic visual } \\
\text { preference' condition). }\end{array}$ \\
\hline-- & 96 & 102 & 166 & -- & $\begin{array}{l}\text { Means and SDs recovered from figure } 3 \\
\text { ('Biological Motion' condition). }\end{array}$ \\
\hline
\end{tabular}




$\begin{array}{llllll}- & 96 & 102 & 167 & - & \begin{array}{l}\text { Means and SDs recovered from figure } 4 \\ \text { ('static' condition). }\end{array}\end{array}$

\section{Social Seeking}

Table S3

Summary of Effects Included in the Analysis of Social Seeking Effects

\begin{tabular}{|c|c|c|c|c|c|}
\hline Study & Sample & Experiment & Effect & $N A S D, N N T$ & Notes \\
\hline $\begin{array}{l}\text { (Scott-Van } \\
\text { Zeeland, Dapretto, } \\
\text { Ghahremani, } \\
\text { Poldrack, \& } \\
\text { Bookheimer, } \\
\text { 2010) }\end{array}$ & 1 & 1 & 1 & 16,16 & $\begin{array}{l}\text { Effect size computed from the means } \\
\text { and SDs for the accuracy data reported } \\
\text { in table } 2 \text {. Insufficient information is } \\
\text { reported to compute an effect size } \\
\text { based on the RT data. }\end{array}$ \\
\hline \multirow{2}{*}{$\begin{array}{l}\text { (Demurie, } \\
\text { Roeyers, } \\
\text { Baeyens, \& } \\
\text { Sonuga-Barke, } \\
\text { 2011) }\end{array}$} & 2 & 2 & 2 & 31,40 & $\begin{array}{l}\text { Means and and SDs are taken from } \\
\text { table 3. We pool these statistics across } \\
\text { reward magnitude } 5 \text { and } 15 . \text { (RT data) }\end{array}$ \\
\hline & -- & -- & 3 & -- & (Accuracy data) \\
\hline \multirow[t]{2}{*}{$\begin{array}{l}\text { (Kohls et al., } \\
\text { 2011) }\end{array}$} & 3 & 3 & 4 & 16,20 & $\begin{array}{l}\text { Means and and SDs are taken from } \\
\text { table 2. (RT for hits). }\end{array}$ \\
\hline & -- & -- & 5 & -- & Hit rate (accuracy) \\
\hline $\begin{array}{l}\text { (Delmonte et al., } \\
\text { 2012) }\end{array}$ & 4 & 4 & 6 & 21,21 & $\begin{array}{l}\text { Means and SDs are extracted from } \\
\text { Figure 2. These statistics are pooled } \\
\text { across reward levels (RT data). }\end{array}$ \\
\hline $\begin{array}{l}\text { (Dichter, Richey, } \\
\text { Rittenberg, } \\
\text { Sabatino, \& } \\
\text { Bodfish, 2012) }\end{array}$ & 5 & 5 & 7 & 16,20 & $\begin{array}{l}\text { Means and SDs recovered from figure } \\
2(R T) \text {. }\end{array}$ \\
\hline $\begin{array}{l}\text { (Lin, Rangel, \& } \\
\text { Adolphs, 2012) }\end{array}$ & 6 & 6 & 8 & 10,10 & $\begin{array}{l}\text { Means and SDs are recovered from } \\
\text { figure 5. (accuracy). }\end{array}$ \\
\hline \multirow[t]{2}{*}{$\begin{array}{l}\text { (Kohls et al., } \\
\text { 2013) }\end{array}$} & 7 & 7 & 9 & 15,17 & $\begin{array}{l}\text { Means and SDs taken from table } 2 \\
(R T) \text {. }\end{array}$ \\
\hline & - & - & 10 & -- & (Accuracy for go trials). \\
\hline (Ewing, Pellicano, & 8 & 8 & 11 & 19,19 & Means and SDs are recovered from \\
\hline
\end{tabular}


figure 1. These statistics are pooled across nonsocial stimulus categories (number of key presses).

(Richey et al., 9 9 2014)

(Pankert, Pankert, 10

Herpertz-

Dahlmann,

Konrad, \& Kohls,

2014)

(Dubey, Ropar, \&

11

Hamilton, 2015)

(Neuhaus,

Bernier, \&

Beauchaine,

2015)

(Damiano et al., 2015)

(Watson et al.,

14 2015)

(Ruta et al., 2017)

15

(Dubey, Ropar, \& 16 de $\mathrm{C}$ Hamilton,

2017)

(Goldberg et al.,

17

2017)

(Goldberg et al., 17

2017)

(Gilbertson, Lutfi, 18

\& Ellis Weismer,

2017)

(Kohls, Antezana,

19

Mosner, Schultz,

\& Yerys, 2018)
Means and SDs are recovered from figure 2. (RT data).

Means and SDs are taken from table 2. These statistics are pooled across 'familiar' and 'unfamiliar' stimuli. (RT, visual condition).

(RT, auditory).

Means and SDs obtained from author. These statistics are pooled across effort conditions (choice proportion).

Effect size is computed from $p$ value in table 2 for the 'condition x group' interaction. Direction of the effect can be inferred from figure 1 - but there are no error bars (RT).

(Accuracy).

Means and SDs are recovered from figure 2. It is not indicated whether the error bars in this figure are SE or SD and so we assume that they are SE. (RT).

Means and SDs are recovered from figure 2. Data are only taken from the 'equivalent' condition. We pool across 'high autism interest' and 'low autism interest' conditions.

Means and SDs are recovered from figure 2 (button press proportion).

Means and SDs obtained from the author. These statistics are pooled across effort levels (choice proportion).

Means and standard deviations are recovered from figure 1. (choice proportion).

Means and standard deviations are recovered from figure 2. (break points).

Means and standard deviations are recovered from figure 1 (number of button presses).

Means and SDs taken from table 2 $(R T)$. Accuracy data is also reported, but it is unusable because the task uses a performance-based algorithm to 
keep performance thresholded at $50 \%$.

\begin{tabular}{|c|c|c|c|c|c|}
\hline $\begin{array}{l}\text { (Wang et al., } \\
\text { 2018) }\end{array}$ & 20 & 21 & 26 & 22,25 & $\begin{array}{l}\text { Means, and SDs are recovered from } \\
\text { figure } 3 \text { (proportion of choices). }\end{array}$ \\
\hline $\begin{array}{l}\text { (Traynor, Gough, } \\
\text { Duku, Shore, \& } \\
\text { Hall, 2019) }\end{array}$ & 20 & 22 & 27 & 10,19 & $\begin{array}{l}\text { Means and SDs taken from figure } 2 \text {. } \\
\text { These statistics are pooled across } \\
\text { neutral and interest conditions (number } \\
\text { of button presses). }\end{array}$ \\
\hline $\begin{array}{l}\text { (Gale, Eikeseth, \& } \\
\text { Klintwall, 2019) }\end{array}$ & 21 & 22 & 28 & 27,40 & $\begin{array}{l}\text { Experiment } 1 \text {. Means and SDs are } \\
\text { reported in the text on p } 4 \text {. Note the } \\
\text { data from experiment } 2 \text { could not be } \\
\text { included, since this experiment uses } \\
\text { 'nonhuman' social stimuli, which would } \\
\text { render a comparison to other effects } \\
\text { within this analysis problematic. Also } \\
\text { note that data from experiment } 3 \text { could } \\
\text { not be included, since social and } \\
\text { nonsocial stimuli were presented on } \\
\text { separate trials, and the data for } \\
\text { nonsocial stimuli are not reported. }\end{array}$ \\
\hline
\end{tabular}

\section{Supplementary Material S5: Influential case diagnostics}

\section{Social Orienting}

To identify potentially outlying studies, we removed each individual effect from the analysis and observed the impact of removing this effect on model outcomes (Viechtbauer \& Cheung, 2010 - see Figure S3). Any effects whose removal led to a change that was +/- 3 SD

from the mean influence of a removed studies in any measure were inspected further. 

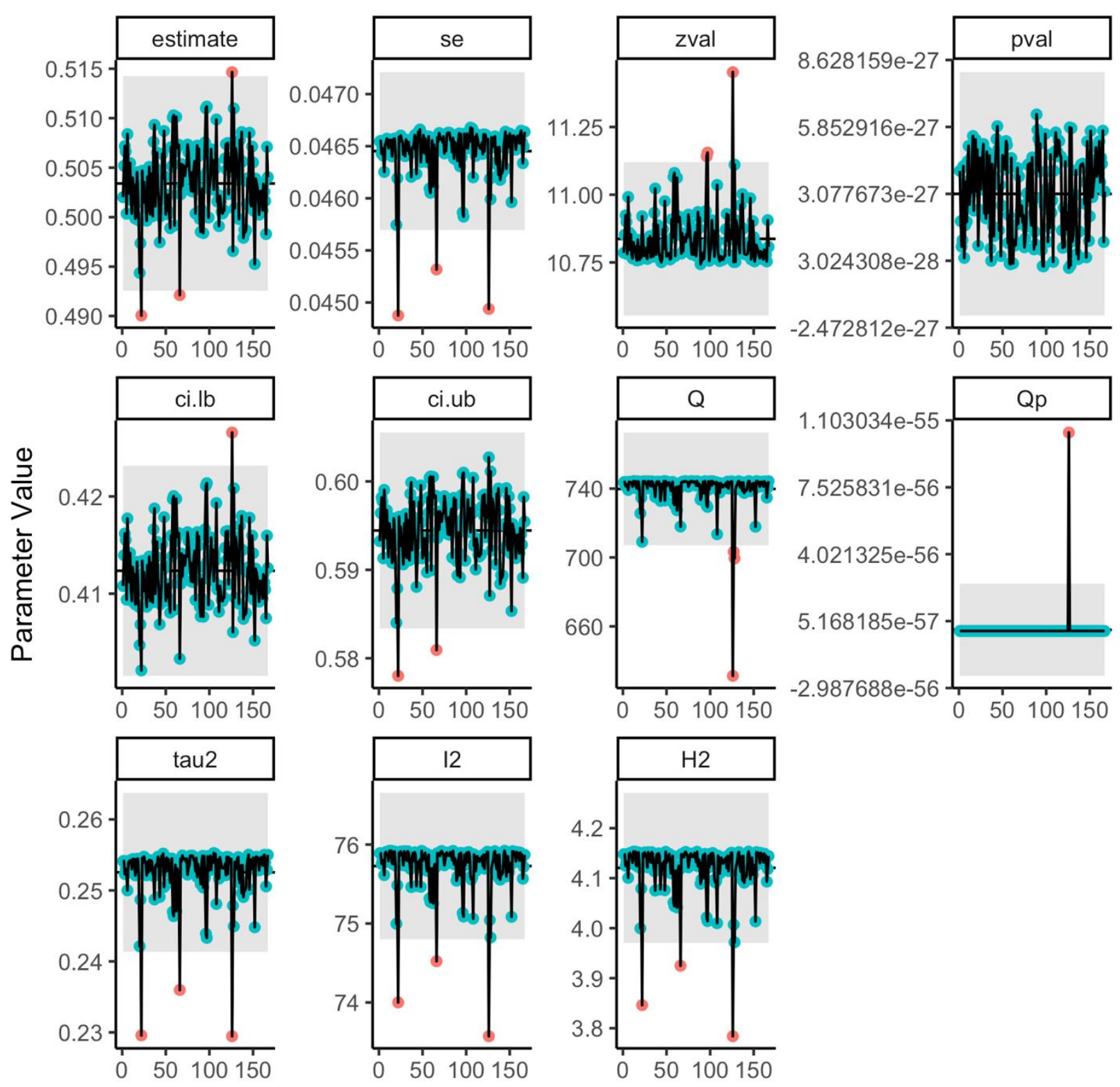

Effect

Figure S3. Depicts model parameters as a function of the effect that was removed from the analysis. Shaded region depicts values +/- 3 SD from the mean. Red points indicate effects identified as outliers.

7 effects, from 4 studies (Billeci et al., 2016; D. M. Riby \& Hancock, 2009; D. M. Riby et al., 2013; Wang et al., 2018) were identified as an outlier on at least one measure, indicating that the removal of these studies have a disproportionate impact on the results. Further 
examination revealed that the large influence of these studies reflected the fact that they

involved very large effects, large effects in the negative direction, or they emanated from very

large samples. No data entry errors were detected. Thus, we reasoned that there was no

justification for removing these effects from the analysis.

\section{Table S4}

Summary of Orienting Effects Identified as Influential Cases

\begin{tabular}{|c|c|c|c|}
\hline Study & Parameter estimate & $\begin{array}{l}\text { Effect } \\
\text { number }\end{array}$ & Comment \\
\hline $\begin{array}{l}\text { (D. M. Riby \& } \\
\text { Hancock, 2009) }\end{array}$ & $d=2.95$ & 22 & $\begin{array}{l}\text { This effect is based on latency to first fixation } \\
\text { data. The effect does genuinely seem to be } \\
\text { large - it is in the order of over a second (NT } \\
\text { mean }=762, \text { ASC mean }=2011 \text { ). }\end{array}$ \\
\hline $\begin{array}{l}\text { (D. M. Riby et al., } \\
\text { 2013) }\end{array}$ & $d=2.55$ & 66 & $\begin{array}{l}\text { This effect is computed from a } t \text { value ( } 8.47) \\
\text { reported in the text, which is very large. }\end{array}$ \\
\hline (Billeci et al., 2016) & $d=-0.97, d=-1.01$ & 96,97 & $\begin{array}{l}\text { These effects are based on } p \text { values reported } \\
\text { in the text. The large influence of these effects } \\
\text { probably reflects the fact that they are quite } \\
\text { large and in the negative direction. }\end{array}$ \\
\hline (Wang et al., 2018) & $\begin{array}{l}d=-1.05, d=1.33, d= \\
-0.5\end{array}$ & $\begin{array}{l}126,127 \\
128\end{array}$ & $\begin{array}{l}\text { The large influence of these studies probably } \\
\text { reflects the very large sample size of this study } \\
\text { (112 NT and } 162 \text { ASD). }\end{array}$ \\
\hline
\end{tabular}

\section{Social Seeking}




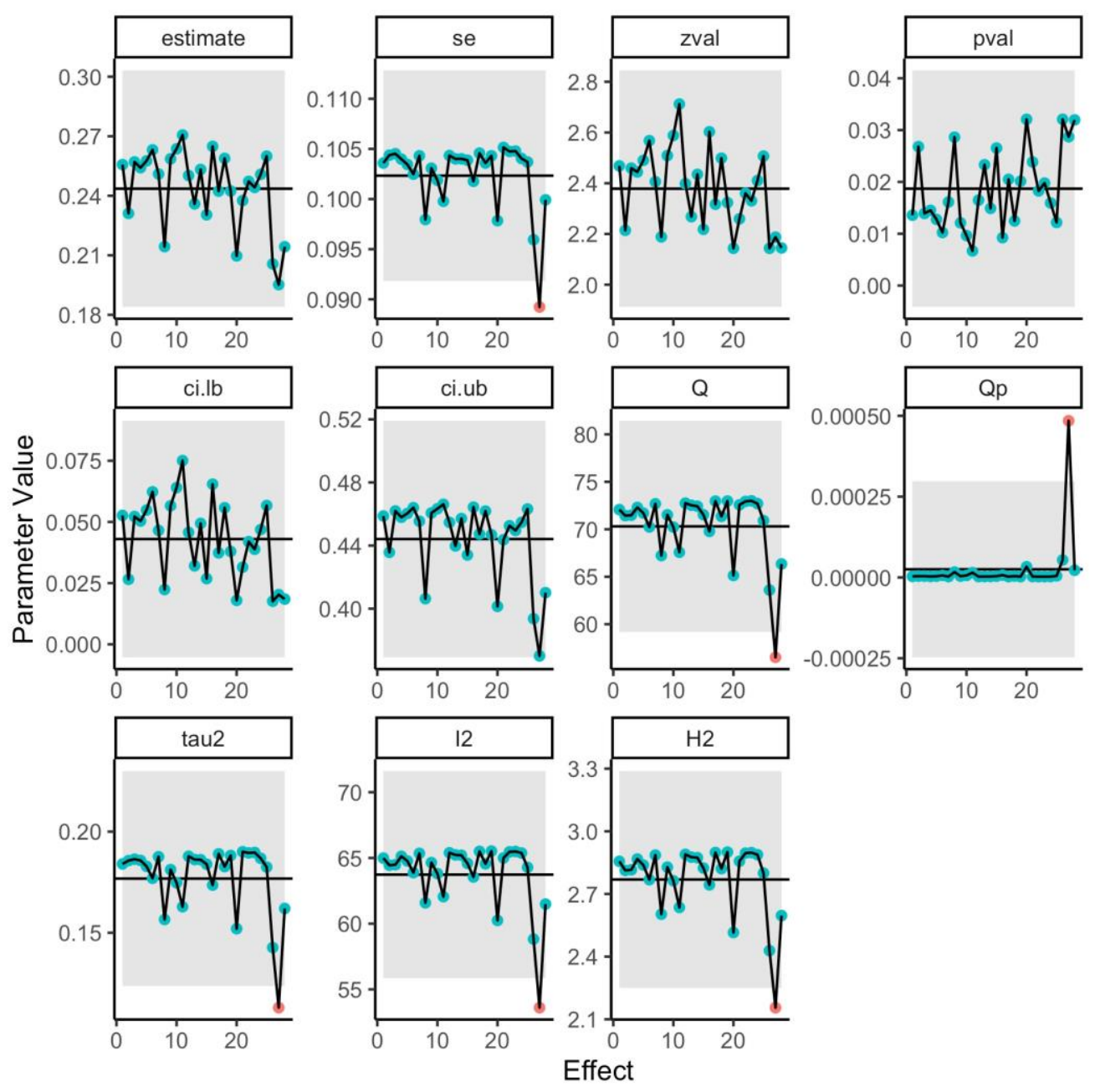

Figure S4. Depicts model parameters as a function of the effect that was removed from the analysis. Shaded region depicts values +/- 3SD from the mean. Red points indicate effects identified as outliers.

Effect number 27 (Traynor et al., 2019) was identified as an outlier on several measures, indicating that the removal of this study has a disproportionate impact on the results. There were no obvious errors in data entry - and the effect size estimate was within the confidence intervals of other estimates. Therefore, there was no justification for removing the effect from the analysis. 


\section{Table S5}

Summary of Seeking Effects Identified as Influential Cases

\begin{tabular}{|l|l|l|l}
\hline \multicolumn{2}{l}{ Study } & Parameter estimate & \multicolumn{1}{l}{$\begin{array}{l}\text { Effect } \\
\text { number }\end{array}$} \\
\hline (Traynor et al., 2019) & $d=2.19$ & 27 & $\begin{array}{l}\text { Comment } \\
\text { The effect reported in the paper is large. } \\
\text { Moreover, the parameter estimate overlaps } \\
\text { with the confidence intervals of other studies. }\end{array}$ \\
\hline
\end{tabular}

\section{Supplementary Material S6: Summary of Parameter Estimates}

\section{Social Orienting}

\section{Table S6}

Parameter Estimates for Moderators of Social Orienting Effects

\begin{tabular}{|c|c|c|c|}
\hline Parameter & Main effect & $R^{2}$ & Fitted parameter estimates \\
\hline VIQ match & $Q(1)=2.22, p=.136$ & $2.13 \%$ & $\begin{array}{l}\text { Unmatched }\left(\mathrm{k}=100, \beta=0.56,[0.440 .67]^{\star \star \star}\right) \\
\text { Matched }\left(\mathrm{k}=67, \beta=0.42,[0.270 .56]^{\star * *}\right)\end{array}$ \\
\hline NVIQ match & $Q(1)=0.20, p=.651$ & $0.04 \%$ & $\begin{array}{l}\text { Unmatched }\left(\mathrm{k}=100, \beta=0.49,[0.370 .60]^{* \star *}\right) \\
\text { Matched }\left(\mathrm{k}=67, \beta=0.53,[0.390 .68]^{\star \star *}\right)\end{array}$ \\
\hline Sex ratio & $Q(1)=0.47, p=.494$ & $0.12 \%$ & $\begin{array}{l}\mathrm{b} 0=0.54,\left[\begin{array}{ll}0.40 & 0.67\end{array}\right] \\
\mathrm{b} 1=-0.01,\left[\begin{array}{ll}-0.02 & 0.01\end{array}\right]\end{array}$ \\
\hline Age & $Q(1)=2.31, p=.128$ & $0.13 \%$ & $\begin{array}{l}\mathrm{b} 0=0.43,\left[\begin{array}{ll}0.29 & 0.56\end{array}\right] \\
\mathrm{b} 1=0.01,\left[\begin{array}{ll}-0.02 & 0.02\end{array}\right]\end{array}$ \\
\hline $\begin{array}{l}\text { Diagnostic } \\
\text { Assessment }\end{array}$ & $Q(2)=9.76, p=.008$ & $6.76 \%$ & $\begin{array}{l}\text { No ADOS }\left(k=55, \beta=0.71,\left[\begin{array}{ll}0.55 & 1.88\end{array}\right]^{* * \star}\right) \\
\text { ADOS }\left(k=103, \beta=0.40,\left[\begin{array}{ll}0.30 & 0.52\end{array}\right]^{* *}\right) \\
\text { ADOS/ADI-R }\left(k=9, \beta=0.47,\left[\begin{array}{ll}0.07 & 0.87\end{array}\right]^{*}\right)\end{array}$ \\
\hline $\begin{array}{l}\text { Orienting } \\
\text { Measure }\end{array}$ & $Q(5)=8.12, p=.150$ & $4.16 \%$ & $\begin{array}{l}\text { Total Gaze Duration }\left(k=135, \beta=0.48,[0.38,0.58]^{* * *}\right) \\
\text { Latency to first fixation }\left(k=18, \beta=0.84,[0.55,1.12]^{* * *}\right) \\
\text { Proportion of first fixations }(k=6, \beta=0.48,[0.01,0.95]) \\
\text { Dot probe latency }(k=4, \beta=0.29,[-0.27,0.85]) \\
\text { Visual search Latency }(k=2, \beta=0.01,[-0.78,0.81]) \\
\text { CFS detection latency }(k=2, \beta=0.17,[-0.65,1.0])\end{array}$ \\
\hline $\begin{array}{l}\text { Stimulus } \\
\text { modality }\end{array}$ & $Q(1)=0.03, p=.867$ & 0.00 & $\begin{array}{l}\text { Image }\left(k=71, \beta=0.62,[0.46,0.77]^{* * *}\right) \\
\text { Video }\left(k=96, \beta=0.50,[0.370 .62]^{* * *}\right)\end{array}$ \\
\hline Stimulus AOI & $Q(4)=11.02, p=.026$ & $9.11 \%$ & $\begin{array}{l}\text { Face }\left(k=75, \beta=0.40,[0.27,0.53]^{\star * *}\right) \\
\text { Person }\left(k=61, \beta=0.49,[0.35,0.64]^{* \star *}\right)\end{array}$ \\
\hline
\end{tabular}


Social scene $\left(k=21, \beta=0.83,[0.59,1.08]^{* * *}\right)$

Biological motion $\left(k=7, \beta=0.55,[0.12,0.98]^{*}\right)$

Eyes $\left(k=3, \beta=0.92,[0.22,1.62]^{*}\right)$

Stimulus $\quad Q(6)=16.56, p=.011 \quad 11.36 \%$

Free-viewing $\left(k=109, \beta=0.60,[0.49,0.71]^{* * *}\right)$

context

Active engage $\left(k=15, \beta=0.52,[0.24,0.81]^{* * *}\right)$

Active present $(k=8, \beta=-0.00,[-0.40,0.39])$

Active social task $\left(k=14, \beta=0.50,[0.17,0.82]^{* *}\right)$

Active nonsocial task $(k=6, \beta=0.27,[-0.19,0.73])$

Active joint-attention $(k=11, \beta=0.16,[-0.16,0.49])$

Search $(k=4, \beta=0.09,[-0.47,0.65])$

Interactive $\quad Q(2)=12.63, p=.002 \quad 9.92 \% \quad$ None $\left(k=99, \beta=0.45,[0.34,0.56]^{* * *}\right)$

content

Interaction in stimulus $\left(k=43, \beta=0.76,[0.5893]^{* * *}\right)$

Interaction with observer $\left(k=25, \beta=0.29,[0.07,0.51]^{\star}\right)$

Note. ${ }^{*} p<.05,{ }^{* *} p<.01,{ }^{* * *} p<.001$

\section{Social Seeking}

\section{Table S7}

Parameter Estimates for Moderators of Social Seeking Effects

\begin{tabular}{|c|c|c|c|}
\hline Parameter & Main effect & $R^{2}$ & Fitted parameter estimates \\
\hline VIQ match & $\begin{array}{l}Q(1)=3.50, p \\
=.061\end{array}$ & $22.12 \%$ & $\begin{array}{l}\text { Matched }(k=14, \beta=0.06,[-0.190 .32]) \\
\text { Unmatched }\left(k=14, \beta=0.40,[0.150 .65]^{* * *}\right)\end{array}$ \\
\hline NVIQ match & $\begin{array}{l}Q(1)=7.43, p \\
=.006\end{array}$ & $38.96 \%$ & $\begin{array}{l}\text { Matched }\left(k=17, \beta=0.04,\left[\begin{array}{ll}-0.17 & 0.26\end{array}\right]\right) \\
\text { Unmatched }\left(k=11, \beta=0.51,[0.250 .78]^{* * *}\right)\end{array}$ \\
\hline Sex ratio & $\begin{array}{l}Q(1)=7.71, p \\
=.006\end{array}$ & $33.93 \%$ & $\begin{array}{l}\text { b0 }=0.59,[0.290 .89],{ }^{* *} \\
\text { b1 }=-0.04,[-0.07-0.01],{ }^{* *}\end{array}$ \\
\hline Age & $\begin{array}{l}Q(1)=0.08, p \\
=.774\end{array}$ & $0.00 \%$ & $\begin{array}{l}\text { b0 }=0.18,[-0.210 .58], p=.359 \\
b 1=0.00,[-0.020 .03], p=.774\end{array}$ \\
\hline $\begin{array}{l}\text { Diagnostic } \\
\text { Assessment }\end{array}$ & $\begin{array}{l}Q(1)=8.33, p \\
=.004\end{array}$ & $34.88 \%$ & $\begin{array}{l}\text { No ADOS }\left(k=3, \beta=0.95,\left[\begin{array}{ll}0.44 & 1.47\end{array}\right]^{* *}\right) \\
\operatorname{ADOS}(k=25, \beta=0.15,[-0.030 .33])\end{array}$ \\
\hline Seeking measure & $\begin{array}{l}Q(3)=12.56, p \\
=.006\end{array}$ & $61.72 \%$ & $\begin{array}{l}\text { Accuracy }(k=9, \beta=0.11,[-0.170 .38]) \\
\text { RT }(k=8, \beta=-0.05,[-0.320 .23]) \\
\text { Button Press }(k=4, \beta=0.29,[-0.140 .72]) \\
\text { Choice proportion }\left(k=7, \beta=0.64,[0.350 .94]^{* * *}\right)\end{array}$ \\
\hline $\begin{array}{l}\text { Social stimulus } \\
\text { type }\end{array}$ & $\begin{array}{l}Q(5)=6.21, p \\
=.286\end{array}$ & $26.60 \%$ & $\begin{array}{l}\text { Smiling face }\left(k=15, \beta=0.32,\left[\begin{array}{lll}0.08 & 0.56\end{array}\right]^{* *}\right) \\
\text { Interaction }\left(k=3, \beta=0.63,[0.111 .14]^{\star}\right) \\
\text { Neutral face }\left(k=4, \beta=-0.14,\left[\begin{array}{lll}-0.59 & 0.31\end{array}\right]\right)\end{array}$ \\
\hline
\end{tabular}


Praise $(k=3, \beta=-0.03,[-0.570 .51])$

Social activity $(k=2, \beta=0.20,[-0.440 .84])$

Speech $(k=1, \beta=0.04,[-0.941 .02])$

$\begin{array}{ll}\text { Stimulus modality } & Q(3)=1.47, p \\ & =.690\end{array}$

$12.45 \%$

Video $\left(k=7, \beta=0.40,[0.050 .76]^{*}\right)$

Image $(k=17, \beta=0.19,[-0.050 .42])$

Sound $(k=2, \beta=0.00,[-0.700 .72])$

Real world $(k=2, \beta=0.20,[-0.470 .87])$

Note. ${ }^{*} p<.05,{ }^{* *} p<.01,{ }^{* * *} p<.001$

\section{Supplementary Material S7: Interactive Models.}

A report of meta analytic outcomes, which includes details of all 2-way interactive models can be found here: https://figshare.com/articles/Data supplements for ASD metaanalysis/12327767 (Hedger, 2020). 


\section{References}

Akechi, H., Stein, T., Kikuchi, Y., Tojo, Y., Osanai, H., \& Hasegawa, T. (2015). Preferential awareness of protofacial stimuli in autism. Cognition, 143, 129-134.

Amso, D., Haas, S., Tenenbaum, E., Markant, J., \& Sheinkopf, S. J. (2014). Bottom-up attention orienting in young children with autism. Journal of Autism and Developmental Disorders, 44(3), 664-673.

Benjamin, D. P., Mastergeorge, A. M., McDuffie, A. S., Kover, S. T., Hagerman, R. J., \& Abbeduto, L. (2014). Effects of labeling and pointing on object gaze in boys with fragile $X$ syndrome: an eye-tracking study. Research in Developmental Disabilities, 35(11), 26582672.

Benson, V., Piper, J., \& Fletcher-Watson, S. (2009). Atypical saccadic scanning in autistic spectrum disorder. Neuropsychologia, 47(4), 1178-1182.

Billeci, L., Narzisi, A., Campatelli, G., Crifaci, G., Calderoni, S., Gagliano, A., ... ALERT group. (2016). Disentangling the initiation from the response in joint attention: an eye-tracking study in toddlers with autism spectrum disorders. Translational Psychiatry, 6, e808.

Bird, G., Press, C., \& Richardson, D. C. (2011). The role of alexithymia in reduced eye-fixation in Autism Spectrum Conditions. Journal of Autism and Developmental Disorders, 41(11), $1556-1564$.

Birmingham, E., Cerf, M., \& Adolphs, R. (2011). Comparing social attention in autism and amygdala lesions: effects of stimulus and task condition. Social Neuroscience, 6(5-6), 420435.

Bradshaw, J., Shic, F., Holden, A. N., Horowitz, E. J., Barrett, A. C., German, T. C., \& Vernon, T. W. (2019). The Use of Eye Tracking as a Biomarker of Treatment Outcome in a Pilot Randomized Clinical Trial for Young Children with Autism. Autism Research: Official 
Journal of the International Society for Autism Research, 12(5), 779-793.

Burnside, K., Wright, K., \& Poulin-Dubois, D. (2017). Social motivation and implicit theory of mind in children with autism spectrum disorder. Autism Research: Official Journal of the International Society for Autism Research, 10(11), 1834-1844.

Cao, W., Song, W., Li, X., Zheng, S., Zhang, G., Wu, Y., ... Chen, J. (2019). Interaction With Social Robots: Improving Gaze Toward Face but Not Necessarily Joint Attention in Children With Autism Spectrum Disorder. Frontiers in Psychology, 10, 1503.

Chawarska, K., Macari, S., Powell, K., DiNicola, L., \& Shic, F. (2016). Enhanced Social Attention in Female Infant Siblings at Risk for Autism. Journal of the American Academy of Child and Adolescent Psychiatry, 55(3), 188-195.e1.

Chawarska, K., Macari, S., \& Shic, F. (2012). Context modulates attention to social scenes in toddlers with autism. Journal of Child Psychology and Psychiatry, and Allied Disciplines, 53(8), 903-913.

Chawarska, K., Macari, S., \& Shic, F. (2013). Decreased spontaneous attention to social scenes in 6-month-old infants later diagnosed with autism spectrum disorders. Biological Psychiatry, 74(3), 195-203.

Chevallier, C., Parish-Morris, J., Tonge, N., Le, L., Miller, J., \& Schultz, R. T. (2014). Susceptibility to the audience effect explains performance gap between children with and without autism in a theory of mind task. Journal of Experimental Psychology. General, 143(3), 972-979.

Chita-Tegmark, M. (2016). Social attention in ASD: A review and meta-analysis of eye-tracking studies. Research in Developmental Disabilities, 48, 79-93.

Damiano, C. R., Cockrell, D. C., Dunlap, K., Hanna, E. K., Miller, S., Bizzell, J., ... Dichter, G. S. (2015). Neural mechanisms of negative reinforcement in children and adolescents with autism spectrum disorders. Journal of Neurodevelopmental Disorders, 7(1), 12.

Delmonte, S., Balsters, J. H., McGrath, J., Fitzgerald, J., Brennan, S., Fagan, A. J., \& Gallagher, 
L. (2012). Social and monetary reward processing in autism spectrum disorders. Molecular Autism, 3(1), 7 .

Demurie, E., Roeyers, H., Baeyens, D., \& Sonuga-Barke, E. (2011). Common alterations in sensitivity to type but not amount of reward in ADHD and autism spectrum disorders. Journal of Child Psychology and Psychiatry, and Allied Disciplines, 52(11), 1164-1173.

Dichter, G. S., Richey, J. A., Rittenberg, A. M., Sabatino, A., \& Bodfish, J. W. (2012). Reward circuitry function in autism during face anticipation and outcomes. Journal of Autism and Developmental Disorders, 42(2), 147-160.

Dubey, I., Ropar, D., \& de C Hamilton, A. F. (2017). Brief Report: A Comparison of the Preference for Viewing Social and Non-social Movies in Typical and Autistic Adolescents. Journal of Autism and Developmental Disorders, 47(2), 514-519.

Dubey, I., Ropar, D., \& Hamilton, A. F. de C. (2015). Measuring the value of social engagement in adults with and without autism. Molecular Autism, 6, 35.

Elsabbagh, M., Fernandes, J., Webb, S. J., Dawson, G., Charman, T., Johnson, M. H., \& British Autism Study of Infant Siblings Team. (2013). Disengagement of visual attention in infancy is associated with emerging autism in toddlerhood. Biological Psychiatry, 74(3), 189-194.

Ewing, L., Pellicano, E., \& Rhodes, G. (2013). Reevaluating the selectivity of face-processing difficulties in children and adolescents with autism. Journal of Experimental Child Psychology, 115(2), 342-355.

Falck-Ytter, T., Carlström, C., \& Johansson, M. (2015). Eye contact modulates cognitive processing differently in children with autism. Child Development, 86(1), 37-47.

Falck-Ytter, T., Nyström, P., Gredebäck, G., Gliga, T., Bölte, S., \& EASE team. (2018). Reduced orienting to audiovisual synchrony in infancy predicts autism diagnosis at 3 years of age. Journal of Child Psychology and Psychiatry, and Allied Disciplines, 59(8), 872-880.

Falck-Ytter, T., Rehnberg, E., \& Bölte, S. (2013). Lack of visual orienting to biological motion and audiovisual synchrony in 3-year-olds with autism. PloS One, 8(7), e68816. 
Fischer, J., Koldewyn, K., Jiang, Y. V., \& Kanwisher, N. (2014). Unimpaired Attentional Disengagement and Social Orienting in Children with Autism. Clinical Psychological Science, 2(2), 214-223.

Fletcher-Watson, S., Leekam, S. R., Benson, V., Frank, M. C., \& Findlay, J. M. (2009). Eyemovements reveal attention to social information in autism spectrum disorder. Neuropsychologia, 47(1), 248-257.

Franchini, M., Glaser, B., Wood de Wilde, H., Gentaz, E., Eliez, S., \& Schaer, M. (2017). Social orienting and joint attention in preschoolers with autism spectrum disorders. PloS One, 12(6), e0178859.

Franchini, M., Wood de Wilde, H., Glaser, B., Gentaz, E., Eliez, S., \& Schaer, M. (2016). Brief Report: A Preference for Biological Motion Predicts a Reduction in Symptom Severity 1 Year Later in Preschoolers with Autism Spectrum Disorders. Frontiers in Psychiatry / Frontiers Research Foundation, 7, 143.

Freeth, M., \& Bugembe, P. (2019). Social partner gaze direction and conversational phase; factors affecting social attention during face-to-face conversations in autistic adults? Autism: The International Journal of Research and Practice, 23(2), 503-513.

Freeth, M., Chapman, P., Ropar, D., \& Mitchell, P. (2010). Do gaze cues in complex scenes capture and direct the attention of high functioning adolescents with ASD? Evidence from eye-tracking. Journal of Autism and Developmental Disorders, 40(5), 534-547.

Freeth, M., Ropar, D., Mitchell, P., Chapman, P., \& Loher, S. (2011). How adolescents with ASD process social information in complex scenes. combining evidence from eye movements and verbal descriptions. Journal of Autism and Developmental Disorders, 41(3), 364-371.

Fujioka, T., Inohara, K., Okamoto, Y., Masuya, Y., Ishitobi, M., Saito, D. N., ... Kosaka, H. (2016). Gazefinder as a clinical supplementary tool for discriminating between autism spectrum disorder and typical development in male adolescents and adults. Molecular Autism, 7, 19. 
Fujisawa, T. X., Tanaka, S., Saito, D. N., Kosaka, H., \& Tomoda, A. (2014). Visual attention for social information and salivary oxytocin levels in preschool children with autism spectrum disorders: an eye-tracking study. Frontiers in Neuroscience, 8, 295.

Gale, C. M., Eikeseth, S., \& Klintwall, L. (2019). Children with Autism show Atypical Preference for Non-social Stimuli. Scientific Reports, 9(1), 10355.

Garon, M., Forgeot d'Arc, B., Lavallée, M. M., Estay, E. V., \& Beauchamp, M. H. (2018). Visual Encoding of Social Cues Contributes to Moral Reasoning in Autism Spectrum Disorder: An Eye-Tracking Study. Frontiers in Human Neuroscience, 12, 409.

Gilbertson, L. R., Lutfi, R. A., \& Ellis Weismer, S. (2017). Auditory preference of children with autism spectrum disorders. Cognitive Processing, 18(2), 205-209.

Goldberg, M. C., Allman, M. J., Hagopian, L. P., Triggs, M. M., Frank-Crawford, M. A., Mostofsky, S. H., ... DeLeon, I. G. (2017). Examining the reinforcing value of stimuli within social and non-social contexts in children with and without high-functioning autism. Autism: The International Journal of Research and Practice, 21(7), 881-895.

Gray, K. L. H., Haffey, A., Mihaylova, H. L., \& Chakrabarti, B. (2018). Lack of Privileged Access to Awareness for Rewarding Social Scenes in Autism Spectrum Disorder. Journal of Autism and Developmental Disorders, 48(10), 3311-3318.

Hanley, M., McPhillips, M., Mulhern, G., \& Riby, D. M. (2013). Spontaneous attention to faces in Asperger syndrome using ecologically valid static stimuli. Autism: The International Journal of Research and Practice, 17(6), 754-761.

Harrop, C., Jones, D., Zheng, S., Nowell, S., Schultz, R., \& Parish-Morris, J. (2019). Visual attention to faces in children with autism spectrum disorder: are there sex differences? Molecular Autism, 10, 28.

Hedger, N. (2020). Data supplements for ASD meta-analysis. https://doi.org/10.6084/m9.figshare.12327767.v1 
Higuchi, T., Ishizaki, Y., Noritake, A., Yanagimoto, Y., Kobayashi, H., Nakamura, K., \& Kaneko, K. (2017). Spatiotemporal characteristics of gaze of children with autism spectrum disorders while looking at classroom scenes. PloS One, 12(5), e0175912.

Hong, M. P., Eckert, E. M., Pedapati, E. V., Shaffer, R. C., Dominick, K. C., Wink, L. K., ... Erickson, C. A. (2019). Differentiating social preference and social anxiety phenotypes in fragile $X$ syndrome using an eye gaze analysis: a pilot study. Journal of Neurodevelopmental Disorders, 11(1), 1.

Hong, M. P., Guilfoyle, J. L., Mooney, L. N., Wink, L. K., Pedapati, E. V., Shaffer, R. C., ... Erickson, C. A. (2017). Eye gaze and pupillary response in Angelman syndrome. Research in Developmental Disabilities, 68, 88-94.

Hosozawa, M., Tanaka, K., Shimizu, T., Nakano, T., \& Kitazawa, S. (2012). How children with specific language impairment view social situations: an eye tracking study. Pediatrics, 129(6), e1453-e1460.

Jones, W., Carr, K., \& Klin, A. (2008). Absence of preferential looking to the eyes of approaching adults predicts level of social disability in 2-year-old toddlers with autism spectrum disorder. Archives of General Psychiatry, 65(8), 946-954.

Kanat, M., Spenthof, I., Riedel, A., van Elst, L. T., Heinrichs, M., \& Domes, G. (2017). Restoring effects of oxytocin on the attentional preference for faces in autism. Translational Psychiatry, 7(4), e1097.

Kemner, C., van der Geest, J. N., Verbaten, M. N., \& van Engeland, H. (2007). Effects of object complexity and type on the gaze behavior of children with pervasive developmental disorder. Brain and Cognition, 65(1), 107-111.

Kirchner, J. C., Hatri, A., Heekeren, H. R., \& Dziobek, I. (2011). Autistic symptomatology, face processing abilities, and eye fixation patterns. Journal of Autism and Developmental Disorders, 41(2), 158-167.

Kleberg, J. L., Thorup, E., \& Falck-Ytter, T. (2017). Visual orienting in children with autism: 
Hyper-responsiveness to human eyes presented after a brief alerting audio-signal, but hyporesponsiveness to eyes presented without sound. Autism Research: Official Journal of the International Society for Autism Research, 10(2), 246-250.

Klin, A., Jones, W., Schultz, R., Volkmar, F., \& Cohen, D. (2002). Visual fixation patterns during viewing of naturalistic social situations as predictors of social competence in individuals with autism. Archives of General Psychiatry, 59(9), 809-816.

Klin, A., Lin, D. J., Gorrindo, P., Ramsay, G., \& Jones, W. (2009). Two-year-olds with autism orient to non-social contingencies rather than biological motion. Nature, 459(7244), 257261.

Kohls, G., Antezana, L., Mosner, M. G., Schultz, R. T., \& Yerys, B. E. (2018). Altered reward system reactivity for personalized circumscribed interests in autism. Molecular Autism, 9, 9.

Kohls, G., Peltzer, J., Schulte-Rüther, M., Kamp-Becker, I., Remschmidt, H., HerpertzDahlmann, B., \& Konrad, K. (2011). Atypical brain responses to reward cues in autism as revealed by event-related potentials. Journal of Autism and Developmental Disorders, 41(11), 1523-1533.

Kohls, G., Schulte-Rüther, M., Nehrkorn, B., Müller, K., Fink, G. R., Kamp-Becker, I., ... Konrad, K. (2013). Reward system dysfunction in autism spectrum disorders. Social Cognitive and Affective Neuroscience, 8(5), 565-572.

Kou, J., Le, J., Fu, M., Lan, C., Chen, Z., Li, Q., ... Kendrick, K. M. (2019). Comparison of three different eye-tracking tasks for distinguishing autistic from typically developing children and autistic symptom severity. Autism Research: Official Journal of the International Society for Autism Research, 12(10), 1529-1540.

Kovarski, K., Siwiaszczyk, M., Malvy, J., Batty, M., \& Latinus, M. (2019). Faster eye movements in children with autism spectrum disorder. Autism Research: Official Journal of the International Society for Autism Research, 12(2), 212-224.

Krogh-Jespersen, S., Kaldy, Z., Valadez, A. G., Carter, A. S., \& Woodward, A. L. (2018). Goal 
prediction in 2-year-old children with and without autism spectrum disorder: An eye-tracking study. Autism Research: Official Journal of the International Society for Autism Research, 11(6), 870-882.

Kuhn, G., Kourkoulou, A., \& Leekam, S. R. (2010). How magic changes our expectations about autism. Psychological Science, 21(10), 1487-1493.

Kwon, M.-K., Moore, A., Barnes, C. C., Cha, D., \& Pierce, K. (2019). Typical Levels of EyeRegion Fixation in Toddlers With Autism Spectrum Disorder Across Multiple Contexts. Journal of the American Academy of Child and Adolescent Psychiatry, 58(10), 1004-1015.

Liang, J., \& Wilkinson, K. (2018). Gaze Toward Naturalistic Social Scenes by Individuals With Intellectual and Developmental Disabilities: Implications for Augmentative and Alternative Communication Designs. Journal of Speech, Language, and Hearing Research: JSLHR, 61(5), 1157-1170.

Lin, A., Rangel, A., \& Adolphs, R. (2012). Impaired learning of social compared to monetary rewards in autism. Frontiers in Neuroscience, 6, 143.

López-López, J. A., Marín-Martínez, F., Sánchez-Meca, J., Van den Noortgate, W., \& Viechtbauer, W. (2013). Estimation of the predictive power of the model in mixed-effects meta-regression: A simulation study. The British Journal of Mathematical and Statistical Psychology. https://doi.org/10.1111/bmsp.12002

Marsh, L. E., Pearson, A., Ropar, D., \& Hamilton, A. F. de C. (2015). Predictive gaze during observation of irrational actions in adults with autism spectrum conditions. Journal of Autism and Developmental Disorders, 45(1), 245-261.

Moore, A., Wozniak, M., Yousef, A., Barnes, C. C., Cha, D., Courchesne, E., \& Pierce, K. (2018). The geometric preference subtype in ASD: identifying a consistent, early-emerging phenomenon through eye tracking. Molecular Autism, 9, 19.

Moore, D. J., Heavey, L., \& Reidy, J. (2012). Attentional processing of faces in ASD: a DotProbe study. Journal of Autism and Developmental Disorders, 42(10), 2038-2045. 
Moore, D. J., Reidy, J., \& Heavey, L. (2016). Attentional allocation of autism spectrum disorder individuals: Searching for a Face-in-the-Crowd. Autism: The International Journal of Research and Practice, 20(2), 163-171.

Moriuchi, J. M., Klin, A., \& Jones, W. (2017). Mechanisms of Diminished Attention to Eyes in Autism. The American Journal of Psychiatry, 174(1), 26-35.

Müller, N., Baumeister, S., Dziobek, I., Banaschewski, T., \& Poustka, L. (2016). Validation of the Movie for the Assessment of Social Cognition in Adolescents with ASD: Fixation Duration and Pupil Dilation as Predictors of Performance. Journal of Autism and Developmental Disorders, 46(9), 2831-2844.

Nadig, A., Lee, I., Singh, L., Bosshart, K., \& Ozonoff, S. (2010). How does the topic of conversation affect verbal exchange and eye gaze? A comparison between typical development and high-functioning autism. Neuropsychologia, 48(9), 2730-2739.

Nakano, T., Tanaka, K., Endo, Y., Yamane, Y., Yamamoto, T., Nakano, Y., ... Kitazawa, S. (2010). Atypical gaze patterns in children and adults with autism spectrum disorders dissociated from developmental changes in gaze behaviour. Proceedings. Biological Sciences / The Royal Society, 277(1696), 2935-2943.

Neuhaus, E., Bernier, R. A., \& Beauchaine, T. P. (2015). Electrodermal Response to Reward and Non-Reward Among Children With Autism. Autism Research: Official Journal of the International Society for Autism Research, 8(4), 357-370.

Norbury, C. F., Brock, J., Cragg, L., Einav, S., Griffiths, H., \& Nation, K. (2009). Eye-movement patterns are associated with communicative competence in autistic spectrum disorders. Journal of Child Psychology and Psychiatry, and Allied Disciplines, 50(7), 834-842.

Noris, B., Nadel, J., Barker, M., Hadjikhani, N., \& Billard, A. (2012). Investigating gaze of children with ASD in naturalistic settings. PloS One, 7(9), e44144.

Nuske, H. J., Vivanti, G., \& Dissanayake, C. (2016). Others' emotions teach, but not in autism: an eye-tracking pupillometry study. Molecular Autism, 7(1), 36. 
Pankert, A., Pankert, K., Herpertz-Dahlmann, B., Konrad, K., \& Kohls, G. (2014). Responsivity to familiar versus unfamiliar social reward in children with autism. Journal of Neural Transmission , 121(9), 1199-1210.

Parish-Morris, J., Chevallier, C., Tonge, N., Letzen, J., Pandey, J., \& Schultz, R. T. (2013). Visual attention to dynamic faces and objects is linked to face processing skills: a combined study of children with autism and controls. Frontiers in Psychology, 4, 185.

Parish-Morris, J., Pallathra, A. A., Ferguson, E., Maddox, B. B., Pomykacz, A., Perez, L. S., ... Brodkin, E. S. (2019). Adaptation to different communicative contexts: an eye tracking study of autistic adults. Journal of Neurodevelopmental Disorders, 11(1), 5.

Pierce, K., Conant, D., Hazin, R., Stoner, R., \& Desmond, J. (2011). Preference for geometric patterns early in life as a risk factor for autism. Archives of General Psychiatry, 68(1), 101109.

Pierce, K., Marinero, S., Hazin, R., McKenna, B., Barnes, C. C., \& Malige, A. (2016). Eye Tracking Reveals Abnormal Visual Preference for Geometric Images as an Early Biomarker of an Autism Spectrum Disorder Subtype Associated With Increased Symptom Severity. Biological Psychiatry, 79(8), 657-666.

Pruett, J. R., Jr, Hoertel, S., Constantino, J. N., Moll, A. L., McVey, K., Squire, E., ... Petersen, S. E. (2013). Impaired eye region search accuracy in children with autistic spectrum disorders. PloS One, 8(3), e58167.

Riby, D., \& Hancock, P. J. B. (2009). Looking at movies and cartoons: eye-tracking evidence from Williams syndrome and autism. Journal of Intellectual Disability Research: JIDR, 53(2), 169-181.

Riby, D. M., \& Hancock, P. J. B. (2008). Viewing it differently: social scene perception in Williams syndrome and autism. Neuropsychologia, 46(11), 2855-2860.

Riby, D. M., \& Hancock, P. J. B. (2009). Do faces capture the attention of individuals with Williams syndrome or autism? Evidence from tracking eye movements. Journal of Autism 
and Developmental Disorders, 39(3), 421-431.

Riby, D. M., Hancock, P. J., Jones, N., \& Hanley, M. (2013). Spontaneous and cued gazefollowing in autism and Williams syndrome. Journal of Neurodevelopmental Disorders, 5(1), 13.

Rice, K., Moriuchi, J. M., Jones, W., \& Klin, A. (2012). Parsing heterogeneity in autism spectrum disorders: visual scanning of dynamic social scenes in school-aged children. Journal of the American Academy of Child and Adolescent Psychiatry, 51(3), 238-248.

Richey, J. A., Rittenberg, A., Hughes, L., Damiano, C. R., Sabatino, A., Miller, S., ... Dichter, G. S. (2014). Common and distinct neural features of social and non-social reward processing in autism and social anxiety disorder. Social Cognitive and Affective Neuroscience, 9(3), $367-377$.

Ruta, L., Famà, F. I., Bernava, G. M., Leonardi, E., Tartarisco, G., Falzone, A., ... Chakrabarti, B. (2017). Reduced preference for social rewards in a novel tablet based task in young children with Autism Spectrum Disorders. Scientific Reports, 7(1), 3329.

Sasson, N. J., Pinkham, A. E., Weittenhiller, L. P., Faso, D. J., \& Simpson, C. (2016). Context Effects on Facial Affect Recognition in Schizophrenia and Autism: Behavioral and EyeTracking Evidence. Schizophrenia Bulletin, 42(3), 675-683.

Sasson, N. J., \& Touchstone, E. W. (2014). Visual attention to competing social and object images by preschool children with autism spectrum disorder. Journal of Autism and Developmental Disorders, 44(3), 584-592.

Sasson, N., Tsuchiya, N., Hurley, R., Couture, S. M., Penn, D. L., Adolphs, R., \& Piven, J. (2007). Orienting to social stimuli differentiates social cognitive impairment in autism and schizophrenia. Neuropsychologia, 45(11), 2580-2588.

Schwartzman, J. S., Velloso, R. de L., D’Antino, M. E. F., \& Santos, S. (2015). The eye-tracking of social stimuli in patients with Rett syndrome and autism spectrum disorders: a pilot study. Arquivos de Neuro-Psiquiatria, 73(5), 402-407. 
Scott-Van Zeeland, A. A., Dapretto, M., Ghahremani, D. G., Poldrack, R. A., \& Bookheimer, S. Y. (2010). Reward processing in autism. Autism Research: Official Journal of the International Society for Autism Research, 3(2), 53-67.

Sekigawa-Hosozawa, M., Tanaka, K., Shimizu, T., Nakano, T., \& Kitazawa, S. (2017). A group of very preterm children characterized by atypical gaze patterns. Brain \& Development, 39(3), 218-224.

Shaffer, R. C., Pedapati, E. V., Shic, F., Gaietto, K., Bowers, K., Wink, L. K., \& Erickson, C. A. (2017). Brief Report: Diminished Gaze Preference for Dynamic Social Interaction Scenes in Youth with Autism Spectrum Disorders. Journal of Autism and Developmental Disorders, 47(2), 506-513.

Shah, P., Gaule, A., Bird, G., \& Cook, R. (2013). Robust orienting to protofacial stimuli in autism. Current Biology: CB, 23(24), R1087-R1088.

Shic, F., Bradshaw, J., Klin, A., Scassellati, B., \& Chawarska, K. (2011). Limited activity monitoring in toddlers with autism spectrum disorder. Brain Research, 1380, 246-254.

Shic, F., Wang, Q., Macari, S. L., \& Chawarska, K. (2019). The role of limited salience of speech in selective attention to faces in toddlers with autism spectrum disorders. Journal of Child Psychology and Psychiatry, and Allied Disciplines. https://doi.org/10.1111/jcpp.13118

Shi, L., Zhou, Y., Ou, J., Gong, J., Wang, S., Cui, X., ... Luo, X. (2015). Different visual preference patterns in response to simple and complex dynamic social stimuli in preschoolaged children with autism spectrum disorders. PloS One, 10(3), e0122280.

Speer, L. L., Cook, A. E., McMahon, W. M., \& Clark, E. (2007). Face processing in children with autism: Effects of stimulus contents and type. Autism: The International Journal of Research and Practice, 11(3), 265-277.

Tang, J. S. Y., Chen, N. T. M., Falkmer, M., Bölte, S., \& Girdler, S. (2019). Atypical Visual Processing but Comparable Levels of Emotion Recognition in Adults with Autism During the Processing of Social Scenes. Journal of Autism and Developmental Disorders, 49(10), 
4009-4018.

Tenenbaum, E. J., Amso, D., Abar, B., \& Sheinkopf, S. J. (2014). Attention and word learning in autistic, language delayed and typically developing children. Frontiers in Psychology, 5, 490.

Tenenbaum, E. J., Amso, D., Righi, G., \& Sheinkopf, S. J. (2017). Attempting to "Increase Intake from the Input": Attention and Word Learning in Children with Autism. Journal of Autism and Developmental Disorders, 47(6), 1791-1805.

Traynor, J. M., Gough, A., Duku, E., Shore, D. I., \& Hall, G. B. C. (2019). Eye Tracking Effort Expenditure and Autonomic Arousal to Social and Circumscribed Interest Stimuli in Autism Spectrum Disorder. Journal of Autism and Developmental Disorders, 49(5), 1988-2002.

Trembath, D., Vivanti, G., lacono, T., \& Dissanayake, C. (2015). Accurate or assumed: visual learning in children with ASD. Journal of Autism and Developmental Disorders, 45(10), 3276-3287.

Unruh, K. E., Sasson, N. J., Shafer, R. L., Whitten, A., Miller, S. J., Turner-Brown, L., \& Bodfish, J. W. (2016). Social Orienting and Attention Is Influenced by the Presence of Competing Nonsocial Information in Adolescents with Autism. Frontiers in Neuroscience, 10, 586.

van der Geest, J. N., Kemner, C., Camfferman, G., Verbaten, M. N., \& van Engeland, H. (2002). Looking at images with human figures: comparison between autistic and normal children. Journal of Autism and Developmental Disorders, 32(2), 69-75.

Van Herwegen, J., Smith, T. J., \& Dimitriou, D. (2015). Exploring different explanations for performance on a theory of mind task in Williams syndrome and autism using eye movements. Research in Developmental Disabilities, 45-46, 202-209.

Vargas-Cuentas, N. I., Roman-Gonzalez, A., Gilman, R. H., Barrientos, F., Ting, J., Hidalgo, D., ... Zimic, M. (2017). Developing an eye-tracking algorithm as a potential tool for early diagnosis of autism spectrum disorder in children. PloS One, 12(11), e0188826.

Vernetti, A., Senju, A., Charman, T., Johnson, M. H., Gliga, T., \& BASIS Team. (2018). 
Simulating interaction: Using gaze-contingent eye-tracking to measure the reward value of social signals in toddlers with and without autism. Developmental Cognitive Neuroscience, 29, 21-29.

Viechtbauer, W., \& Cheung, M. W.-L. (2010). Outlier and influence diagnostics for metaanalysis. Research Synthesis Methods, 1(2), 112-125.

Vivanti, G., \& Dissanayake, C. (2014). Propensity to imitate in autism is not modulated by the model's gaze direction: an eye-tracking study. Autism Research: Official Journal of the International Society for Autism Research, 7(3), 392-399.

Vivanti, G., Fanning, P. A. J., Hocking, D. R., Sievers, S., \& Dissanayake, C. (2017). Social Attention, Joint Attention and Sustained Attention in Autism Spectrum Disorder and Williams Syndrome: Convergences and Divergences. Journal of Autism and Developmental Disorders, 47(6), 1866-1877.

Vivanti, G., Trembath, D., \& Dissanayake, C. (2014). Atypical monitoring and responsiveness to goal-directed gaze in autism spectrum disorder. Experimental Brain Research.

Experimentelle Hirnforschung. Experimentation Cerebrale, 232(2), 695-701.

Wang, Q., Campbell, D. J., Macari, S. L., Chawarska, K., \& Shic, F. (2018). Operationalizing atypical gaze in toddlers with autism spectrum disorders: a cohesion-based approach. Molecular Autism, 9, 25.

Wang, Q., Wall, C. A., Barney, E. C., Bradshaw, J. L., Macari, S. L., Chawarska, K., \& Shic, F. (2019). Promoting Social Attention in 3-Year-Olds with ASD through Gaze-Contingent Eye Tracking. Autism Research: Official Journal of the International Society for Autism Research. https://doi.org/10.1002/aur.2199

Watson, K. K., Miller, S., Hannah, E., Kovac, M., Damiano, C. R., Sabatino-DiCrisco, A., ... Dichter, G. S. (2015). Increased reward value of non-social stimuli in children and adolescents with autism. Frontiers in Psychology, 6, 1026.

Wilkinson, K. M., \& Light, J. (2014). Preliminary Study of Gaze Toward Humans in Photographs 
by Individuals with Autism, Down Syndrome, or Other Intellectual Disabilities: Implications for Design of Visual Scene Displays. Augmentative and Alternative Communication , 30(2), 130-146.

Wilson, C. E., Brock, J., \& Palermo, R. (2010). Attention to social stimuli and facial identity recognition skills in autism spectrum disorder. Journal of Intellectual Disability Research: JIDR, 54(12), 1104-1115.

Zantinge, G., van Rijn, S., Stockmann, L., \& Swaab, H. (2017). Psychophysiological responses to emotions of others in young children with autism spectrum disorders: Correlates of social functioning. Autism Research: Official Journal of the International Society for Autism Research, 10(9), 1499-1509. 


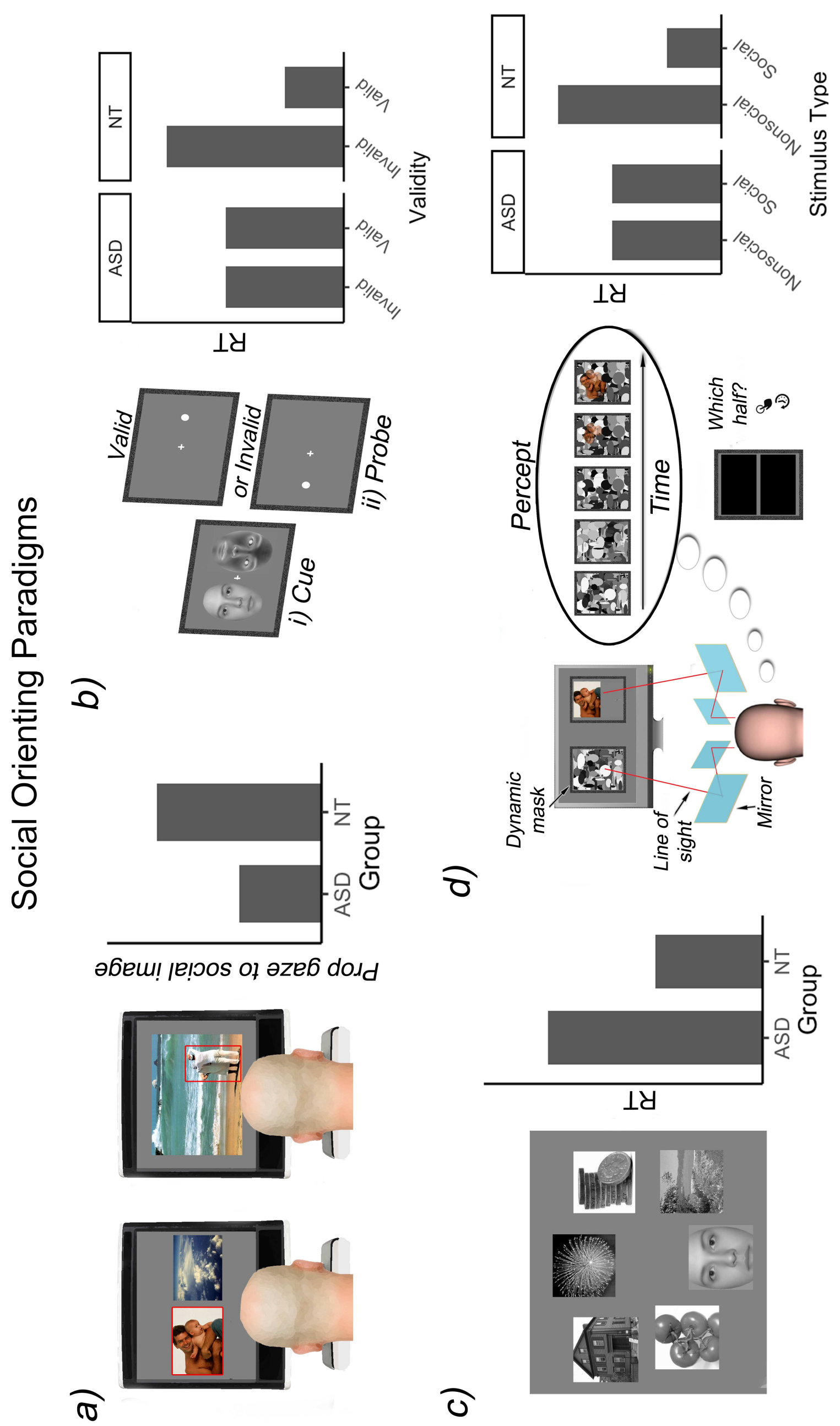


a)
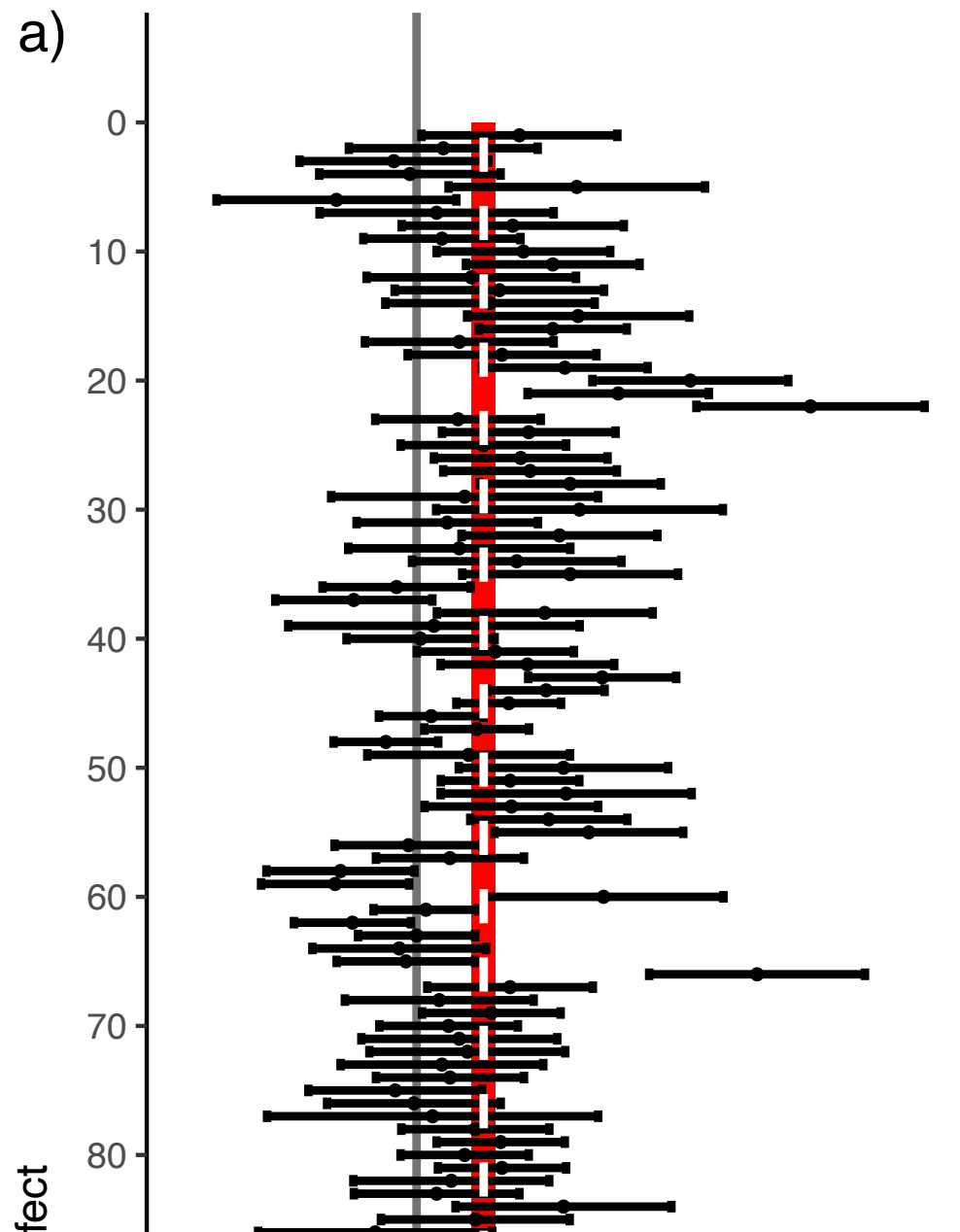

总

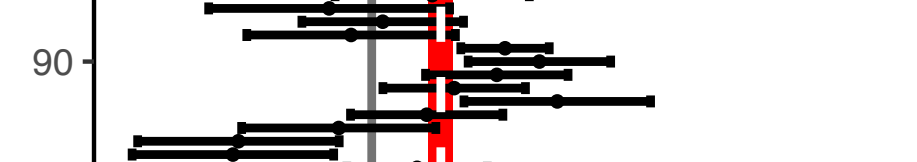

100
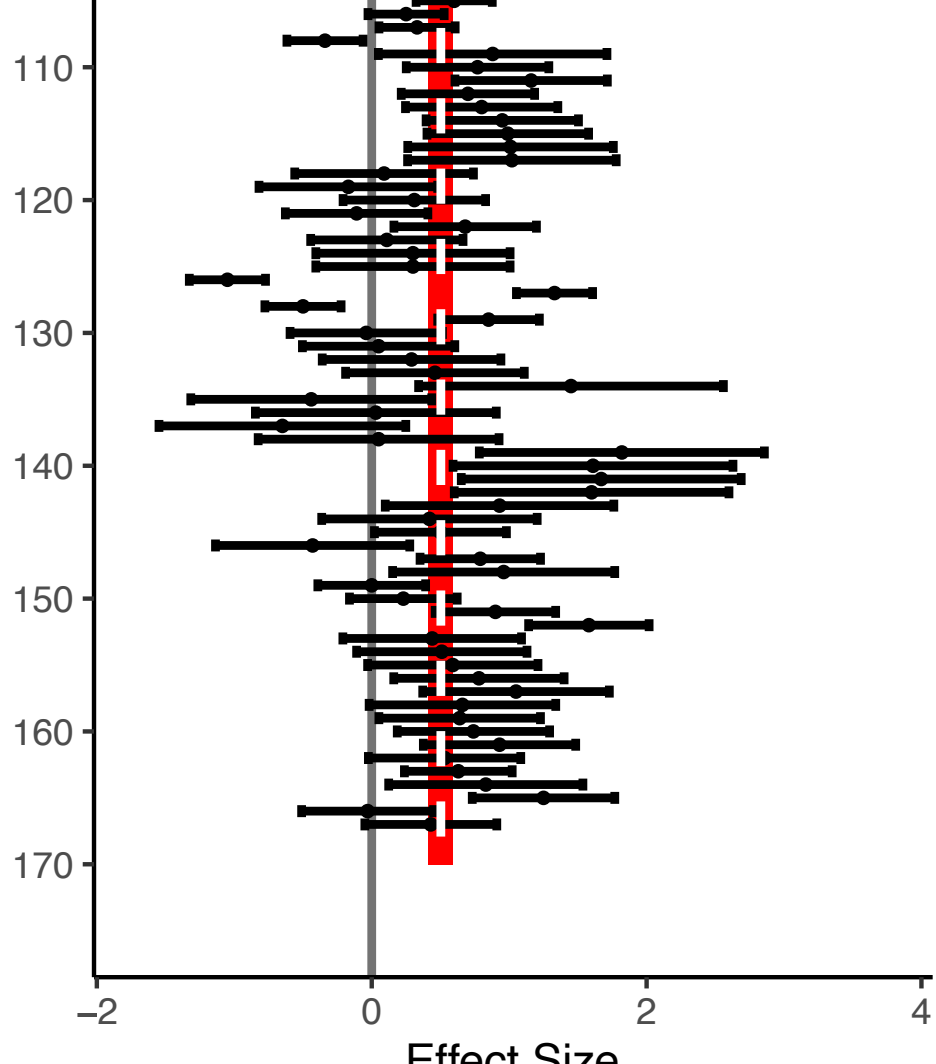

Effect Size b)

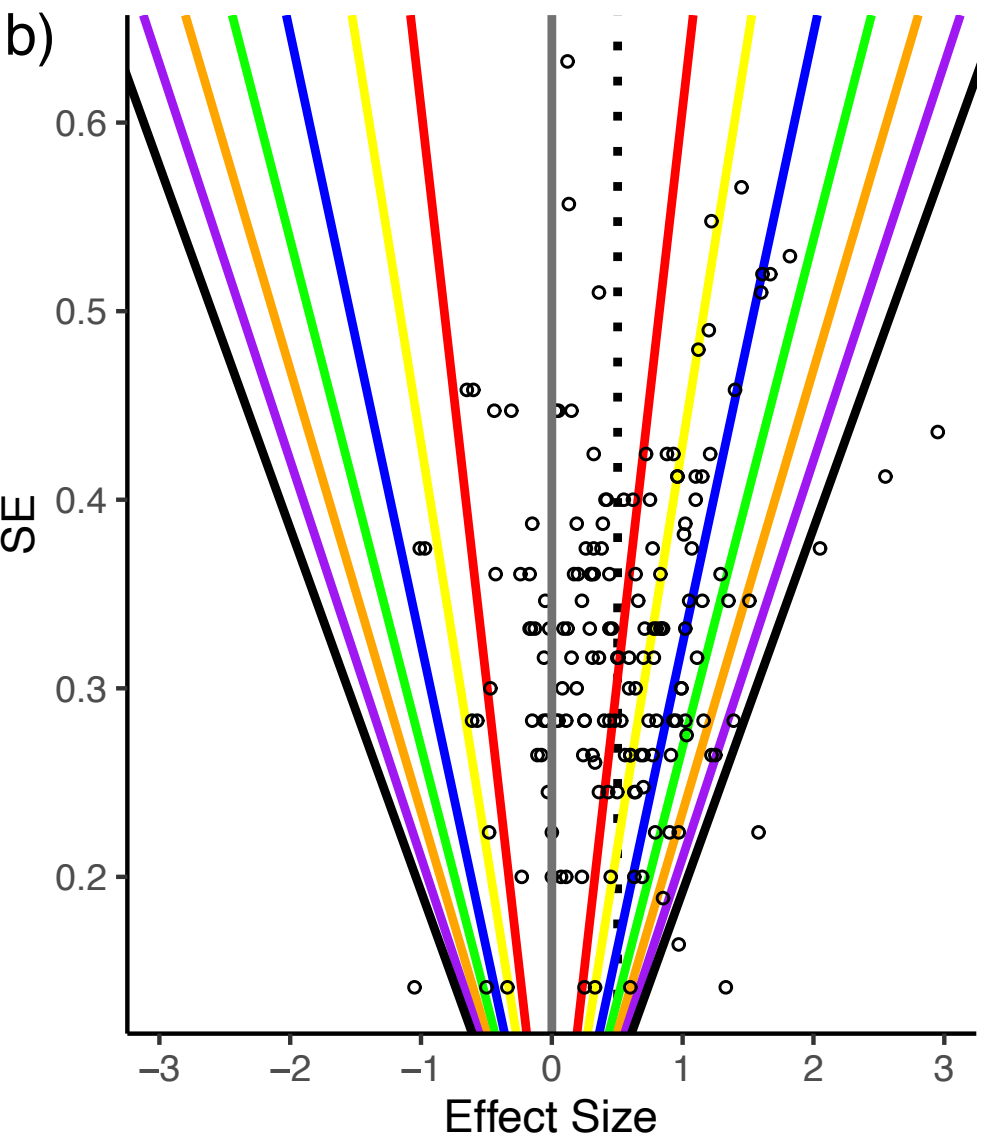

Ш

C)

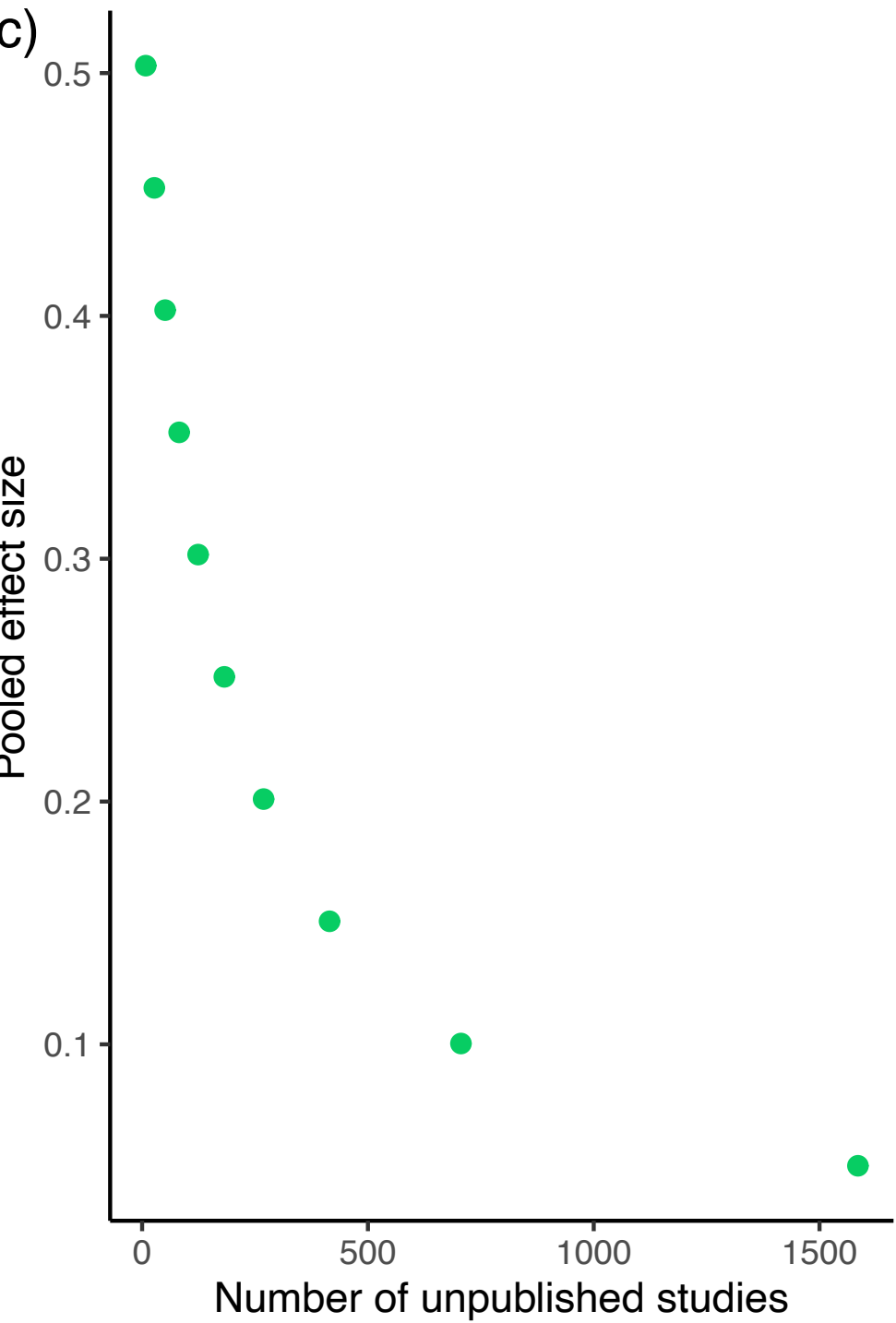


$\mathrm{SE}=0.632$

a)

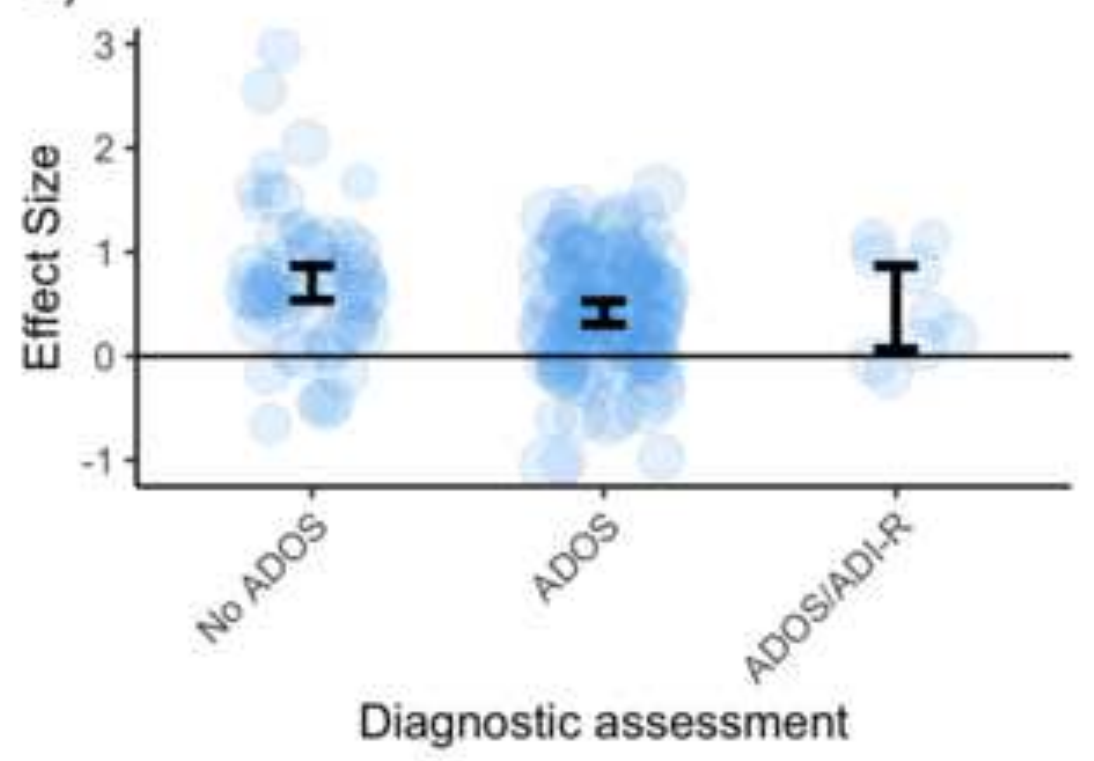

c)

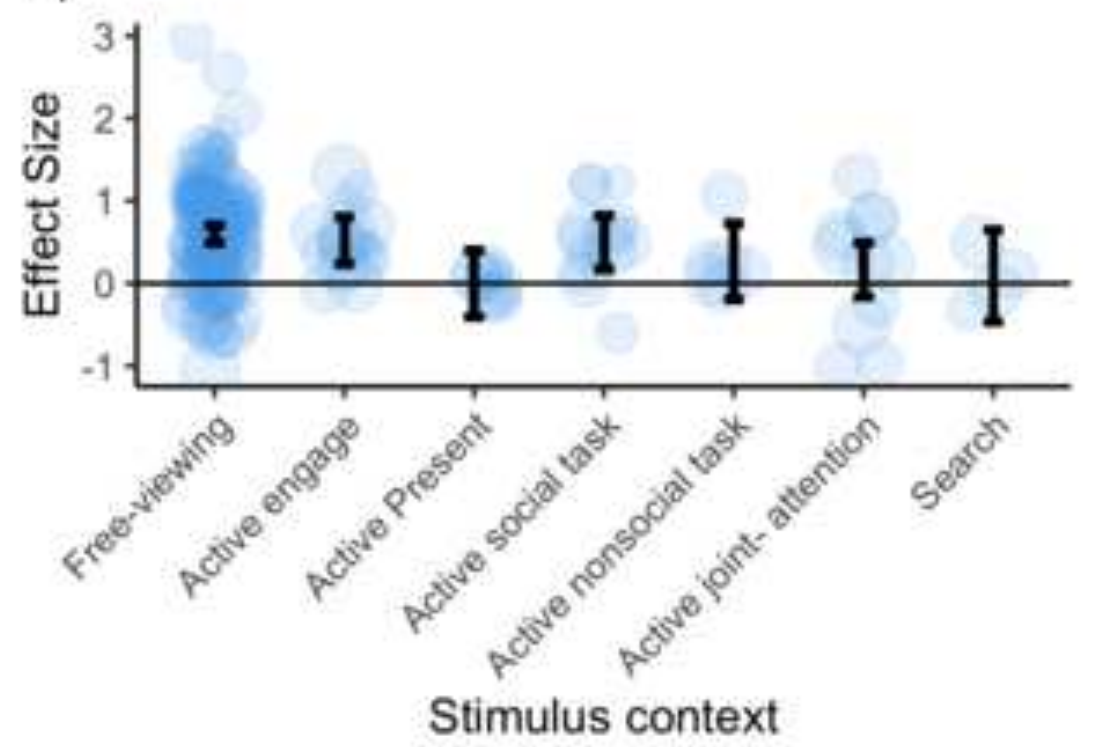

b)

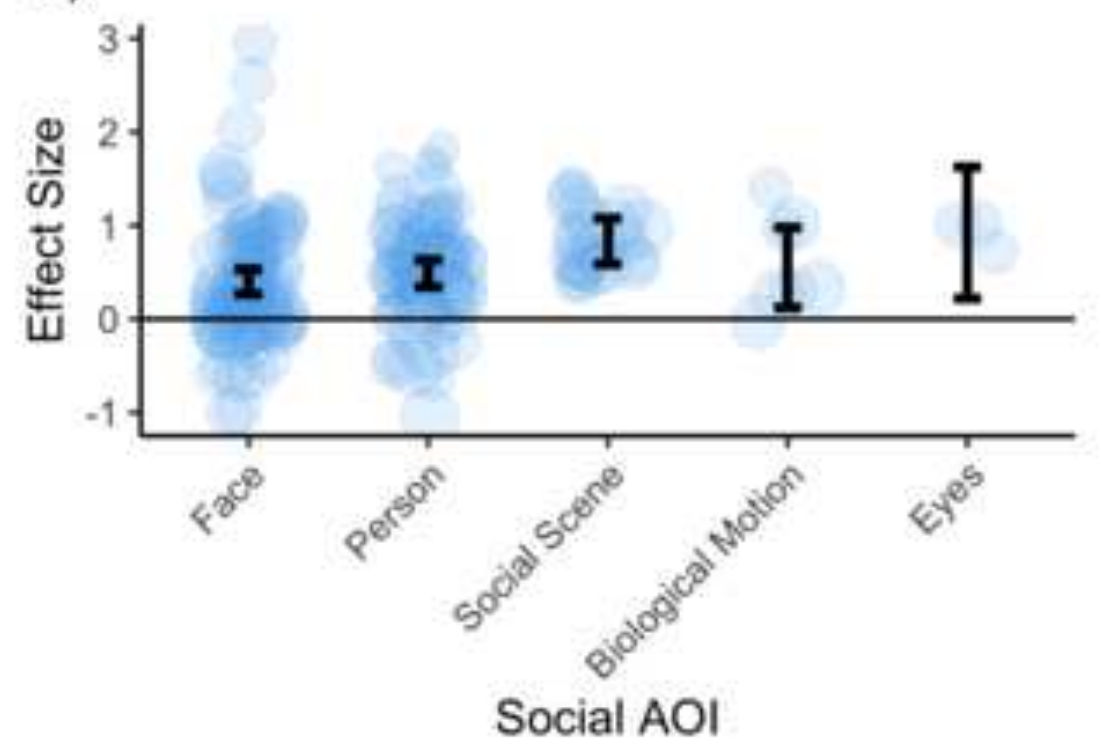

d)

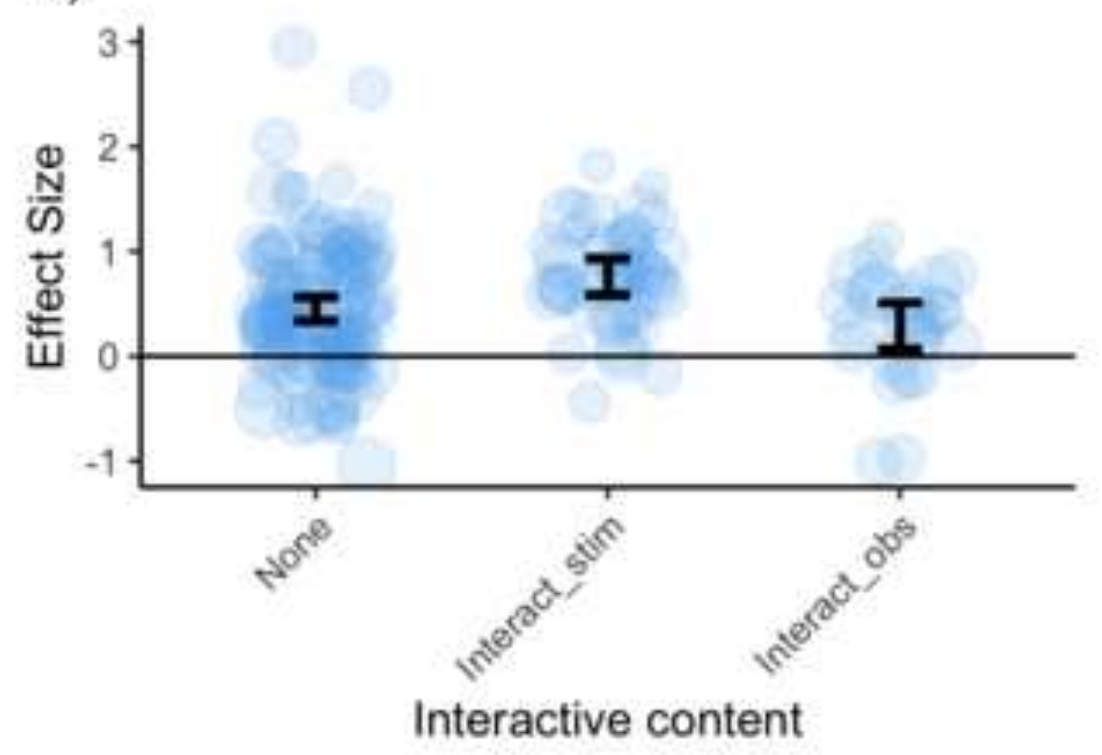




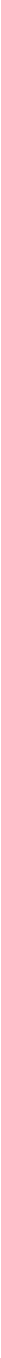



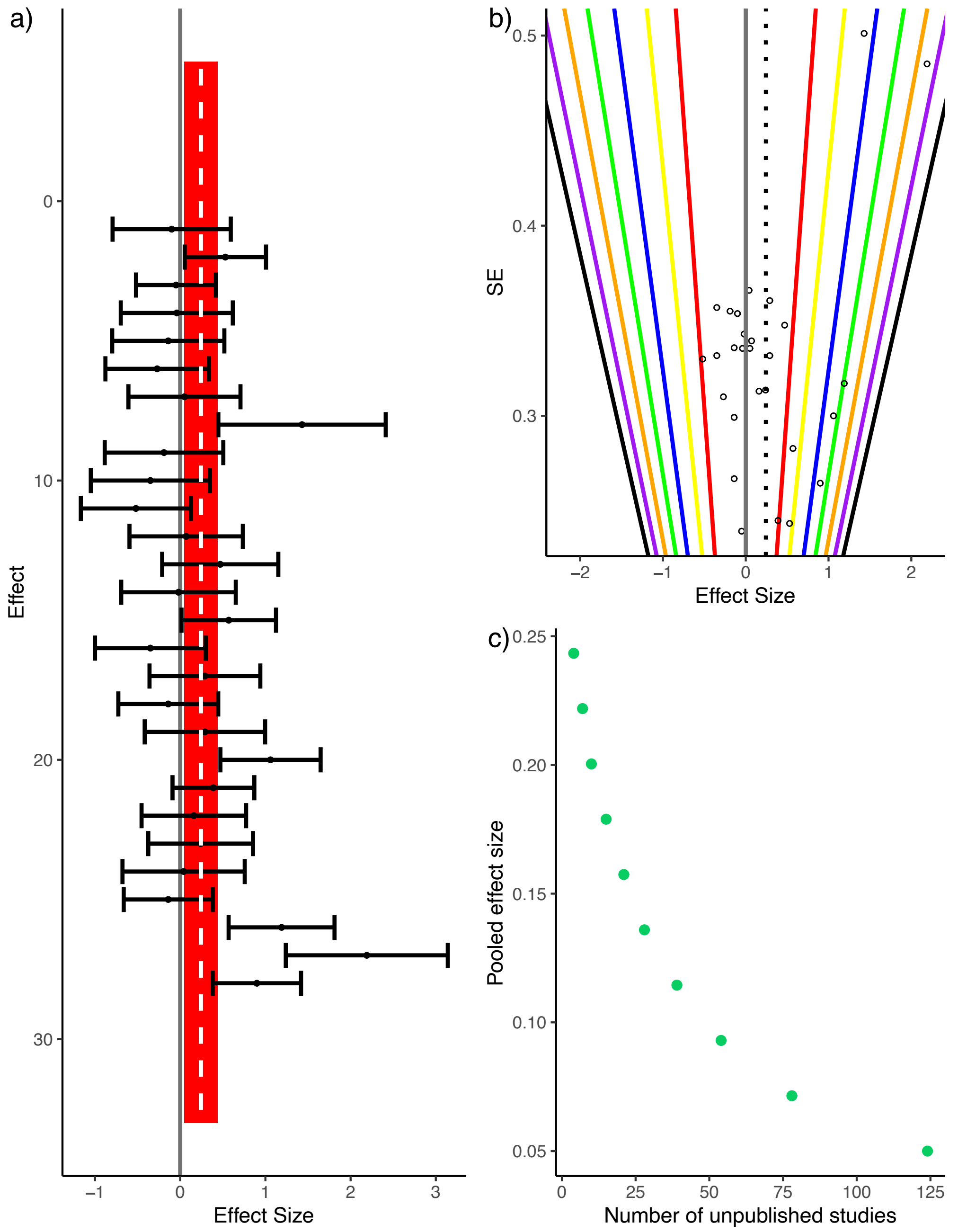
$\mathrm{SE}=0.501$

a)

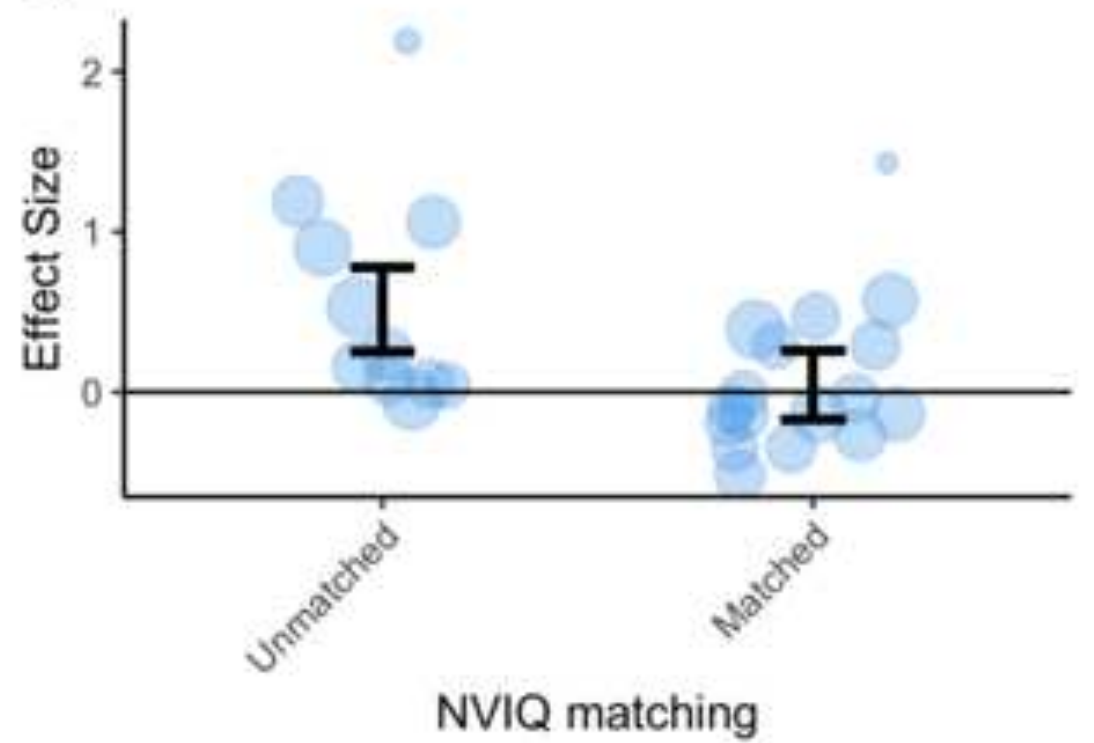

c)

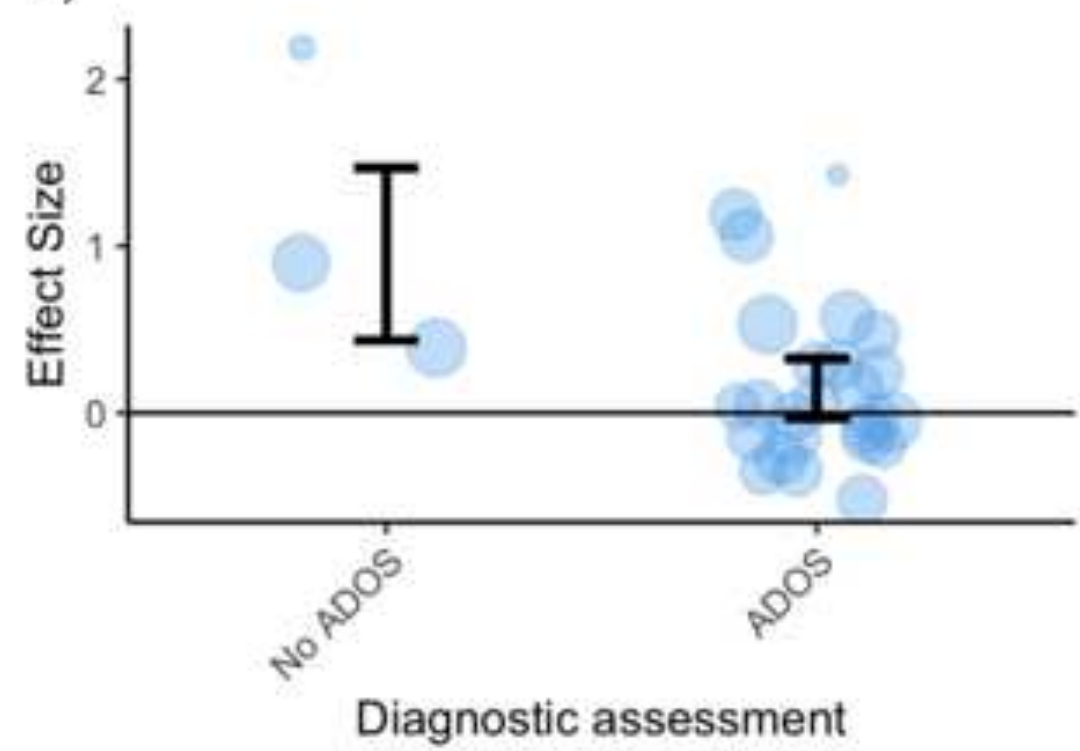

b)

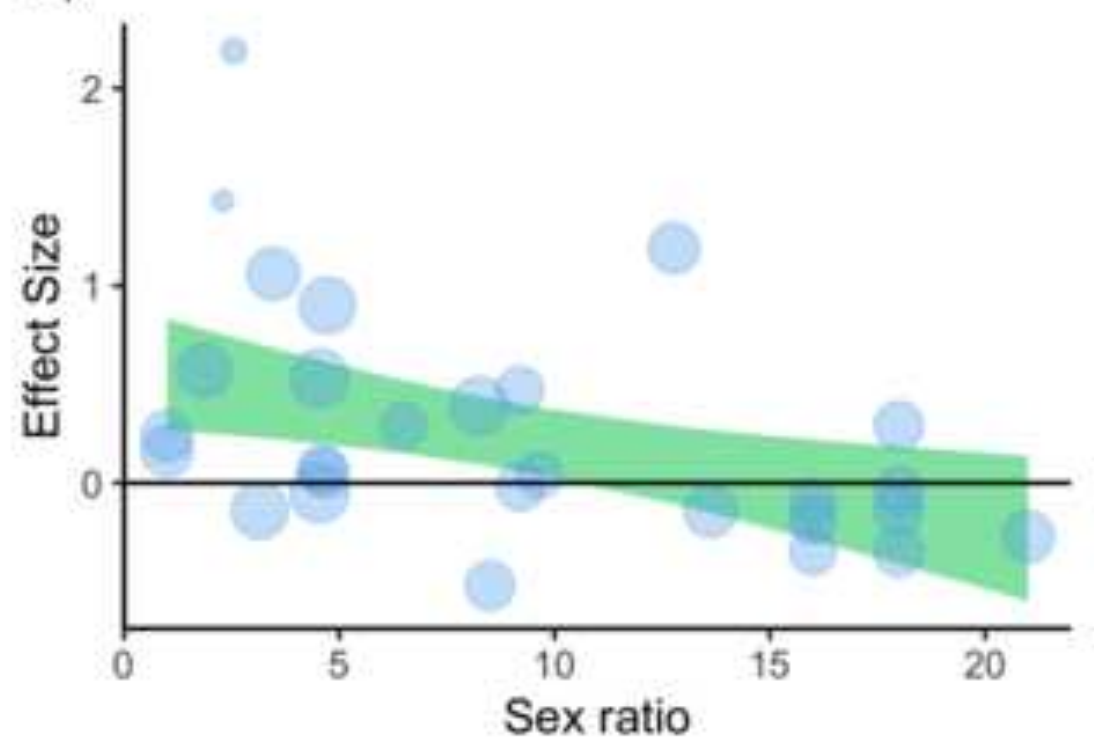

d)

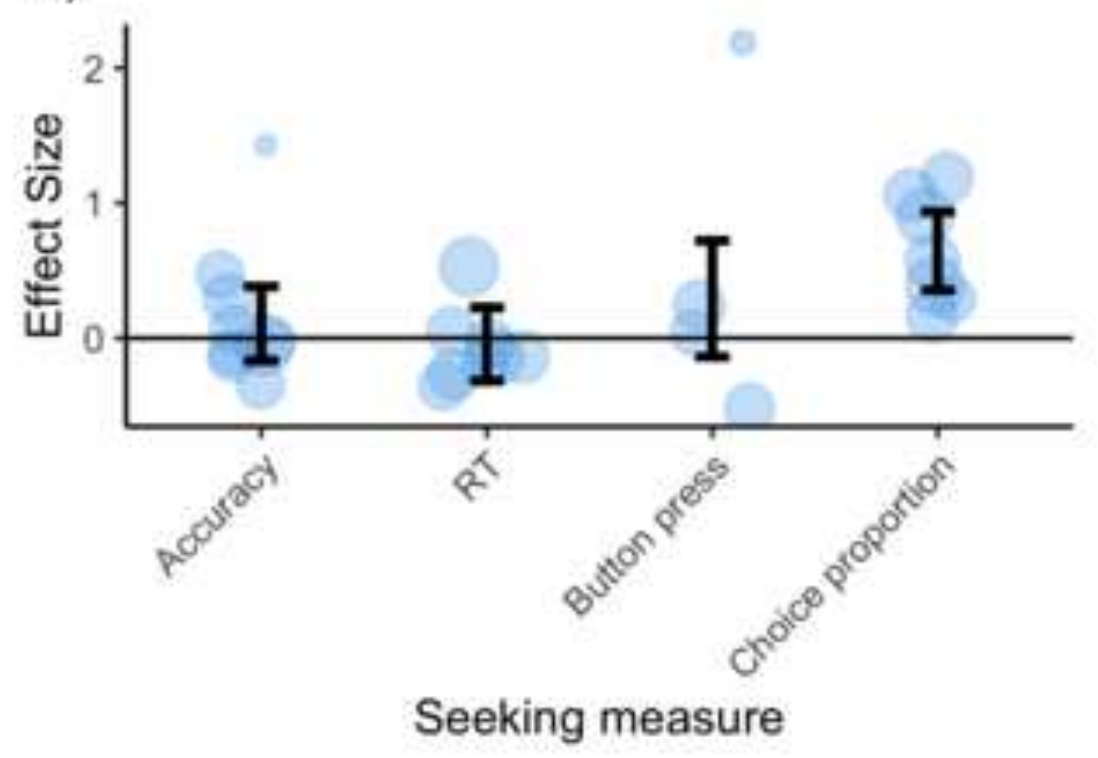




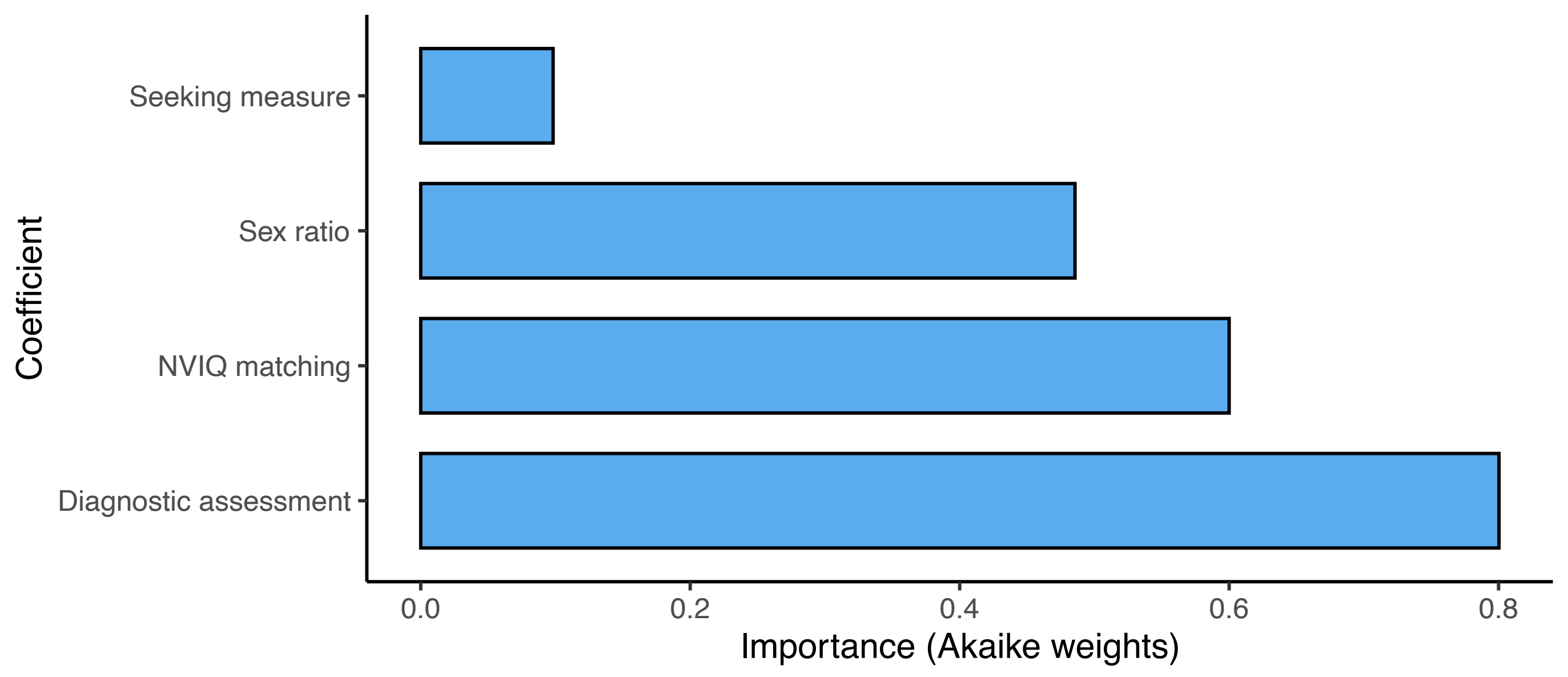

